\title{
Análise de dados de expressão gênica: normalização de microarrays e modelagem de redes regulatórias
}

André Fujita

\author{
TESE APRESENTADA \\ $\mathrm{AO}$ \\ INSTITUTO DE MATEMÁTICA E ESTATÍSTICA \\ DA \\ UNIVERSIDADE DE SÃO PAULO \\ PARA \\ OBTENÇÃO DO GRAU DE DOUTOR \\ EM \\ CIÊNCIAS \\ Área de Concentração: Bioinformática \\ Orientador: Prof. Dr. Carlos Eduardo Ferreira (IME-USP) \\ Co-orientadora: Profa. Dra. Mari Cleide Sogayar (IQ-USP)
}

Durante o desenvolvimento deste trabalho, o autor recebeu apoio financeiro da CAPES e da JICA

— São Paulo, Setembro de 2007 — 


\title{
Análise de dados de expressão gênica: normalização de microarrays e modelagem de redes regulatórias
}

\author{
Este exemplar corresponde à redação \\ final da tese devidamente corrigida \\ e apresentada por André Fujita \\ e aprovada pela Comissão Julgadora.
}

São Paulo, 10 de Agosto de 2007.

Banca examinadora:

- Prof. Dr. Carlos Eduardo Ferreira (orientador) - IME/USP

- Profa. Dra. Mari Cleide Sogayar (co-orientadora) - IQ/USP

- Profa. Dra. Eloiza Helena Tajara da Silva - FAMERP

- Prof. Dr. André Carlos Ponce de Leon F. de Carvalho - ICMC/USP

- Prof. Dr. Cássio Polpo de Campos - EACH/USP 
É difícil dizer o que é impossível, pois o sonho do ontem é a esperança do hoje e a realidade do amanhã 
Aos meus queridos pais Hideo e Amélia e à minha irmã Lia 


\section{Agradecimentos}

Meus sinceros agradecimentos aos Professores Dr. Carlos Eduardo Ferreira e Dra. Mari Cleide Sogayar, pela forma dedicada e paciente com que me orientaram/agüentaram. Eles sempre estiveram presentes e prontos para me ajudar em todos os momentos.

Aos Professores Dr. Satoru Miyano e Dr. Rui Yamaguchi por me suvervisionarem no meu estágio na Universidade de Tóquio.

Aos meus pais, Hideo e Amélia, pela confiança, compreensão, carinho e apoio, além de serem minhas fontes de inspiração e perseverança.

À minha irmã, Lia, pela paciência, compreensão e torcida em todos os momentos.

À Marie por todo o apoio nessa reta final.

À Katlin por me ensinar os primeiros passos da pesquisa.

Ao Mário por me mostrar que ciência é "legal".

Ao João pelos conselhos, dicas e "consultorias".

Ao Miguel pela ajuda na interpretação dos resultados biológicos.

Ao Renato pelos momentos inesquecíveis de diversão e entretenimento.

Ao Daniel pelas várias horas filosóficas.

À Dona Helena pela paciência e pelos docinhos de todo dia.

Aos meus amigos IMEanos Paulo, Manoel, Carlos, Ednei, Rodney, Márcio, Macris, Taty, João, Daniel, Débora pelos encontros e almoços mensais que renderam muitos momentos divertidos.

Aos meus amigos de Laboratório, Adriano, Ana Carolina, Ana Cláudia, Professora Anna Carla, Antero, Cristiane, Daniel, Débora, Edmilson, Erica, Fernando, Flávia Siqueira, Flávia Tobaruella, Gisella, Guilherme, Gustavo, Dona Helena, Helene, Humberto Miguel, Ilana, Ícaro, Isnar, Juan, Karin, Letícia Labriola, Letícia Terra, Luciana Cruz, Luciana Gomes, Marcos, Maria das Graças, Maria Fernanda, Marina, Marluce, Mayara, Milena, Newton, Nicole, Patrícia Barros, Patrícia Kossugue, Ricardo Corrêa, Ricardo Krett, Sandra, Tatiane, Thelma, Theri, Thiago e Zizi que me ensinaram muito sobre Biologia Molecular e Bioquímica. 
Aos ex-membros do Laboratório, Ana Paula, Beth, Christian, Cléber, Fernanda Festa, Fernanda Ortis, Gabriela, Isis, Jae, Jean, Juliana, Juliane, Katlin, Leonardo, Luana, Lúcia Helena, Maki, Mário, Rafael, Renato, Rita, Sheila, Wagner pelos momentos agradáveis de conversas e discussões.

Aos meus amigos que estão longe, Asako, Atsushi, Ayako, Ayumu, Emi, Eric, Euna, Hiroko, Kaname, Kazuko, Kazuyuki, Masao, Osamu, Ryo, Seiya, que me acolheram e me trataram muito bem para que eu pudesse me sentir em casa no Laboratório do Prof. Miyano.

Aos meus amigos que estão um pouco menos longe agora, César, Eduardo, Graziela, Henry, Ivana, Marie, Mie, Renato, Shogo, Valéria, Yunko, pelos ótimos momentos vividos no Japão.

À Patrícia, por me ajudar de forma eficiente e eficaz em todos os problemas burocráticos que tive durante estes anos.

À Universidade de São Paulo e à Universidade de Tóquio e todos os seus funcionários, pelas contribuições "invisíveis" nesta tese, mas que sem elas, este trabalho não existiria.

À CAPES pelo apoio financeiro proporcionado durante o desenvolvimento desta tese e à JICA pela oportunidade concedida de realizar parte da pesquisa no Japão.

E a Deus, por ter me dado tudo que eu sempre precisei, para que eu pudesse tornar cada sonho em realidade. 


\section{Resumo}

A análise da expressão gênica através de dados gerados em experimentos de microarrays de DNA vêm possibilitando uma melhor compreensão da dinâmica e dos mecanismos envolvidos nos processos celulares ao nível molecular. O aprimoramento desta análise é crucial para o avanço do conhecimento sobre as bases moleculares das neoplasias e para a identificação de marcadores moleculares para uso em diagnóstico, desenho de novos medicamentos em terapias anti-tumorais. Este trabalho tem como objetivos o desenvolvimento de modelos de análise desses dados, propondo uma nova forma de normalização de dados provenientes de microarrays e dois modelos para a construção de redes regulatórias de expressão gênica, sendo uma baseada na conectividade dinâmica entre diversos genes ao longo do ciclo celular e a outra que resolve o problema da dimensionalidade, em que o número de experimentos de microarrays é menor que o número de genes. Apresenta-se, ainda, um pacote de ferramentas com uma interface gráfica de fácil uso contendo diversas técnicas de análise de dados já conhecidas como também as abordagens propostas neste trabalho. 


\begin{abstract}
The analyses of DNA microarrays gene expression data are allowing a better comprehension of the dynamics and mechanisms involved in cellular processes at the molecular level. In the cancer field, the improvement of gene expression interpretation is crucial to better understand the molecular basis of the neoplasias and to identify molecular markers to be used in diagnosis and in the design of new anti-tumoral drugs. The main goals of this work were to develop a new method to normalize DNA microarray data and two models to construct gene expression regulatory networks. One method analyses the dynamic connectivity between genes through the cell cycle and the other solves the dimensionality problem in regulatory networks, meaning that the number of experiments is lower than the number of genes. We also developed a toolbox with a user-friendly interface, displaying several established statistical methods implemented to analyze gene expression data as well as the new approaches presented in this work.
\end{abstract}




\section{Conteúdo}

$\begin{array}{ll}\text { Introdução } & 1\end{array}$

1 Preliminares $\quad 5$

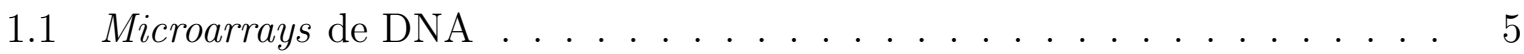

1.1.1 Hibridização . . . . . . . . . . . . . . . . . . . 5

1.1.2 Affymetrix microarray ................... 6

1.1.3 Arrays marcados ..................... 9

1.1 .4 CodeLink ${ }^{\mathrm{TM}} \ldots \ldots \ldots \ldots \ldots \ldots$

1.2 Redes regulatórias . . . . . . . . . . . . . . . . . . 13

2 Normalização de dados de microarrays $\quad 14$

2.1 Introdução . . . . . . . . . . . . . . . . . . . . . . . 14

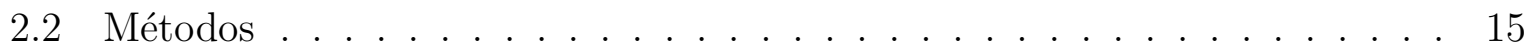

2.2 .1 Loess . . . . . . . . . . . . . . . . . . 16

2.2 .2 Cubic Splines . . . . . . . . . . . . . . . . . . . . . 17

2.2 .3 Wavelets ........................... 18

2.2 .4 Kernel . . . . . . . . . . . . . . . . . . . . . 19

2.2.5 Support Vector Regression . . . . . . . . . . . . . . . . . . 19 
2.3 Descrição dos experimentos . . . . . . . . . . . . . . . . 23

2.3.1 Protocolo CodeLink TM ................... 23

2.3.2 Microarrays artificiais .................. 24

2.4 Simulações . . . . . . . . . . . . . . . . . . . . . . 25

2.5 Discussão . . . . . . . . . . . . . . . . . . . . 30

3 Redes regulatórias $\quad 34$

3.1 Introdução . . . . . . . . . . . . . . . . . . . . . 34

3.2 Vetor autoregressivo $(\mathrm{VAR}) \ldots \ldots . \ldots . \ldots . \ldots$

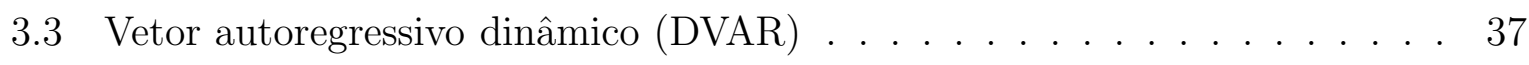

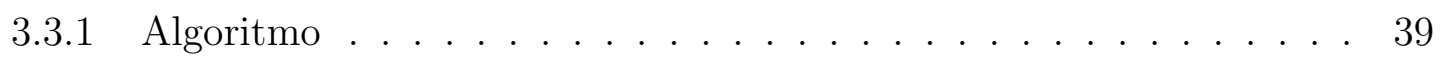

3.3.2 Aplicação em dados reais . . . . . . . . . . . . . . . . 41

3.3.3 Resultados e Discussões . . . . . . . . . . . . . . . . . 41

3.4 Vetor autoregressivo esparso $(\mathrm{SVAR}) \ldots \ldots \ldots \ldots$. . . . . . . 51

3.4.1 Ajuste da variável $\lambda \ldots \ldots \ldots \ldots$. . . . . . . . . . . . . 52

3.4.2 Controle da taxa de falso-positivos . . . . . . . . . . . 53

3.4 .3 Simulações . . . . . . . . . . . . . . . . . 53

3.4.4 Resultados e Discussão . . . . . . . . . . . . . . . . . 55

4 Pacote de ferramentas $\quad 65$

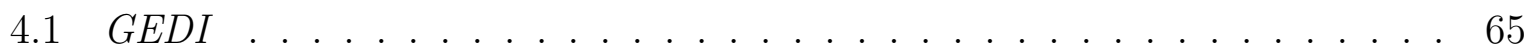

4.2 Funcionalidades . . . . . . . . . . . . . . . . 66

4.2.1 Normalização de microarrays de DNA . . . . . . . . . . . . . 67

4.2.2 Identificação de genes diferencialmente expressos . . . . . . . . . . 68

4.2 .3 Classificação . . . . . . . . . . . . . . . . . 69

4.2.4 Modelagem de redes regulatórias . . . . . . . . . . . . 70 
4.3 Arquivo de entrada . . . . . . . . . . . . . . . . . . 72

4.4 Interface . . . . . . . . . . . . . . . . . . . 73

$\begin{array}{lll}5 & \text { Conclusões } & 75\end{array}$

5.1 Normalização de microarrays . . . . . . . . . . . . . . . . . . . 76

5.2 Modelagem de redes regulatórias . . . . . . . . . . . . 76

5.3 Pacote de ferramentas . . . . . . . . . . . . . . . . 77

5.4 Trabalhos futuros . . . . . . . . . . . . . . . . 77 


\section{Introdução}

Bioinformática é a área que estuda o projeto e implementação de novos métodos computacionais para auxiliar pesquisadores de Biologia Molecular, Bioquímica, e outras áreas na análise de quantidades grandes de dados biológicos. Os avanços tecnológicos e da pesquisa em áreas como genômica, transcriptoma e proteômica têm produzido massas enormes de dados que precisam, agora, de uma análise mais aprofundada para sua compreensão. A análise manual não é mais possível e surge a necessidade da utilização de técnicas estatísticas, matemáticas e procedimentos computacionais que auxiliem os pesquisadores a extrair destes dados informações importantes a respeito de processos biológicos.

Não é necessário salientar a importância que a área de Bioinformática vem tomando no cenário da pesquisa científica. Iniciativas como o seqüenciamento do genoma humano (International Human Genome Sequencing Consortium, 2001) podem estar trazendo conhecimentos preciosos para a área e no futuro poderão ser decisivos para a produção de drogas ou procedimentos terapêuticos para doenças importantes como o câncer.

No Brasil, a área floresceu com a iniciativa de seqüenciamento da Xylella fastidiosa (Simpson et al., 2000) que colocou o país no cenário mundial da pesquisa na área.

Alguns dos problemas mais importantes que se estuda na área estão ligados à compreensão do funcionamento do sistema celular. Sabe-se da importância dos genes neste sistema, mas ainda é tema de pesquisa intensa entender como seus produtos interagem para desencadear os processos celulares, isto é, como os genes são ativados, expressos, seus produtos interagem e em que extensão. Este trabalho tenta trazer uma contribuição nesta área.

A expressão gênica é regulada por complexas redes de interação entre DNA, RNA, 
proteínas e outras moléculas pequenas, sendo muito difícil termos uma compreensão intuitiva do seu dinamismo (Jong, 2002). O estudo destas estruturas regulatórias é de grande interesse para que possamos predizer e simular seu comportamento sem ambigüidades e de forma sistemática.

A modelagem das redes regulatórias é feita a partir de dados provenientes de técnicas de expressão. Uma destas técnicas que produz dados em larga escala são os microarrays. Como qualquer procedimento biológico, os dados muitas vezes necessitam ser normalizados antes de sua análise. Neste trabalho propomos novas abordagens de normalização que mostramos ser mais eficientes que as usadas na literatura. Propomos também novas técnicas de construção de redes regulatórias. Um estudo da literatura mostra que as técnicas disponíveis mais usadas atualmente falham em dois pontos principais. Primeiro, as técnicas supõem estacionaridade no mecanismo de interação, i.e., a topologia da rede não se altera no ciclo de vida celular. Entretanto, já é conhecido que esta hipótese simplificadora não encontra respaldo na literatura da área, pois é bem sabido que as interações variam muito nas diferentes fases. Segundo, é muito freqüente trabalharmos com um número muito maior de genes (para os quais buscamos conhecer as interações de seus produtos) do que observações. A maior parte dos métodos estatísticos usados largamente não se adequa bem a essa situação, sendo necessário o estudo de métodos mais modernos que tratem este caso.

É importante ressaltar que o desenvolvimento de novas técnicas de análise de dados não implica automaticamente no seu uso pela comunidade de pesquisadores da área. Há a necessidade de se implementar ferramentas computacionais de uso simples e interface amigável para que tais técnicas possam realmente atingir o objetivo. Esta foi uma de nossas preocupações no decorrer do desenvolvimento deste trabalho.

Esta tese está dividida em 5 capítulos:

O Capítulo 1 explica a técnica de microarray, sua importância na pesquisa na área de ciências biológicas, em particular, na quantificação do nível de expresão gênica. Descrições sobre as plataformas Affymetrix e CodeLink ${ }^{\mathrm{TM}}$ são apresentadas. Em seguida, é introduzida a idéia de rede regulatória e sua relevância na descoberta de novos processos biológicos, como também na compreensão do complexo circuito molecular.

O Capítulo 2 apresenta diversos tipos de normalização de microarrays já existentes na literatura (Loess, Splines e Wavelets) e propõe dois novos métodos de normalização (Kernel e SVR), sendo que, o SVR mostrou-se superior aos demais nas nossas análises. 
No Capítulo 3 introduzimos o problema da modelagem de redes regulatórias de genes e diversos modelos presentes na literatura. Apresentamos brevemente o conceito sobre a causalidade de Granger e o modelo Vetor Autoregressivo clássico para o tratamento dos dados de expressão gênica em séries temporais. Propomos duas variantes do Vetor Autoregressivo clássico para a modelagem de redes regulatórias: o modelo Vetor Autoregressivo Dinâmico, a fim de identificar conectividades em determinadas fases do ciclo celular, e o Vetor Autoregessivo Esparso, uma técnica de modelagem de redes regulatórias para solucionar o problema da dimensionalidade, ou seja, quando o número de variáveis a serem analisadas (genes) é maior que o número de observações (microarrays).

O Capítulo 4 mostra o pacote de ferramentas GEDI (Gene Expression Data Interpreter), uma ferramenta com uma interface gráfica de fácil uso para pesquisadores sem o expertise em ciências da computação. Este pacote de ferramentas contêm implementados, todos os modelos descritos nos capítulos anteriores e mais outros que podem ser de utilidade para a análise da expressão gênica em suas diversas fases (normalização de microarrays, identificação de genes diferencialmente expressos, classificação de amostras, construção e estimação de redes regulatórias a partir de dados de expressão gênica).

O Capítulo 5 apresenta as conclusões gerais da tese.

As principais contribuições deste trabalho estão sintetizadas em 4 artigos científicos:

- Fujita A, Sato JR, Rodrigues LO, Ferreira CE, Sogayar MC. Evaluating different methods of microarray data normalization. BMC Bioinformatics. 7:469, 2006: Neste artigo avaliamos diferentes procedimentos de normalização de dados de microarrays e propomos abordagens inéditas para o problema que se mostraram superior às comumente usadas na área. Vale ressaltar que o artigo foi classificado pela revista como "Highly accessed", sendo consultado mais de 2000 vezes nos 3 primeiros meses depois de publicado.

- Fujita A, Sato JR, Garay-Malpartida HM, Morettin PA, Sogayar MC, Ferreira CE. Time-varying modeling of gene expression regulatory networks using the wavelet dynamic vector autoregressive method. Bioinformatics. 23:1623-1630, 2007a: neste artigo mostramos um método de construção de redes regulatórias que incorpora a dinâmica do ciclo celular.

- Fujita A, Sato JR, Garay-Malpartida, Yamaguchi R, Miyano S, Sogayar MC, Ferreira $\mathrm{CE}$. Modeling large gene expression regulatory networks with the sparse vector 
autoregressive model. BMC Systems Biology, 2007b (no prelo): neste artigo, feito em colaboração com o Laboratory of DNA information analysis da Universidade de Tóquio, propomos um método para inferência de redes em que o número de genes estudado é muito maior do que o número de observações disponíveis.

- Fujita A, Sato JR, Sogayar MC, Ferreira CE. GEDI: a user-friendly gene expression data toolbox. (submetido): Neste artigo descrevemos o GEDI, uma ferramenta computacional de fácil uso e interface amigável para a análise de dados de microarrray. 
CAPÍtulo 1

\section{Preliminares}

Esta tese tem como objetivos estudar métodos de análise de dados gerados de experimentos de microarrays de DNA e propor novos modelos de análise de dados de expressão gênica baseados nestes experimentos. Nesta seção buscamos descrever de forma concisa como estes dados são obtidos e que tipos de redes de interação pretendemos modelar. O leitor interessado pode consultar (Knudsen, 2001) para maiores detalhes.

\section{$1.1 \quad$ Microarrays de DNA}

O microarray é uma técnica desenvolvida recentemente, que tem se mostrado bastante útil para a quantificação simultânea dos níveis de expressão gênica de milhares de genes. Nesta seção, apresentamos uma breve introdução sobre a técnica e dos princípios de funci-

onamento das plataformas Affymetrix e CodeLink ${ }^{\mathrm{TM}}$, que são as plataformas comerciais mais populares, e também dos microarrays de DNA marcados.

\subsubsection{Hibridização}

O fundamento base dos microarrays de DNA é o processo de hibridização. Duas fitas de DNA se hibridizam se elas são complementares uma da outra. Se uma ou ambas as fitas de DNA forem trocadas por RNA, a hibridização ainda ocorrerá proporcionalmente à sua complementaridade.

Por décadas, a hibridização vem sendo utilizada na Biologia Molecular, como base 
para técnicas como Southern blotting e Northern blotting. No Southern blotting, o oligonucleotídeo é usado para se hibridizar ao fragmento complementar de DNA que foi separado de acordo com seu tamanho no gel de eletroforese. Se o oligonuleotídeo for marcado radioativamente, a hibridização pode ser visualizada por um filme fotográfico que é sensível à radiação. No Northern blotting, o oligonucleotídeo marcado é usado para hibridizar ao mRNA. Em seguida, este se liga à banda do mRNA no gel. A quantidade de radiação capturada no filme fotográfico é dependente da quantidade de sonda marcada presente na banda que, por sua vez, é dependente da quantidade de mRNA. Logo, esse método é um método de detecção semi-quantitativo dos diferentes mRNAs.

Os microarrays de DNA são métodos muito semelhantes ao Northern e Southern blotting. Ao invés das sondas de oligonucleotídeos estarem no gel que contém as amostras de RNA ou DNA, as sondas são imobilizadas em uma superfície. Estas sondas podem ser imobilizadas a micrômetros de distância, o que possibilita fixar milhares de sondas diferentes em uma pequena superfície. No lugar da marcação radioativa, a amostra é geralmente marcada com um fluoróforo que pode ser detectado por uma luz emitida por um scanner. O scanner faz a leitura da superfície do chip que contém o material.

Quando antes era possível somente realizar alguns experimentos de Northern ou Southern blots por dia, agora com os microarrays é possível realizar dezenas de milhares de hibridizações. Isto foi, em algum sentido, revolucionário nos campos da biologia molecular e da medicina. Ao invés do estudo de um único gene ou um único mRNA por vez, biólogos são capazes agora, de estudar vários genes e mRNAs ao mesmo tempo. A tecnologia de microarrays permite a quantificação simultânea dos níveis de expressão de milhares de genes, permitindo a análise dos padrões de genes diferencialmente expressos sob diferentes condições, como doenças ou tratamentos com diferentes drogas. De fato, os microarrays são freqüentemente usados para estudar todos os mRNAs de um organismo. Isto abriu portas para uma inteira, nova, e sistemática forma de observar a reação de resposta das células, analisando os efeitos no nível de expressão de todos os seus genes.

\subsubsection{Affymetrix microarray}

A Affymetrix utiliza um equipamento similar aos usados na construção de chips de silício de computadores para a construção dos microarrays, assim, viabilizando a produção em massa de vários chips (microarrays) a um custo mais baixo. 
O grande número de oligos, cada um deles com no mínimo 25 nucleotídeos de comprimento, fez com que essa ferramenta fosse introduzida no lugar de técnicas clássicas de detecção, como o Southern, o Northern e o dot blotting.

Para a análise de expressão, mais de 40 oligos são usados para a detecção de cada gene. Para cada gene, uma região que presumidamente tem a menor similaridade com outros genes é escolhida. Dessa região, de 11 à 20 oligos são selecionados como matches perfeitos (i.e., perfeitamente complementares ao mRNA do gene). Ademais, são gerados de 11 à 20 oligos mismatches, que são idênticos aos matches perfeitos exceto pela posição central 13, onde um nucleotídeo é modificado para o seu nucleotídeo complementar. A Affymetrix afirma que os oligos mismatches são capazes de detectar hibridizações não-específicas que são importantes para a quantificação dos mRNAs de baixa expressão.

Para detectar a hibridização de um mRNA alvo pela sonda do chip, o mRNA alvo necessita de marcação com um flurófulo. Os passos (Figura 1.1) desde a extração do RNA da célula até o chip geralmente são os seguintes:

- Extração do RNA total da célula (geralmente usando os kits TRIzol ou RNeasy).

- Conversão do mRNA para cDNA usando a transcriptase reversa e um primer poli-T.

- Amplificação resultando no cDNA, usando a polimerase T7 RNA na presença de biotina-UTP e biotina-CTP. Assim, cada cDNA terá de 50 à 100 cópias de cRNA marcados com biotina.

- Incubação do cRNA a $94^{\circ} \mathrm{C}$ em um tampão de fragmentação para produzir cRNAs fragmentados de comprimento entre 35 a 200 nucleotídeos.

- Hibridização para o chip e lavagem para remoção do material não hibridizado.

- Hibridização do cRNA marcado com biotina e lavagem.

- Escaneamento do chip com scanner confocal.

- Amplificação do sinal no chip com o IgG e anticorpo biotinilado.

- Novo escaneamento.

Geralmente, de 5 a $10 \mu \mathrm{g}$ do RNA total são necessários para o procedimento, mas graças aos novos avanços nos protocolos de síntese de cDNA, a quantidade foi reduzida 


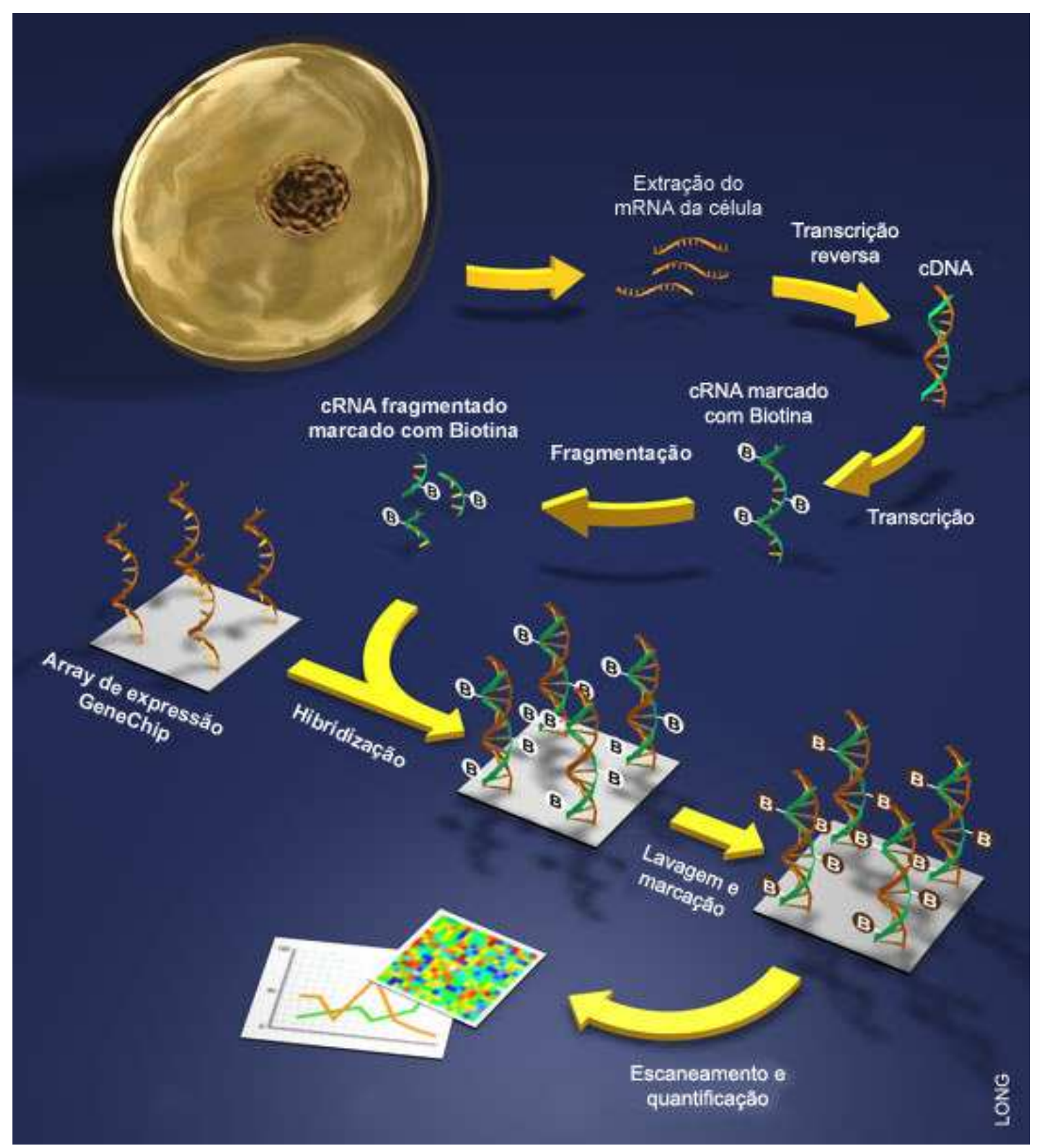

Figura 1.1: Diagrama ilustrativo do procedimento de microarray da plataforma Affymetrix. Figura retirada e modificada de http://plasticdog.cheme.columbia.edu/undergraduate_research/projects/sahil_mehta_project/ 
para 100ng. Com dois ciclos de síntese de cDNA e de cRNA, a detecção limite pode ser reduzida para 2ng do RNA total (Baugh et al., 2001).

\subsubsection{Arrays marcados}

Em uma outra tecnologia, chamada arrays marcados, um robô (spotter) é usado para mover pequenas quantidades de sonda em solução numa micro placa para a superfície de uma lâmina de vidro. A sonda pode consistir de cDNA, produto de PCR (polymerase chain reaction), ou oligonucleotídeos, sendo que cada sonda é complementar a um único gene. Essas sondas podem ser fixadas à superfície de inúmeras maneiras, sendo que, o modo clássico é por ligação não-específica a lâminas cobertas por polilisina. Os passos (Figura 1.2) envolvidos na construção das lâminas podem ser resumidos como descrito abaixo:

- Lâminas cobertas por polilisina.

- Preparação das sondas nas micro placas.

- Uso do robô para espotar as sondas nas lâminas de vidro.

- Bloqueio do restante das aminas de polilisina expostas.

- Denaturação do DNA (caso seja dupla fita) por calor.

Os passos envolvidos na preparação das amostras e hibridização ao array podem ser resumidos como:

- Extração do RNA total das células.

- Opcional: isolamento do mRNA pela cauda de poli-A.

- Conversão para cDNA na presença de Aminoalil1-dUTP (AA-dUTP).

- Marcação com os fluoróforos Cy3 e Cy5 ligando ao AA-dUTP.

- Hibridização do mRNA marcado às lâminas de vidro.

- Lavagem do material não hibridizado. 


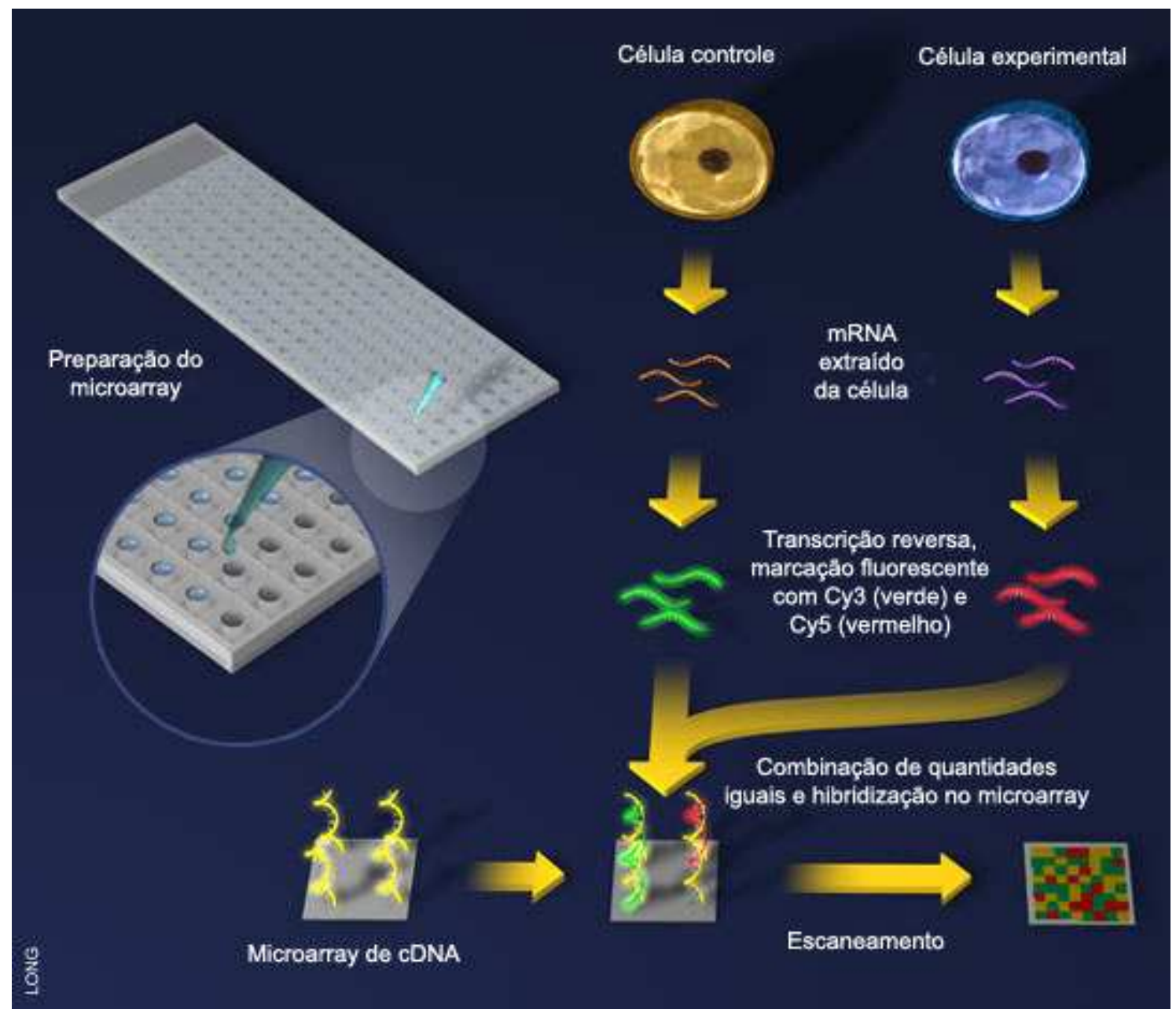

Figura 1.2: Diagrama ilustrativo do procedimento do spotted microarray. Figura retirada e modificada de http://plasticdog.cheme.columbia.edu/undergraduate_research/projects/sahil_mehta_project/ 
- Escaneamento da lâmina e análise da imagem.

A vantagem dessa técnica, se comparado ao Affymetrix GeneChip, é que, nesta abordagem, é possível desenhar quaisquer sondas para serem espotadas no array. As desvantagens são que a espotagem não é uniforme como nos sintetizados in situ como nos chips da Affymetrix, e o custo dos oligos, para chips contendo milhares de sondas, pode ser alto.

Do ponto de vista da análise dos dados, a principal diferença é que no array de cDNA, geralmente a amostra e o controle são hibridizados no mesmo chip usando diferentes fluoróforos, enquanto que no chip da Affymetrix, somente um fluoróforo é usado. Logo, são necessários dois chips para comparar a amostra e o controle (Knudsen, 2001).

\subsubsection{CodeLink TM}

A plataforma CodeLink ${ }^{\mathrm{TM}}$ consiste em microarrays de oligonucleotídeos préfabricados, onde as lâminas são previamente cobertas com um polímero hidrofóbico formando uma matriz 3D que orienta os oligonucleotídeos imobilizados para o sentido oposto ao do vidro. A característica hidrofóbica do polímero dificulta a ligação de sondas inespecíficas tanto ao DNA imobilizado quanto à lâmina de vidro, diminuindo assim o background. Juntamente com os oligonucleotídeos, é dispensado um fluoróforo derivado de fluorosceína que permite uma futura inspeção da qualidade de cada spot dispensado. Após a ligação dos oligonucleotídeos ao polímero, sítios adicionais para a ligação são bloqueados, o bioarray é lavado, seco e então é colado sobre a lâmina um adesivo de polipropileno que irá formar a câmera de hibridização (Figura 1.3) (Ramakrishnan et al., 2002).

$\mathrm{O}_{\text {CodeLink }}{ }^{\mathrm{TM}}$ possui algumas vantagens em relação às outras plataformas de microarray. Primeiramente, o fato dos oligos estarem ligados em uma matriz tridimensional aumenta o número de oligos por área de lâmina, além de facilitar o acesso das sondas aos oligos, aumentando assim a sensibilidade da técnica. Para dispensar as amostras, é utilizado um robô acoplado a um dispensador pizoelétrico, que garante maior precisão do volume dispensado, além de diminuir as chances de contaminação da lâmina, uma vez que o mesmo não toca a toca (Dorris et al., 2003).

Na Tabela 1.1 estão sintetizadas as principais vantagens e desvantagens de cada uma das plataformas de microarrays. 


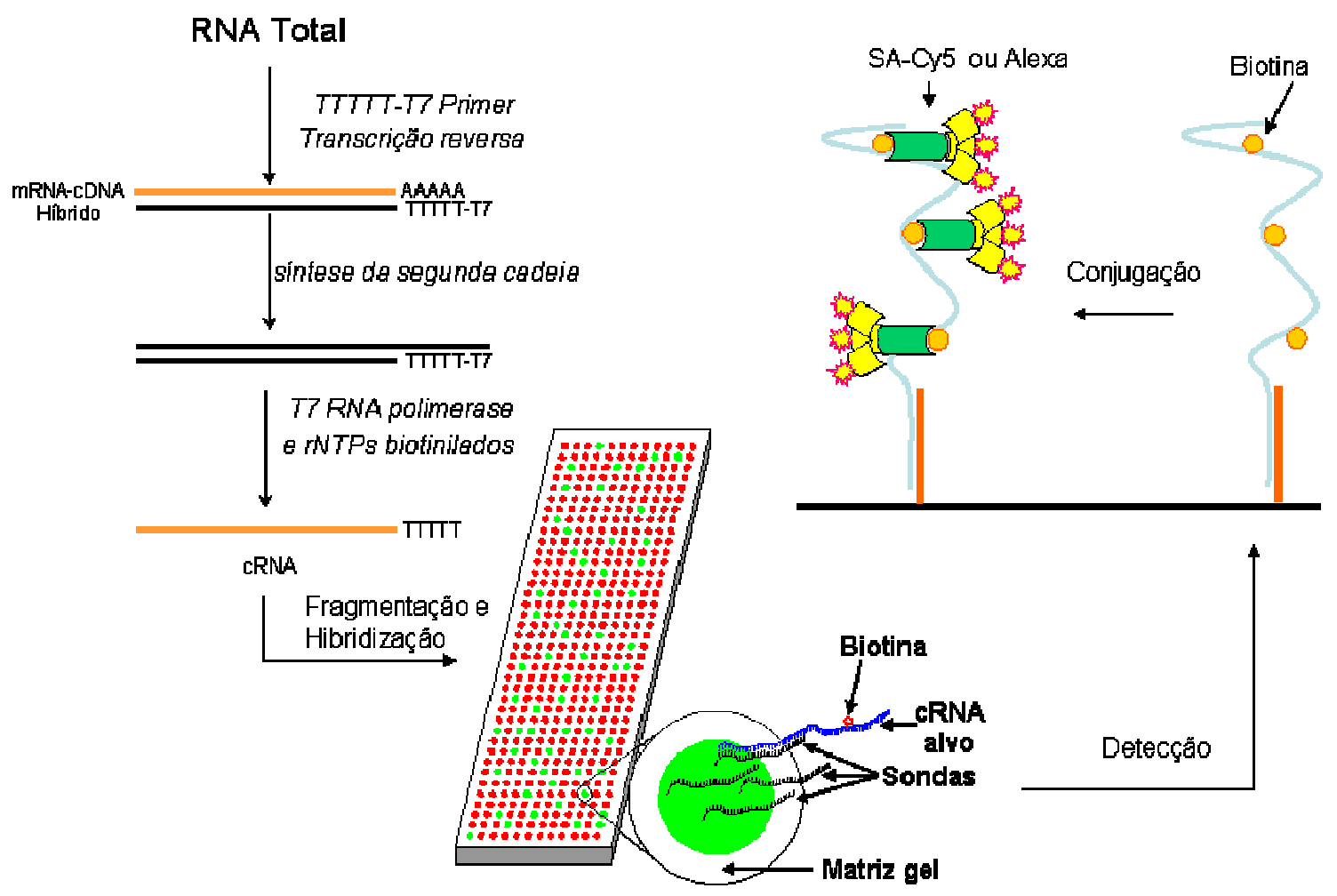

Figura 1.3: Diagrama ilustrativo do procedimento do microarray da plataforma CodeLink $^{\text {TM }}$. Figura cedida gentilmente pela GE Healthcare Life Sciences. 


\begin{tabular}{|c|cc|}
\hline & Vantagens & Desvantagens \\
\hline Affymetrix & Reprodutibilidade & Satálogo extenso \\
& Plataforma madura & Oligonucleotídeos curtos (menos sensitivos) \\
& Mais barato & Oligonucleotídeos múltiplos por gene \\
\hline Espotados & Customização & Sistema aberto (pode ser usado qualquer scanner) \\
& & Baixa especificidade \\
& Viés devido aos dois fluoróforos & Baixa reprodutibilidade \\
\hline CodeLink & Superfície 3D (mais sensível) & Ocasionalmente spots com baixa morfologia \\
& Sistema aberto (pode ser usado qualquer scanner) & Pequenos oligonucleotídeos \\
& Customização & \\
\hline
\end{tabular}

Tabela 1.1: Comparação das plataformas de microarrays.

\subsection{Redes regulatórias}

Com o advento da técnica de microarrays de DNA, é possível agora, obter uma visão geral dos níveis de transcrição dos genes na célula. Um grande desafio em Bioinformática consiste em inferir, através dessas medidas de expressão gênica, interações gene-proteína, proteína-proteína e características biológicas chaves do sistema celular.

O mecanismo de regulação dessas interações é um sistema complexo formado por diversos sinais atuando em momentos específicos e, muitas vezes, através de feedbacks. Em resumo, primeiramente, fatores de transcrição se ligam a regiões promotoras dos genes, ativando sua transcrição. Então, o transcrito ou mRNA é processado (splicing) para que depois haja a tradução para a proteína. Na rede de regulação gênica, as proteínas formam complexos multi-protéicos, os quais são os sinais atuantes no sistema de controle celular. Eles interagem com outros complexos multi-protéicos, em níveis tanto intra quanto extra celular, controlando vias metabólicas e recebendo feedbacks dos processos por eles controlados. Sinais são enviados para os níveis de transcrição e tradução. Estes sinais modificam os padrões futuros de expressão gênica e, conseqüentemente, a produção das proteínas. Desta forma, estes complexos multi-protéicos formam uma rede de sinalização que controla a atividade da célula, por exemplo, pela regulação da expressão gênica.

Para a modelagem matemática e inferência dessa rede, assume-se que o padrão de expressão gênica contenha a informação sobre a quantidade de tradução e atividade das proteínas, além disso, de que o nível de expressão de cada gene dependa tanto do seu próprio valor de expressão quanto dos valores de expressão de outros genes em instantes prévios de tempo. Em outras palavras, os dados de expressão gênica são utilizados para inferir a estrutura da rede regulatória, ou seja, a conectividade dos produtos gênicos (proteínas). 
CApítulo 2

\section{Normalização de dados de}

\section{microarrays}

Neste capítulo serão apresentados os diversos métodos de normalização de microarrays de DNA existentes na literatura, e uma comparação em termos de perturbação causada pelos genes diferencialmente expressos, além de apresentar uma proposta de normalização com desempenho superior aos já existentes (Fujita et al., 2006).

\subsection{Introdução}

Devido a pequenas diferenças na quantidade de RNA e flutuações geradas pela própria técnica de microarrays, os níveis de intensidade do spot podem variar de uma replicata a outra devido aos efeitos não relacionados aos genes, requerendo, portanto, uma normalização para que os valores possam ser comparados.

Assim, a normalização é um passo importante para a análise dos dados provenientes de microarrays. O objetivo da normalização é de minimizar os efeitos causados pelas variações técnicas e, assim, permitir que os dados sejam comparáveis, a fim de identificar as alterações biológicas. Diversas formas de normalização têm sido propostas. Alguns autores propõem o uso de razões da intensidade de hibridização, outros usam métodos lineares, enquanto outros utilizam métodos não-lineares ou globais. Vários ainda sugerem o uso de genes controles ou genes invariantes (Quackenbush, 2002; Cullane et al., 2002; Durbin et al., 2002; Kepler et al., 2002; Yang et al., 2002; Schadt et al., 2001; Hill et al., 2001). 
Recentemente, alguns autores sugeriram o uso de métodos de normalização não-lineares (Yang e Speed, 2002; Perou, 2001; Brazma et al., 2001) como sendo superiores aos mencionados anteriormente. O procedimento Lowess (Yang et al., 2002) tem sido amplamente utilizado para esse propósito, e está implementado em diversos pacotes disponíveis para análise de microarrays (Beheshti et al., 2003; Saeed et al., 2003), mas métodos similares têm sido sugeridos recentemente como, por exemplo: Splines (Baird et al., 2004; Workman et al., 2002) e Wavelets (Wang et al., 2004).

Nesta seção comparamos três diferentes métodos de normalização: Loess, Cubic Splines e Wavelets. Além destes, avaliamos duas novas propostas: Kernel (Nadaraya, 1964; Watson, 1964) e Support Vector Regression (SVR) (Vapnik, 1995), que, até então, ainda não haviam sido aplicadas para a normalização de microarrays. Com o propósito de identificar o melhor método de normalização, comparamos os diversos métodos utilizando dados reais de microarrays de camundongo da plataforma CodeLink ${ }^{\mathrm{TM}}$ (Ramakrishnan et al., 2002) gerados no Laboratório de Biologia Celular e Molecular do Instituto de Química da Universidade de São Paulo e em microarrays simulados. Este trabalho foi publicado na revista BMC Bioinformatics (Fujita et al, 2006).

\subsection{Métodos}

Do ponto de vista biológico, a normalização consiste em retirar o viés gerado na intensidade dos spots pela técnica de microarrays. Do ponto de vista matemático, a normalização consiste em realizar uma regressão não-paramétrica, assumindo como premissa, que a maior parte dos genes não são diferencialmente expressos.

Considere $n$ medidas observadas (número de spots) e, para cada uma delas, duas variáveis aleatórias $x_{i}$ e $y_{i}$, onde $x_{i}$ é a variável preditora e $y_{i}$ é a variável resposta esperada, para $i=1, \ldots, n$. Na nossa aplicação, $x_{i}$ é o log da intensidade de um dos microarrays ou log da intensidade de um dos fluoróforos caso seja um microarray de dois canais e $y_{i}$ é o log da intensidade do outro microarray ou log da intensidade do outro fluoróforo.

Neste modelo, $x$ e $y$ supostamente estão relacionadas da seguinte forma

$$
y_{i}=g\left(x_{i}+\varepsilon_{i}\right) \quad i=1, \ldots, n
$$


onde $g$ é a função de regressão que queremos encontrar e $\varepsilon_{i}$ é um erro aleatório.

Nas seções seguintes serão apresentados os métodos de normalização (Loess, Splines, Wavelets, Kernel e SVR) e nas seções 2.3 e 2.4 apresentamos as comparações e estudos realizados.

\subsubsection{Loess}

A regressão local Loess estima a função de normalização $\hat{g}(x)$ da seguinte maneira. Seja o parâmetro de suavização $q$ um número inteiro, tal que $1 \leq q \leq n$. A estimativa de $\hat{g}$ em $x$ usa as $q$ observações dos $x_{i}$ valores mais próximos de $x$, i.e., $q$ é o tamanho da vizinhança dos pontos a ser analisado. Cada ponto dessa vizinhança é ponderado de acordo com a distância de $x$ : pontos próximos de $x$ têm pesos grandes enquanto pontos distantes de $x$ têm pesos pequenos. Uma função linear ou quadrática das variáveis independentes $x$ é ajustada nas variáveis dependentes $y$ usando regressões por mínimos quadrados ponderados com estes pesos e $\hat{g}(x)$ é o valor de $y$ ajustado no ponto $x$. O procedimento termina quando todas as regressões são computadas para os $n$ pontos dos dados.

Para o cálculo de $\hat{g}(x)$, precisa-se de uma função de distância $\rho$, no caso, a distância Euclidiana. Além disso, o Loess necessita de uma função peso e a especificação da vizinhança dos pontos a ser analisada.

A tradicional função de peso usada para o Loess é a função de peso cúbica

$$
W(u)= \begin{cases}\left(1-|u|^{3}\right)^{3} & \text { para }|u|<1 \\ 0 & \text { para }|u| \geq 1\end{cases}
$$

Então, o peso da observação $\left(x_{i}, y_{i}\right)$ é dado por:

$$
w_{i}(x)=W\left(\rho\left(x, x_{i}\right) / d(x)\right)
$$

onde $d(x)$ é a distância do $q$-ésimo $x_{i}$ mais próximo de $x$.

Ao invés de se pensar em termos de $q$, pode-se pensar em termos de $f=q / n$, i.e., na fração de pontos da vizinhança. O valor de $q$ é a proporção dos dados usados para o ajuste. Quanto maior o valor de $q$, maior é a suavização. Quanto menor o $q$, mais a função se aproximará dos valores dos dados (Cleveland et al., 1992). 


\subsubsection{Cubic Splines}

Devido à simplicidade de sua estrutura, polinômios são largamente utilizados na prática para aproximar funções (Schumaker, 1981; Prenter, 1975). Sejam $x$ e $y$ como definidos na seção 2.2 , i.e., $\left(x_{i}, y_{i}\right)$ com $i=1,2, \ldots, n$, e a função $y_{i}=g\left(x_{i}+\varepsilon_{i}\right)$. Então, obtém-se $n$ pontos e $n-1$ intervalos. Para cada intervalo, define-se um polinômio de grau igual a três, com seus próprios coeficientes:

$$
g_{i}(x)=a_{i}\left(x-x_{i}\right)^{3}+b_{i}\left(x-x_{i}\right)^{2}+c_{i}\left(x-x_{i}\right)+d_{i} \quad \text { para } x \in\left[x_{i}, x_{i+1}\right] .
$$

Juntando todos os segmentos de polinômios, denota-se $g(x)$ como o spline.

Como existem $n-1$ intervalos e quatro coeficientes para cada intervalo, requere-se um total de $4(n-1)$ parâmetros para definir o spline $g(x)$. Precisa-se então encontrar $4(n-1)$ condições independentes para obter-se uma solução determinada dos parâmetros. Duas condições para cada intervalo podem ser obtidas através de:

$$
g_{i}\left(x_{i}\right)=y_{i} \quad g_{i}\left(x_{i+1}\right)=y_{i+1}
$$

Note que estas condições implicam em uma função contínua.

Ainda precisa-se de mais $2(n-1)$ condições. Como se quer interpolar os pontos de forma mais suave possível, espera-se que a primeira e segunda derivadas sejam também contínuas:

$$
g_{i-1}^{\prime}\left(x_{i}\right)=g_{i}^{\prime}\left(x_{i}\right) \quad g_{i-1}^{\prime \prime}\left(x_{i}\right)=g_{i}^{\prime \prime}\left(x_{i}\right) \quad \forall i \geq 2
$$

Logo, obtem-se mais $2(n-2)$ condições. Assim, ainda faltam mais duas condições para resolver o problema.

Pode-se então usar

$$
g_{1}^{\prime \prime}\left(x_{1}\right)=0 \quad g_{n-1}^{\prime \prime}\left(x_{n}\right)=0
$$

Com 4(n-1) coeficientes e 4(n-1) condições lineares, agora é possível realizar a suavização. As condições podem ser reduzidas para um sistema de equações tri-diagonal (matriz quadrada com elementos não-zero somente na diagonal e nas posições imediatamente adjacentes horizontalmente ou verticalmente a diagonal, i.e., ao longo da subdiagonal e superdiagonal) com coeficientes desconhecidos. 


\subsubsection{Wavelets}

A transformada de Wavelet é um método relativamente novo que tem algumas similaridades com a transformada de Fourier (transformada que expressa uma função como soma de funções senoidais multiplicadas por coeficientes). Wavelets diferem das transformadas de Fourier no sentido de que as Wavelets permitem a localização do sinal tanto no tempo quanto na freqüência. Em teoria, a função é representada por uma série infinita de expansões em termos de dilatações e translações de uma função básica $\psi$, chamada de Wavelet "mãe".

O termo Wavelet significa onda pequena, assim, elas são oscilações que decaem rapidamente. Como as B-Splines, as funções Wavelets $\psi(x)$ podem ser usadas para gerar a função base para certos espaços (Meyer, 1993). Uma base ortonormal pode ser gerada a partir de dilatações e translações da Wavelet mãe $\psi(x)$ por

$$
\psi_{j, k}(x)=2^{j / 2} \psi\left(2^{j} j-k\right) \quad j, k \in \mathbb{Z}
$$

Estas funções satisfazem as seguintes propriedades:

1. $\int_{-\infty}^{\infty} \psi(x) d x=0$

2. $\int_{-\infty}^{\infty}|\psi(x)| d x<\infty$

3. $\int_{-\infty}^{\infty} \frac{\left|\psi(\omega)^{2}\right| d \omega}{|\omega|}=0$ onde a função $\psi(\omega)$ é a transformada de Fourier de $\psi(x)$

4. $\int_{-\infty}^{\infty} t^{j} \psi(x) d x=0, j=0,1, \ldots, r-1$ para $r \geq 1$ e $\int_{-\infty}^{\infty}\left|x^{r} \psi(x)\right| d x<\infty$

Um importante resultado é que qualquer função $g(x) \operatorname{com} \int_{-\infty}^{\infty} g^{2}(x)<\infty$ pode ser expandida como

$$
g(x)=\sum_{j=-\infty}^{\infty} \sum_{k=-\infty}^{\infty} c_{j, k} \psi_{j, k}(x)
$$

Em outras palavras, qualquer função $g(x)$ satisfazendo a propriedade mencionada, pode ser representada por uma combinação linear de funções $\psi_{j, k}(x)$. O procedimento de suavização ocorre através de uma aproximação, escolhendo a resolução máxima $J(x)$ para $j=1,2, \ldots, J(x)$ e $k=1,2, \ldots, 2^{j-1}$. Aqui, nós consideramos a Wavelet como o chapéu mexicano (Chui, 1992) definido por

$$
\psi(x)=\left(1-x^{2}\right) e^{\frac{-x^{2}}{2}}
$$


pois outras funções como as funções de Morlet ou Shannon não possuem fórmula analítica fechada.

Os coeficientes $c_{j, k}$ são estimados via uma regressão linear simples.

\subsubsection{Kernel}

O Kernel é um dos métodos mais largamente usados na estimação não-paramétrica de curvas. Dada uma janela $h$ (parâmetro de suavização) e um kernel (função que leva de $R^{k} \rightarrow R^{1}$ ) que pondera os pontos, é feita uma regressão para se estimar a função $g$ que é a função de normalização dos spots do microarray. Nadaraya (1964) e Watson (1964) propuseram um estimador para a curva $g$ dado por

$$
g_{h}(x)=\frac{\sum_{i=1}^{n} K\left(\frac{x-x_{i}}{h}\right) y_{i}}{\sum_{j=1}^{n} K\left(\frac{x-x_{j}}{h}\right)}
$$

Nos nossos dados, usamos o Kernel Gaussiano dado por

$$
K(z)=\frac{1}{\sqrt{2 \pi}} \exp ^{-\frac{1}{2} z^{2}}
$$

pois é simétrico e centralizado na média.

Além de ser de fácil computação, o estimador de Nadaraya-Watson $g_{h}(x)$ é consistente. Quando $h \rightarrow 0$, obtemos uma curva que apresenta grande variabilidade. Quando $h \rightarrow$ $\infty$, obtemos uma curva hiper suavizada (Härdle, 1990). A janela $h$ controla o grau de suavidade da curva. É fácil ver que o estimador Kernel é apenas a soma ponderada das respostas observadas $y_{i}$. O denominador assegura que a soma dos pesos seja igual a 1 .

\subsubsection{Support Vector Regression}

SVR é um algoritmo de regressão não-linear derivado da técnica de Support Vector Machine (SVM) (Vapnik e Lerner, 1963; Vapnik e Chervonenkis, 1964) que vem sendo utilizado com sucesso em Bioinformática (Furey et al., 2000; Lorena e Carvalho, 2007). O SVR foi desenvolvido por Drucker e colaboradores (Drucker et al, 1996) e é baseado na teoria de aprendizagem estatística desenvolvido por Vapnik e Chervonenkis (1974). Em Bioinformática, e mais precisamente na análise de dados de microarray, o algoritmo foi usado segundo pudemos apurar, uma única vez por Hisanori et al. (2004). Aqui, propomos o uso do SVR para a normalização de microarrays. 
Seja $\left\{\left(x_{1}, y_{1}\right), \ldots,\left(x_{n}, y_{n}\right)\right\} \subset \mathbb{R} \times \mathbb{R}$ os dados de expressão gênica derivados dos experimentos de microarray, onde $x$ é o log da intensidade de um microarray e $y$ é o log da intensidade do outro, caso estejamos analisando um microarray de um canal. Se o microarray é da plataforma de dois canais, $x$ é o log da intensidade de um fluoróforo e $y$ é o log da intensidade do outro fluoróforo. No $\varepsilon$-SVR (Vapnik, 1998), o objetivo é obter uma função $g(x)$ que tenha no máximo $\varepsilon$ de desvio de $y_{i}$ de todos os dados, e seja o mais plano possível.

No caso de funções lineares $g$ :

$$
g(x)=\left\langle w^{t} x\right\rangle+b \quad w \in \mathbb{R}^{n}, b \in \mathbb{R}
$$

Planaridade em 2.13 significa encontrar um $w$ pequeno. Uma forma de assegurar isso é minimizando a norma, i.e. $\|w\|^{2}=\left\langle w^{t}, w\right\rangle$. Isso pode ser escrito como um problema de otimização convexa:

Minimize

$$
\frac{1}{2}\|w\|^{2}
$$

Sujeito a

$$
y_{i}-\left\langle w^{t} x_{i}\right\rangle-b \leq \varepsilon \quad\left\langle w^{t} x_{i}\right\rangle+b-y_{i} \leq \varepsilon
$$

Em 2.15 assumimos que existe uma função $g$ que, com precisão $\varepsilon$, aproxima todos os pares $\left(x_{i}, y_{i}\right)$, em outras palavras, assume-se que este problema de otimização é viável. Mas há casos em que isso não é possível ou queremos permitir alguns erros. Para solucionar este problema, são introduzidas as variáveis de folga $\xi_{i}, \xi_{i}^{*}$ para garantir solução viável do problema de otimização, chegando a seguinte formulação (Vapnik, 1998):

Minimize

$$
\frac{1}{2}\|w\|^{2}+C \sum_{i=1}\left(\xi_{i}+\xi_{i}^{*}\right)
$$

Limitado por

$$
\begin{gathered}
y_{i}-\left\langle w^{t} x_{i}\right\rangle-b \leq \varepsilon+\xi_{i} \\
\left\langle w^{t} x_{i}\right\rangle+b-y_{i} \leq \varepsilon+\xi_{i}^{*} \\
\xi_{i}, \xi_{i}^{*} \geq 0
\end{gathered}
$$

onde a constante $C>0$ que determina a quantidade acima do qual os desvios maiores que $\varepsilon$ são tolerados. Isto corresponde a tratar a função de perda $\varepsilon$-intensiva $|\xi|_{\varepsilon}$ descrita 
por:

$$
|\xi|_{\varepsilon}= \begin{cases}0 & \text { se }|\xi| \leq \varepsilon \\ |\xi|-\varepsilon & \text { caso contrário }\end{cases}
$$

A idéia principal consiste em construir uma relaxação da função objetivo primal e os correspondentes limitantes, introduzindo o conjunto de duas variáveis. Mais especificamente, como vemos em Mangasarian (1969), McCormik (1983) e Vanderbei (1997), as restrições 2.17, 2.18, 2.19 são relaxadas, construindo-se uma relaxação lagrangiana que segue:

$$
\begin{aligned}
L:= & \frac{1}{2}\|w\|^{2}+C \sum_{i=1}^{l}\left(\xi_{i}+\xi_{i}^{*}\right)-\sum_{i=1}^{l}\left(\eta_{i} \xi_{i}+\eta_{i}^{*} \xi_{i}^{*}\right)- \\
& -\sum_{i=1}^{l} \alpha_{i}\left(\varepsilon+\xi_{i}-y_{i}+\left\langle w^{t} x_{i}\right\rangle+b\right)-\sum_{i=1}^{l} \alpha_{i}^{*}\left(\varepsilon+\xi_{i}^{*}+y_{i}-\left\langle w^{t} x_{i}\right\rangle-b\right)
\end{aligned}
$$

onde $L$ é o Lagrangiano e $n_{i}, \eta_{i}^{*}, \alpha_{i}, \alpha_{i}^{*}$ são os multiplicadores de Lagrange. As variáveis duais de 2.21 têm que satisfazer

$$
\alpha_{i}, \alpha_{i}^{*}, \eta_{i}, \eta_{i}^{*} \geq 0
$$

Pela condição do ponto de sela (ponto de sela é um ponto da função que é um ponto estacionário (primeira derivada igual a zero) e também um ponto de inflexão (a segunda derivada muda de sinal)), as derivadas parciais de $L$ relacionadas com as variáveis primais $\left(w, b, \xi_{i}, \xi_{i}^{*}\right)$ têm que desaparecer.

$$
\begin{gathered}
\frac{\delta L}{\delta b}=\sum_{i=1}^{l}\left(\alpha_{i}^{(*)}-\alpha_{i}\right)=0 \\
\frac{\delta L}{\delta w}=w-\sum_{i=1}^{l}\left(\alpha_{i}-\alpha_{i}^{(*)}\right) x_{i}=0 \\
\frac{\delta L}{\delta \xi_{i}}=C-\alpha_{i}-\eta_{i}=0 \\
\frac{\delta L}{\delta \xi_{i}^{*}}=C-\alpha_{i}^{*}-\eta_{i}^{*}=0
\end{gathered}
$$

Da substituição de 2.23, 2.24, 2.25 e 2.26 em 2.21, nós obtemos o problema de otimização dual.

Maximizar

$$
-\frac{1}{2} \sum_{i, j=1}^{l}\left(\alpha_{i}-\alpha_{i}^{*}\right)\left(\alpha_{j}-\alpha_{j}^{*}\right)\left\langle x_{i}^{t} x_{j}\right\rangle-\varepsilon \sum_{i=1}^{l}\left(\alpha_{i}-\alpha_{i}^{*}\right)+\sum_{i=1}^{l} y_{i}\left(\alpha_{i}-\alpha_{i}^{*}\right)
$$


Sujeito a

$$
\sum_{i=1}^{l}\left(\alpha_{i}-\alpha_{i}^{*}\right)=0 \quad \alpha_{i}, \alpha_{i}^{*} \in[0, C]
$$

A equação 2.24 pode ser re-escrita como

$$
w=\sum_{i=1}^{l}\left(\alpha_{i}-\alpha_{i}^{*}\right) x_{i} \Rightarrow g(x)=\sum_{i=1}^{l}\left(\alpha_{i}-\alpha_{i}^{*}\right)\left\langle x^{t} x\right\rangle+b
$$

Esta é a chamada Expansão de Suporte Vetorial, i.e., w pode ser descrito como uma combinação linear de $x_{i}$.

Para computar b, é necessário usar a condição de Karush-Kuhn-Tucker (KKT) (Karush, 1939; Kuhn e Tucker, 1951). Seguindo tais condições, no ponto da solução, o produto das variáveis duais e limitantes precisam desaparecer.

$$
\begin{gathered}
\alpha_{i}\left(\varepsilon+\xi_{i}-y_{i}+\left\langle w^{t} x_{i}\right\rangle+b\right)=0 \\
\alpha_{i}^{*}\left(\varepsilon+\xi_{i}^{*}+y_{i}-\left\langle w^{t} x_{i}\right\rangle-b\right)=0
\end{gathered}
$$

e

$$
\left(C-\alpha_{i}\right) \xi_{i}=0 \quad\left(C-\alpha_{i}^{*}\right) \xi_{i}^{*}=0
$$

De $2.30,2.31$ e 2.32 segue que:

1. Somente as observações $\left(x_{i}, y_{i}\right)$ com correspondentes $\alpha_{i}^{*}=C$ estão além da distância $\varepsilon$

2. $\alpha_{i} \alpha_{i}^{*}=0$, i.e., não é possível haver $\alpha_{i}, \alpha_{i}^{*}$ que são ambas simultaneamente diferentes de zero.

De (1) e (2), é possível concluir que

$$
\begin{gathered}
\varepsilon-y_{i}+\left\langle w^{t} x_{i}\right\rangle+b \geq 0 \text { e } \xi_{i}=0 \text { se } \alpha_{i}<0 \\
\varepsilon-y_{i}+\left\langle w^{t} x_{i}\right\rangle+b \leq 0 \text { se } \alpha_{i}>0
\end{gathered}
$$

Em conjunto com uma análise análoga à $\alpha_{i}^{*}$ nós temos

$\max \left\{-\varepsilon+y_{i}-\left\langle w^{t} x_{i}\right\rangle \mid \alpha_{i}<C\right.$ ou $\left.\alpha_{i}^{*}>0\right\} \leq b \leq \min \left\{-\varepsilon+y_{i}-\left\langle w^{t} x_{i}\right\rangle \mid \alpha_{i}>0\right.$ ou $\left.\alpha_{i}^{*}<C\right\}$ 
Se algum $\alpha_{i}^{*} \in(0, C)$ as desigualdades se tornam igualdades.

Para ressaltar a esparsidade da expansão dos Suportes Vetoriais: de 2.30, os multiplicadores de Lagrange podem ser não-zero somente para $\left|g(x)-y_{i}\right| \geq \varepsilon$. Em outras palavras, para todas as observações de distância menor que $\varepsilon$, os $\alpha_{i}$, $\alpha_{i}^{*}$ desaparecem: para $\left|g\left(x_{i}-y_{i}\right)\right|<\varepsilon$ o segundo fator em 2.30 é não-zero, portanto $\alpha_{i}$, $\alpha_{i}^{*}$ têm que ser zero para que as condições KKT sejam satisfeitas.

Assim, nós temos uma expansão esparsa de $w$ em termos de $x_{i}$ (i.e., não precisamos de todos os $x_{i}$ para descrever $w$ ) (Smola e Schölkopf, 2004).

\subsection{Descrição dos experimentos}

Os métodos apresentados nas seções anteriores foram implementados e testados em uma bateria de testes para verificar a quantidade de perturbação sofrida por genes diferencialmente expressos. Nesta seção descrevemos os tipos de experimentos realizados.

Aqui apresentaremos a construção dos dois tipos de microarrays utilizados em nossos experimentos: o protocolo utilizado no microarray real da plataforma CodeLink ${ }^{\mathrm{TM}}$ composto por $\sim 10.000$ genes de camundongo e o algoritmo de geração dos microarrays artificiais simulados.

\subsubsection{Protocolo CodeLink TM}

\section{Lise das células e extração do RNA}

Culturas de células foram lisadas com isocianato de guanidina e o RNA foi purificado das células lisadas pelo cloreto de césio (Chirgwin et al., 1979). A razão de absorbância usada para acessar a pureza do RNA foi de 260/280nm, sendo que uma razão de 1.8 - 2.0 indicava pureza adequada.

\section{Purificação dos alvos}

Amostras de RNA foram preparadas e processadas de acordo com os protocolos fornecidos pelo fabricante (GE Healthcare). Brevemente, cDNAs foram sintetizados a partir do 
RNA purificado $(2 \mu \mathrm{g})$ e mRNAs controle de bactérias. Amostras purificadas usando QIAquick Spin kit (Qiagen) e concentrados por SpeedVac. Peletes concentrados foram usados em UTP biotilados baseados na síntese de cRNA usando o CodeLink ${ }^{\text {TM }}$ Expression Assay Reagent Kit (Amersham). cRNAs marcados foram purificados usando o RNeasy kit (Qiagen) e fragmentados com solução à $94^{\circ} \mathrm{C}$ por 20 minutos.

\section{Hibridização e lavagem dos arrays}

cRNAs fragmentados e marcados com biotina $(10 \mu \mathrm{g})$ foram incubados com arrays CodeLink $^{\text {TM }}$ e centrifugados $(300 \mathrm{rpm})$ por 20 horas. Os bioarrays foram lavados e incubados com Cy5-Streptavidin (30 min). Escaneamento dos bioarrays foram feitos pelo programa GenePix 4000 B Array Scanner (Axon Instruments) e os dados foram coletados usando o CodeLink ${ }^{\mathrm{TM}}$ System Software (Amersham), que forneceu os dados brutos dos spots.

\subsubsection{Microarrays artificiais}

Para que pudéssemos ter o controle dos genes diferencialmente expressos e do viés causado pelos experimentos, optamos por criar microarrays artificiais seguindo o modelo matemático proposto por Balagurunathan (Balagurunathan et al., 2002).

É sabido que a distribuição dos níveis de expressão dos genes na célula é muito semelhante a uma distribuição exponencial (Bishop et al., 1974). Logo, dado um microarray contendo $n$ genes, os níveis de intensidade $I_{k}$, para $k=1, \ldots, n$, relacionados aos níveis de expressão dos $n$ genes, são simulados a partir desta distribuição exponencial. Este nível de intensidade $I_{k}$ é considerado como o sinal que não é diretamente mensurado a partir do microarray, pois se sabe que a partir de dados provenientes de processos biológicos, da extração do mRNA até o processo de hibridização, alguma variação será introduzida na quantificação do sinal final da fluorescência. Para cada microarray, uma particular distribuição exponencial com média $\beta$ é primeiramente escolhida. No nosso trabalho, escolhemos um $\beta$ igual a 3000 como descrito no artigo de Balagurunathan et al., 2002. Em seguida, para cada spot que assumimos representar um gene, um valor $I_{k}$ é gerado a partir da distribuição exponencial. Para duas observações $\left(R_{k}, G_{k}\right)$ provenientes de duas lâminas, dois números são gerados a partir de uma distribuição Normal com média $I_{k}$ e 
desvio padrão $\alpha I_{k}$, onde $\alpha$ é o coeficiente de variação, que, em geral, está em torno de $5 \%$ - 30\% dependendo da relação biológica entre as duas lâminas.

Para incluir os genes diferencialmente expressos, a razão de expressão do $k$-ésimo gene é dado por

$$
t_{k}=10^{ \pm b_{k}}
$$

onde $b_{k}$ satisfaz uma distribuição Beta, $b_{k} \sim B(1.7,4.8)$ (Balagurunathan et al., 2002), e onde os sinais +/- são selecionados com igual probabilidade. Após a obtenção da razão de expressão, a intensidade de fluorescência das duas lâminas pode ser obtida por

$$
R_{k}^{\prime}=R_{k} \sqrt{t_{k}} \quad G_{k}^{\prime}=\frac{G_{k}}{\sqrt{t_{k}}}
$$

onde $R_{k}^{\prime}$ e $G_{k}^{\prime}$ são os valores dos sinais após a conversão.

Devido a várias razões como imprecisão na quantidade de mRNA nas duas lâminas, diferenças na eficiência dos fluoróforos ou até mesmo na potência dos lasers no estágio de escaneamento, a intensidade dos spots nos microarrays reais pode não ser igual mesmo usando as mesmas amostras de mRNA. Além disso, nada impede que a intensidade de fluorescência não esteja relacionada de forma linear com os valores de expressão. A família de funções que caracteriza essa não linearidade é formada por quatro parâmetros $\left(a_{0}, a_{1}, a_{2}, a_{3}\right)$, e a função é dada por

$$
f(x)=a_{3}\left[a_{0}+x\left(1-e^{-x / a_{1}}\right)^{a_{2}}\right] ; \quad a_{3}>1
$$

Tendo definido os valores dos parâmetros $\left(a_{0}, a_{1}, a_{2}, a_{3}\right)$ e aplicando a função 2.38, obtemos os sinais de fluorescência $f_{R}(x)$ e $f_{G}(x)$ como sendo os sinais observados. As intensidades de fluorescência observadas são

$$
R_{k}^{\prime \prime}=f_{R}\left(R_{k}^{\prime}\right), G_{k}^{\prime \prime}=f_{G}\left(G_{k}^{\prime}\right),
$$

onde $f_{R}$ ou $f_{G}$ podem ter diferentes parâmetros.

\subsection{Simulações}

Para as nossas simulações, criamos três tipos de microarrays chamados de banana, sinuosa e mista com os seguintes parâmetros: $\left(R_{1}=(0,500,-1,1), G_{1}=(0,10,-1,1)\right)$ 
(Figura 2.1), $\left(R_{2}=\left(0,100^{1 / 0.7},-0.7,1\right), G_{2}=\left(0,100^{1 / 0.9},-0.9,1\right)\right)\left(\right.$ Figura 2.2) e $\left(R_{3}=\right.$ $\left.(0,500,-1,1), G_{3}=\left(0,100^{1 / 0.9},-0.9,1\right)\right)$ (Figura 2.3), respectivamente. Estes nomes foram dados devido ao formato da figura gerada pela impressão dos spots no gráfico, onde no eixo X estão os spots do R e no eixo $\mathrm{Y}$ os spots do G.

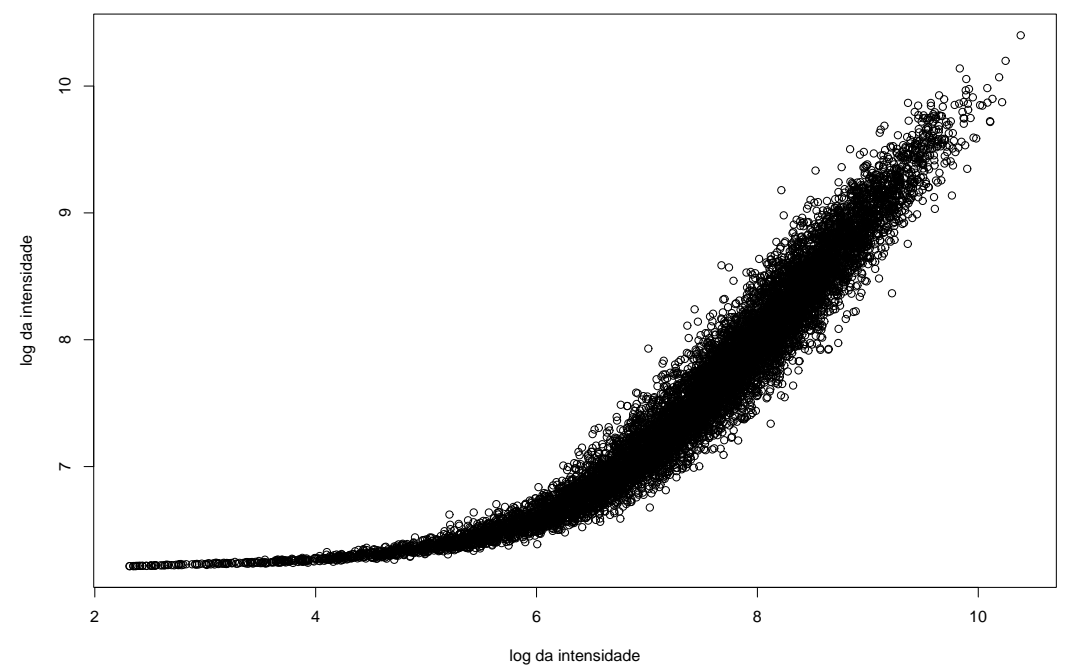

Figura 2.1: Gráfico do log da intensidade de fluorescência de um array pelo log da intensidade de fluorescência do outro array com formato de banana.

Para realizar a comparação dos diversos métodos, realizamos o seguinte experimento para cada um dos três formatos de microarray:

1. Simula-se o microarray como descrito na seção anterior;

2. Divide-se o microarray em três partes: (i) spots de baixa expressão, (ii) spots de expressão mediana e (iii) spots de alta expressão;

3. Para cada uma das partes, geram-se genes direfencialmente expressos como descrito na seção anterior;

4. Calcule o erro quadrático médio entre a curva estimada pelo método de normalização e da curva original na qual foi gerado o microarray;

5. Repita os passos de 1 a 4, 100 vezes. 


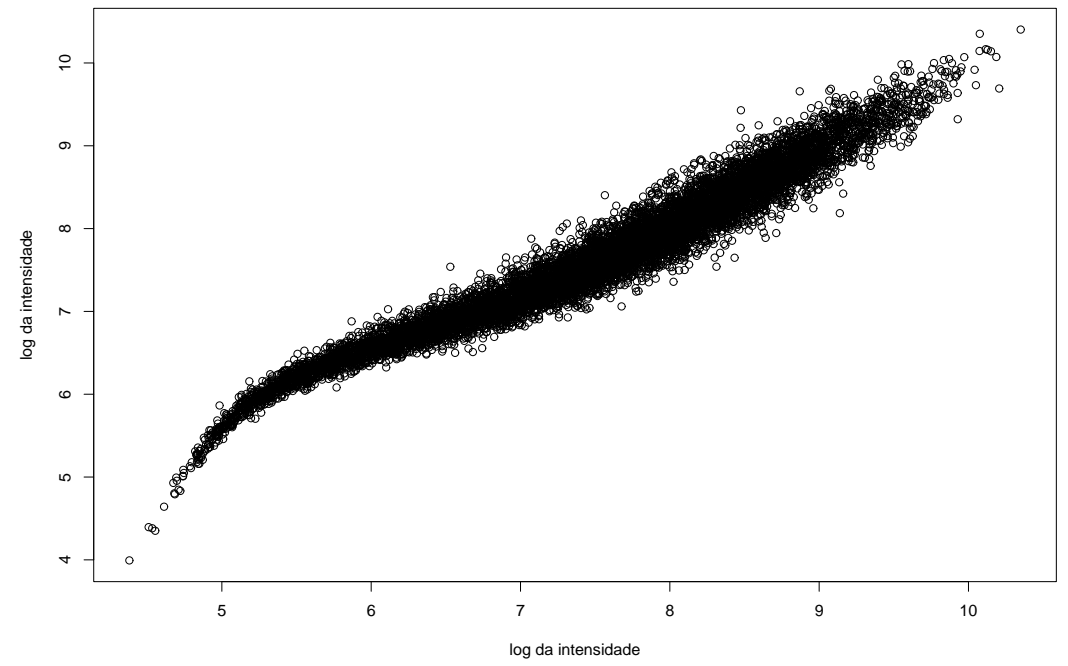

Figura 2.2: Gráfico do log da intensidade de fluorescência de um array pelo log da intensidade de fluorescência do outro array com formato sinuoso.

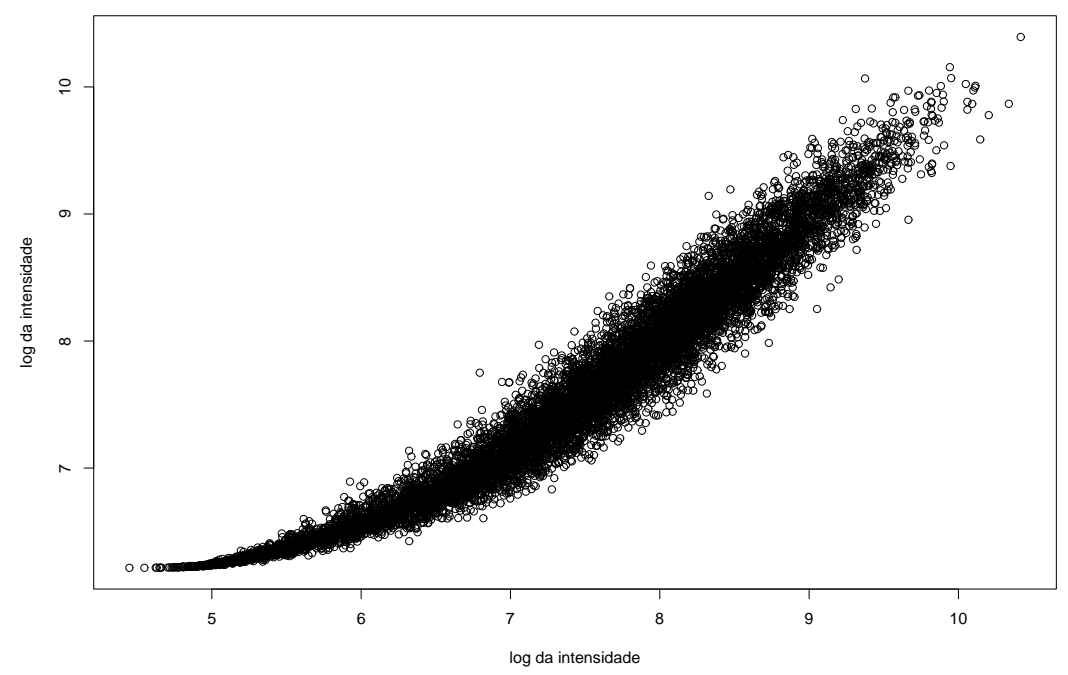

Figura 2.3: Gráfico do log da intensidade de fluorescência de um array pelo log da intensidade de fluorescência do outro array com formato misto (banana+sinuoso). 
Variamos a proporção de genes diferencialmente expressos em cada uma das três partes em: 5, 10, 15, 20 e 40\%.

O melhor método de normalização deve ser aquele no qual obtemos o menor erro quadrático médio, pois seria o que apresenta a menor perturbação aos genes diferencialmente expresssos.

Os parâmetros de suavização usados para cada conjunto de dados estão descritos na Tabela 2.1. Para o SVR, testamos vários valores e, como resultado, selecionamos $\varepsilon=0.01$ e $C=4$ como o mais adequado. É importante notar que os parâmetros são arbitrários, assim, escolhemos os parâmetros ótimos para cada método, i.e., testamos para um intervalo e escolhemos aquele que resulta no menor erro quadrático médio. Na Figura 2.4 estão descritas as médias dos erros quadráticos para cada método de normalização aplicado nas 3 diferentes estruturas de microarrays sem outliers.

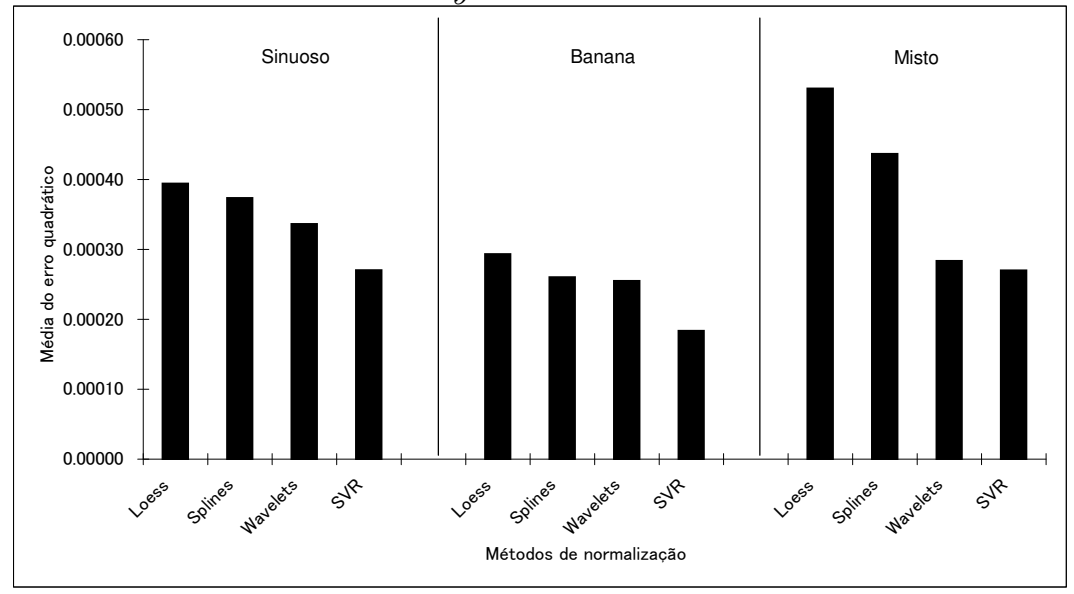

Figura 2.4: Mínimo dos erros quadráticos médios para o conjunto de 3 microarrays simulados. Da esquerda para a direita: 1- sinuoso; 2- banana; 3- misto. A regressão Kernel não foi incluída na figura porque o erro quadrático médio dele foi cerca de $10^{3}$ ordens de magnitude maior que os outros métodos.

Comparando os resultados apresentados nas Tabelas 2.2, 2.3 e 2.4 vemos que não há nenhuma importante diferença entre Loess, Splines e Wavelets. Apesar do método nãoparamétrico Kernel ter tido sucesso na análise de dados econométricos (Dias, 2002), na análise de dados de microarrays, ele apresentou um desempenho insatisfatório devido à alta sensibilidade aos outliers (Archambeau, 2005). 


\begin{tabular}{|c|ccc|}
\hline & Banana & Sinuoso & Misto \\
\hline Loess & 0.30 & 0.10 & 0.10 \\
Splines & 10.00 & 20.00 & 20.00 \\
Wavelets & 16.00 & 64.00 & 16.00 \\
Kernel & 0.50 & 0.50 & 0.70 \\
SVR & 0.20 & 0.20 & 0.60 \\
\hline
\end{tabular}

Tabela 2.1: Parâmetros de suavização usados para conjunto de microarrays. Para o Loess, o parâmetro é o valor do span, para o Splines e Wavelets são o número de funções, para o Kernel é o valor máximo menos o valor mínimo da expressão multiplicado pelo número descrito na tabela.

Analisando a Tabela 2.2, é possível observar que, no caso sinuoso, quando os outliers são inseridos em regiões de baixa expressão, SVR, Wavelets, Splines, Loess e Kernel, nessa ordem, apresentam do menor para o maior erro quadrático médio, sendo estatisticamente diferentes ( $p$ valor < 0.001) um do outro. Para os microarrays em formato de banana e misto, Loess e Splines apresentam menor erro quadrático médio que o Wavelets. Na Tabela 2.3, é interessante notar que, quando os outliers são inseridos em regiões de média expressão gênica, i.e., alta densidade de genes, a ordem de desempenho se mantém a mesma que na Tabela 2.2 e o SVR apresenta o menor erro quadrático médio com diferença siginificante em relação aos demais métodos ( $p$ valor $<0.001)$. Loess e Splines mostraram nenhuma diferença significativa $(p$ valor $>0.05)$ e Kernel é significativamente pior que os outros métodos $(p$ valor $<0.001)$. Na Tabela 2.4 , os outliers são inseridos na região de alta expressão. Mais uma vez, a tendência é mantida, ou seja, Kernel é o mais afetado pelos outliers $(p$ valor $<0.001)$ e nenhuma diferença entre Splines e Wavelets $(p$ valor $>$ 0.05) foi observada para o formato sinuoso. Para os outros dois formatos, Loess e Splines são melhores que o Wavelets ( $p$ valor $<0.001)$.

Nos três casos (outliers inseridos em baixa, média e alta expressão), SVR é o menos afetado pelos outliers ( $p$ valor $<0.001$ ), independente do formato dos microarrays. Além disso, SVR apresenta o menor desvio padrão, seguido por Loess, Splines, Wavelets, com o Kernel apresentando o maior desvio padrão. 


\begin{tabular}{|c|c|c|c|c|c|c|c|c|c|c|}
\hline \multirow[t]{2}{*}{ \%GDE } & & \multicolumn{3}{|c|}{ Sinuoso } & \multicolumn{3}{|c|}{ Banana } & \multicolumn{3}{|c|}{ Misto } \\
\hline & Método & $1^{\circ}$ quartil & $2^{\circ}$ quartil & $3^{\circ}$ quartil & $1^{\circ}$ quartil & $2^{\circ}$ quartil & $3^{\circ}$ quartil & $1^{\circ}$ quartil & $2^{\circ}$ quartil & $3^{\circ}$ quartil \\
\hline \multirow{5}{*}{5} & Loess & 0.00038 & 0.00039 & 0.00040 & 0.00029 & 0.00029 & 0.00029 & 0.04806 & 0.04816 & 0.04825 \\
\hline & Splines & 0.00035 & 0.00036 & 0.00037 & 0.00027 & 0.00028 & 0.00028 & 0.04828 & 0.04839 & 0.04848 \\
\hline & Wavelets & 0.00033 & 0.00034 & 0.00035 & 0.00127 & 0.00128 & 0.00128 & 0.04816 & 0.04827 & 0.04835 \\
\hline & Kernel & 0.03781 & 0.03782 & 0.03783 & 0.14368 & 0.14404 & 0.14416 & 0.19869 & 0.19888 & 0.20098 \\
\hline & SVR & 0.00031 & 0.00032 & 0.00033 & 0.00016 & 0.00016 & 0.00017 & 0.04729 & 0.04733 & 0.04738 \\
\hline \multirow{5}{*}{10} & Loess & 0.00047 & 0.00048 & 0.00050 & 0.00038 & 0.00038 & 0.00039 & 0.04631 & 0.04646 & 0.04661 \\
\hline & Splines & 0.00044 & 0.00045 & 0.00047 & 0.00037 & 0.00038 & 0.00039 & 0.04649 & 0.04663 & 0.04678 \\
\hline & Wavelets & 0.00042 & 0.00043 & 0.00045 & 0.00117 & 0.00118 & 0.00118 & 0.04637 & 0.04651 & 0.04666 \\
\hline & Kernel & 0.03780 & 0.03781 & 0.03783 & 0.15535 & 0.15574 & 0.15602 & 0.19177 & 0.19337 & 0.19596 \\
\hline & SVR & 0.00040 & 0.00041 & 0.00043 & 0.00031 & 0.00032 & 0.00033 & 0.04543 & 0.04548 & 0.04556 \\
\hline \multirow{5}{*}{15} & Loess & 0.00055 & 0.00057 & 0.00059 & 0.00037 & 0.00038 & 0.00040 & 0.05157 & 0.05177 & 0.05194 \\
\hline & Splines & 0.00053 & 0.00055 & 0.00057 & 0.00036 & 0.00036 & 0.00038 & 0.05180 & 0.05199 & 0.05215 \\
\hline & Wavelets & 0.00050 & 0.00053 & 0.00054 & 0.00085 & 0.00087 & 0.00088 & 0.05165 & 0.05184 & 0.05199 \\
\hline & Kernel & 0.03779 & 0.03781 & 0.03784 & 0.16922 & 0.16965 & 0.17000 & 0.18852 & 0.18989 & 0.19142 \\
\hline & SVR & 0.00048 & 0.00050 & 0.00052 & 0.00033 & 0.00034 & 0.00035 & 0.05057 & 0.05069 & 0.05078 \\
\hline \multirow{5}{*}{20} & Loess & 0.00064 & 0.00066 & 0.00068 & 0.00042 & 0.00043 & 0.00044 & 0.04780 & 0.04797 & 0.04819 \\
\hline & Splines & 0.00061 & 0.00063 & 0.00066 & 0.00040 & 0.00042 & 0.00043 & 0.04799 & 0.04818 & 0.04837 \\
\hline & Wavelets & 0.00059 & 0.00061 & 0.00064 & 0.00138 & 0.00140 & 0.00142 & 0.04786 & 0.04807 & 0.04825 \\
\hline & Kernel & 0.03778 & 0.03781 & 0.03785 & 0.14796 & 0.14841 & 0.14864 & 0.18435 & 0.18606 & 0.18721 \\
\hline & SVR & 0.00056 & 0.00058 & 0.00060 & 0.00035 & 0.00036 & 0.00037 & 0.04630 & 0.04638 & 0.04647 \\
\hline \multirow{5}{*}{40} & Loess & 0.00098 & 0.00102 & 0.00104 & 0.00057 & 0.00061 & 0.00065 & 0.07937 & 0.07985 & 0.08031 \\
\hline & Splines & 0.00096 & 0.00099 & 0.00103 & 0.00060 & 0.00064 & 0.00069 & 0.07965 & 0.08014 & 0.08059 \\
\hline & Wavelets & 0.00095 & 0.00098 & 0.00101 & 0.00178 & 0.00182 & 0.00187 & 0.07954 & 0.08003 & 0.08047 \\
\hline & Kernel & 0.03771 & 0.03780 & 0.03786 & 0.14208 & 0.14235 & 0.14271 & 0.20321 & 0.20363 & 0.20426 \\
\hline & SVR & 0.00088 & 0.00091 & 0.00094 & 0.00047 & 0.00048 & 0.00049 & 0.06863 & 0.06901 & 0.06943 \\
\hline
\end{tabular}

Tabela 2.2: Média da raiz dos erros dos níveis de expressão gênica estimados para dados de microarrays simulados com genes diferencialmente expressos inseridos na condição de expressão baixa. GDE: Genes diferencialmente expressos

\subsection{Discussão}

Analisando o quanto os outliers podem causar distúrbios nas curvas de regressão, observamos que Kernel é o mais sensível dos métodos estudados independente do caso (outliers em baixo, médio ou alto nível de expressão). Nos três casos, SVR se mostra o menos afetado.

O melhor desempenho do Splines quando comparado ao Kernel, pode ser explicado pelo grau de suavização, que varia de acordo com a densidade dos pontos, diferentemente do Kernel, que possui janela de tamanho fixo. O método Wavelets também possui um desempenho ligeiramente melhor que o Kernel, provavelmente devido às propriedades multi-resolução. No geral, Splines e Wavelets apresentaram desempenhos similares quando as medianas do erro quadrático médio são comparadas usando o teste de Wilcoxon. Splines e Wavelets constituem técnicas um pouco melhores que Loess quando analisados os microarrays de formato sinuoso, mas para os outros dois formatos, Loess obteve melhores 


\begin{tabular}{|c|c|c|c|c|c|c|c|c|c|c|}
\hline \multirow[t]{2}{*}{ \%GDE } & & \multicolumn{3}{|c|}{ Sinuoso } & \multicolumn{3}{|c|}{ Banana } & \multicolumn{3}{|c|}{ Misto } \\
\hline & Método & $1^{\circ}$ quartil & $2^{\circ}$ quartil & $3^{\circ}$ quartil & $1^{\circ}$ quartil & $2^{\circ}$ quartil & $3^{\circ}$ quartil & $1^{\circ}$ quartil & $2^{\circ}$ quartil & $3^{\circ}$ quartil \\
\hline \multirow{5}{*}{5} & Loess & 0.00356 & 0.00373 & 0.00389 & 0.00379 & 0.00392 & 0.00407 & 0.05214 & 0.05234 & 0.05259 \\
\hline & Splines & 0.00354 & 0.00370 & 0.00387 & 0.00379 & 0.00393 & 0.00407 & 0.05237 & 0.05258 & 0.05283 \\
\hline & Wavelets & 0.00351 & 0.00368 & 0.00384 & 0.00438 & 0.00450 & 0.00466 & 0.05227 & 0.05247 & 0.05272 \\
\hline & Kernel & 0.03799 & 0.03816 & 0.03838 & 0.17380 & 0.17441 & 0.17487 & 0.18858 & 0.18882 & 0.18904 \\
\hline & SVR & 0.00337 & 0.00353 & 0.00369 & 0.00357 & 0.00368 & 0.00382 & 0.05034 & 0.05049 & 0.05067 \\
\hline \multirow{5}{*}{10} & Loess & 0.00709 & 0.00723 & 0.00743 & 0.00758 & 0.00780 & 0.00799 & 0.05483 & 0.05506 & 0.05532 \\
\hline & Splines & 0.00707 & 0.00721 & 0.00741 & 0.00763 & 0.00787 & 0.00805 & 0.05507 & 0.05532 & 0.05556 \\
\hline & Wavelets & 0.00705 & 0.00718 & 0.00739 & 0.00858 & 0.00881 & 0.00898 & 0.05497 & 0.05522 & 0.05547 \\
\hline & Kernel & 0.03837 & 0.03857 & 0.03886 & 0.15366 & 0.15461 & 0.15523 & 0.18801 & 0.18830 & 0.18867 \\
\hline & SVR & 0.00672 & 0.00688 & 0.00707 & 0.00709 & 0.00731 & 0.00750 & 0.05150 & 0.05164 & 0.05183 \\
\hline \multirow{5}{*}{15} & Loess & 0.01041 & 0.01061 & 0.01094 & 0.01108 & 0.01136 & 0.01165 & 0.05964 & 0.05985 & 0.06012 \\
\hline & Splines & 0.01039 & 0.01060 & 0.01091 & 0.01109 & 0.01136 & 0.01165 & 0.05990 & 0.06013 & 0.06039 \\
\hline & Wavelets & 0.01038 & 0.01058 & 0.01089 & 0.01251 & 0.01276 & 0.01310 & 0.05978 & 0.06003 & 0.06029 \\
\hline & Kernel & 0.03867 & 0.03897 & 0.03927 & 0.12923 & 0.13026 & 0.13111 & 0.19337 & 0.19367 & 0.19414 \\
\hline & SVR & 0.00986 & 0.01006 & 0.01032 & 0.01027 & 0.01056 & 0.01081 & 0.05499 & 0.05526 & 0.05550 \\
\hline \multirow{5}{*}{20} & Loess & 0.01393 & 0.01418 & 0.01444 & 0.01487 & 0.01519 & 0.01542 & 0.06362 & 0.06398 & 0.06432 \\
\hline & Splines & 0.01393 & 0.01415 & 0.01442 & 0.01486 & 0.01518 & 0.01542 & 0.06390 & 0.06425 & 0.06460 \\
\hline & Wavelets & 0.01390 & 0.01414 & 0.01440 & 0.01631 & 0.01666 & 0.01689 & 0.06375 & 0.06410 & 0.06445 \\
\hline & Kernel & 0.03915 & 0.03957 & 0.04004 & 0.12265 & 0.12366 & 0.12464 & 0.19808 & 0.19858 & 0.19909 \\
\hline & SVR & 0.01310 & 0.01334 & 0.01365 & 0.01365 & 0.01399 & 0.01416 & 0.05809 & 0.05835 & 0.05858 \\
\hline \multirow{5}{*}{40} & Loess & 0.02772 & 0.02813 & 0.02862 & 0.02969 & 0.03004 & 0.03043 & 0.07856 & 0.07910 & 0.07975 \\
\hline & Splines & 0.02774 & 0.02814 & 0.02861 & 0.02966 & 0.03002 & 0.03038 & 0.07884 & 0.07937 & 0.08002 \\
\hline & Wavelets & 0.02771 & 0.02811 & 0.02859 & 0.03012 & 0.03049 & 0.03092 & 0.07873 & 0.07926 & 0.07995 \\
\hline & Kernel & 0.04195 & 0.04261 & 0.04316 & 0.15640 & 0.15816 & 0.16012 & 0.20368 & 0.20443 & 0.20518 \\
\hline & SVR & 0.02545 & 0.02581 & 0.02614 & 0.02656 & 0.02685 & 0.02724 & 0.06786 & 0.06830 & 0.06862 \\
\hline
\end{tabular}

Tabela 2.3: Média da raiz dos erros dos níveis de expressão gênica estimados para dados de microarrays simulados com genes diferencialmente expressos inseridos na condição de expressão média. GDE: Genes diferencialmente expressos

resultados que Splines e Wavelets. Para fins práticos, as diferenças entre eles em termos de distúrbios causados por outliers são muito pequenas, não sendo portanto, preocupantes.

O SVR se mostrou ser o mais robusto à presença de outliers independente do formato dos microarrays ou localização dos outliers, tornando-se para os nossos testes o melhor método de normalização para identificar genes diferencialmente expressos.

Um problema muito conhecido em identificação de genes diferencialmente expressos é a normalização de genes com baixos níveis de expressão, devido à baixa quantidade de genes com esse perfil e alta variância nos spots. Um problema equivalente ocorre com genes apresentando altas expressões devido à baixa frequência desses genes. Mais uma vez, mesmo nessas condições, o SVR se mostrou melhor que os outros métodos comumente utilizados.

Na Figura 2.5, ilustramos o desempenho dos 5 métodos de normalização aplicados em dados de microarrays reais, sem a inserção de outliers artificiais. Uma pequena diferença pode ser observada nas curvas de normalização na região onde os genes apresentam baixos 


\begin{tabular}{|c|c|c|c|c|c|c|c|c|c|c|}
\hline \multirow[t]{2}{*}{ \%GDE } & & \multicolumn{3}{|c|}{ Sinuoso } & \multicolumn{3}{|c|}{ Banana } & \multicolumn{3}{|c|}{ Misto } \\
\hline & Método & $1^{\circ}$ quartil & $2^{\circ}$ quartil & $3^{\circ}$ quartil & $1^{\circ}$ quartil & $2^{\circ}$ quartil & $3^{\circ}$ quartil & $1^{\circ}$ quartil & $2^{\circ}$ quartil & $3^{\circ}$ quartil \\
\hline \multirow{5}{*}{5} & Loess & 0.00038 & 0.00039 & 0.00040 & 0.00081 & 0.00087 & 0.00094 & 0.04633 & 0.04639 & 0.04648 \\
\hline & Splines & 0.00035 & 0.00036 & 0.00037 & 0.00079 & 0.00086 & 0.00092 & 0.04658 & 0.04665 & 0.04674 \\
\hline & Wavelets & 0.00033 & 0.00034 & 0.00035 & 0.00115 & 0.00121 & 0.00129 & 0.04643 & 0.04650 & 0.04660 \\
\hline & Kernel & 0.03781 & 0.03782 & 0.03783 & 0.16417 & 0.16453 & 0.16513 & 0.17428 & 0.17436 & 0.17447 \\
\hline & SVR & 0.00031 & 0.00032 & 0.00033 & 0.00080 & 0.00087 & 0.00092 & 0.04527 & 0.04534 & 0.04544 \\
\hline \multirow{5}{*}{10} & Loess & 0.00146 & 0.00153 & 0.00168 & 0.00145 & 0.00156 & 0.00167 & 0.04733 & 0.04748 & 0.04758 \\
\hline & Splines & 0.00142 & 0.00149 & 0.00160 & 0.00147 & 0.00157 & 0.00168 & 0.04756 & 0.04767 & 0.04779 \\
\hline & Wavelets & 0.00140 & 0.00147 & 0.00159 & 0.00160 & 0.00170 & 0.00182 & 0.04725 & 0.04736 & 0.04748 \\
\hline & Kernel & 0.02662 & 0.03454 & 0.03789 & 0.23086 & 0.23135 & 0.23245 & 0.18441 & 0.19003 & 0.19176 \\
\hline & SVR & 0.00126 & 0.00133 & 0.00144 & 0.00142 & 0.00154 & 0.00166 & 0.04678 & 0.04687 & 0.04696 \\
\hline \multirow{5}{*}{15} & Loess & 0.00203 & 0.00217 & 0.00234 & 0.00199 & 0.00212 & 0.00224 & 0.04963 & 0.04976 & 0.04991 \\
\hline & Splines & 0.00198 & 0.00211 & 0.00223 & 0.00200 & 0.00211 & 0.00222 & 0.04987 & 0.05001 & 0.05014 \\
\hline & Wavelets & 0.00196 & 0.00209 & 0.00224 & 0.00219 & 0.00240 & 0.00257 & 0.04975 & 0.04989 & 0.05001 \\
\hline & Kernel & 0.02318 & 0.02992 & 0.03729 & 0.17578 & 0.20066 & 0.22763 & 0.18472 & 0.18898 & 0.18923 \\
\hline & SVR & 0.00178 & 0.00190 & 0.00200 & 0.00170 & 0.00180 & 0.00189 & 0.04885 & 0.04898 & 0.04912 \\
\hline \multirow{5}{*}{20} & Loess & 0.00260 & 0.00275 & 0.00293 & 0.00259 & 0.00272 & 0.00289 & 0.04917 & 0.04930 & 0.04944 \\
\hline & Splines & 0.00254 & 0.00268 & 0.00286 & 0.00260 & 0.00270 & 0.00289 & 0.04933 & 0.04946 & 0.04961 \\
\hline & Wavelets & 0.00253 & 0.00267 & 0.00284 & 0.00289 & 0.00304 & 0.00320 & 0.04919 & 0.04933 & 0.04947 \\
\hline & Kernel & 0.02224 & 0.02819 & 0.03468 & 0.16500 & 0.17817 & 0.20385 & 0.18207 & 0.18716 & 0.19141 \\
\hline & SVR & 0.00226 & 0.00239 & 0.00255 & 0.00247 & 0.00258 & 0.00272 & 0.04839 & 0.04850 & 0.04863 \\
\hline \multirow{5}{*}{40} & Loess & 0.00501 & 0.00520 & 0.00545 & 0.00518 & 0.00538 & 0.00555 & 0.04980 & 0.04999 & 0.05020 \\
\hline & Splines & 0.00498 & 0.00519 & 0.00539 & 0.00520 & 0.00538 & 0.00558 & 0.05002 & 0.05022 & 0.05038 \\
\hline & Wavelets & 0.00496 & 0.00517 & 0.00537 & 0.00535 & 0.00551 & 0.00572 & 0.04984 & 0.05004 & 0.05020 \\
\hline & Kernel & 0.02155 & 0.02487 & 0.02810 & 0.18250 & 0.20140 & 0.22296 & 0.17524 & 0.18072 & 0.18433 \\
\hline & SVR & 0.00446 & 0.00467 & 0.00489 & 0.00464 & 0.00483 & 0.00505 & 0.04809 & 0.04829 & 0.04860 \\
\hline
\end{tabular}

Tabela 2.4: Média da raiz dos erros dos níveis de expressão gênica estimados para dados de microarrays simulados com genes diferencialmente expressos inseridos na condição de expressão alta. GDE: Genes diferencialmente expressos

e altos níveis de expressão, devido a baixas quantidades de genes e alta variância. 


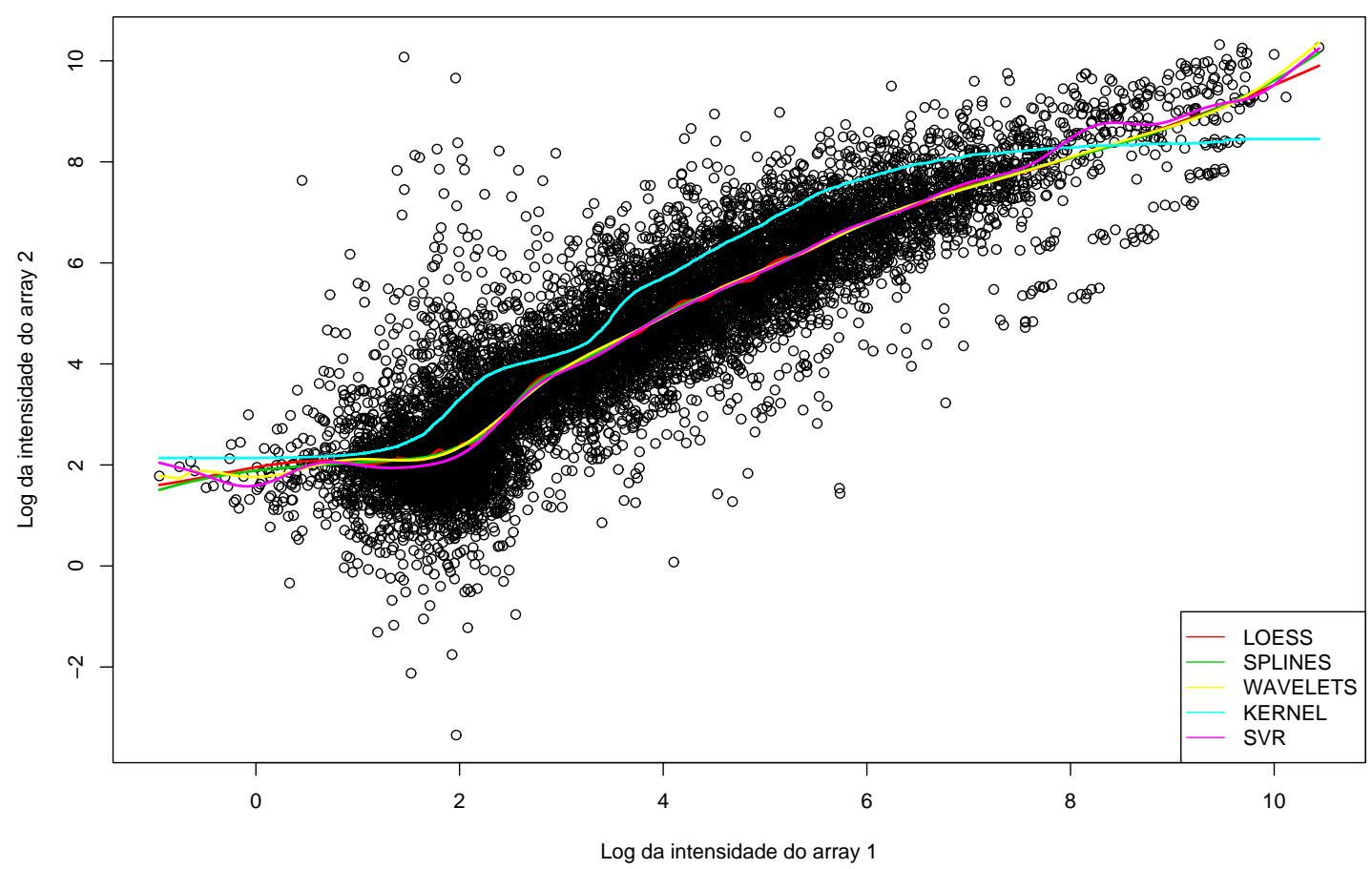

Figura 2.5: Curvas de normalização ajustadas para dados reais de cDNA microarrays, aplicando os cinco diferentes métodos de normalização (Loess, Splines, Wavelets, Kernel e SVR). 
CAPÍtulo 3

\section{Redes regulatórias}

Neste capítulo, serão abordadas as redes regulatórias de produtos gênicos, apresentando os problemas existentes com os diversos modelos já descritos na literatura e introduzindo dois novos modelos, o modelo vetor autoregressivo dinâmico (Fujita et al., 2007a) e o vetor autoregressivo esparso (Fujita et al., 2007b), que propomos como alternativa para a modelagem de tais redes regulatórias.

\subsection{Introdução}

Para um maior entendimento do funcionamento das células como um todo, é necessário entender, ao nível molecular, como os produtos gênicos interagem. Isto pode auxiliar no projeto de novos experimentos e no desenvolvimento de novas ferramentas terapêuticas para o tratamento de doenças. Devido ao elevado número de genes envolvidos nessas redes, ativando e reprimindo feedbacks, sua dinâmica é extremamente complexa e difícil de inferir.

Com o desenvolvimento de tecnologias de análise de expressão gênica em larga escala, como os microarrays de DNA, tornou-se possível a análise de dezenas de milhares de genes simultaneamente, permitindo a construção de redes regulatórias de genes baseadas na inferência sobre os dados de expressão gênica.

Diversas redes genéticas foram propostas nos últimos anos, como as redes Bayesianas (Imoto et al., 2002; Tamada et al., 2003; Friedman, 2004; Dojer et al., 2006), Equações Estruturais (Xiong et al., 2004), Redes Booleanas Probabilísticas (Akutsu et al., 2000; 
Shmulevich et al., 2002; Pal et al., 2005), modelos Gráficos Gaussianos (Schäfer e Strimmer, 2005), controles Fuzzy (Woolf e Wang, 2000) e Equações Diferenciais (Mestl et al., 1995).

Apesar desses métodos modelarem bem diversas redes regulatórias onde há informações biológicas a priori, é difícil determinar as relações de causalidade quando estas não estão disponíveis.

Além disso, todos esses métodos esbarram nos mesmos problemas:

1. até o momento, todos os modelos assumem estacionaridade, i.e., a topologia da rede não se altera em função do tempo, enquanto é bem sabido que a rede não é estática, ou seja, a topologia da rede é variante ao longo do ciclo celular;

2. o número de observações (microarrays) é muito pequeno quando comparado ao alto número de variáveis (genes). Assim, o uso de métodos tradicionais de estatística para a inferência de grandes redes limita a inferência para alguns poucos genes. Como conseqüência, modelar e simular redes grandes se torna um campo de pesquisa intenso e desafiador. Aqui convém definir o que seria uma "grande" rede, que seria uma rede inferida a partir de um número de observações menor que o número de parâmetros estimados. Em outras palavras, o número de experimentos de microarrays de DNA é menor que o número de genes.

Para o primeiro problema citado, até o momento não se conhece nenhuma proposta de solução. Em relação ao segundo, alguns métodos têm sido apresentados a fim de superar esse desafio. Por exemplo, Barrera e colaboradores utilizaram informação mútua para resolver o problema da dimensionalidade (Barrera et al., 2004). Em seu método, a informação mútua é calculada entre os genes e as mais altas informações mútuas são selecionadas. O ponto fraco da abordagem é que ela não apresenta um teste estatístico, sendo arbitrária a escolha do limiar de informação mútua, tornando muito difícil a interpretação e identificação das verdadeiras interações da rede. Assim, a escolha do limiar para determinar se há ou não uma ligação torna-se um pouco subjetiva. Uma alternativa para modelar redes com uma alta quantidade de genes seria a construção de módulos, onde cada módulo é composto por vários genes, e, depois, construir redes módulo-módulo (Segal et al., 2003; Xu et al., 2004; Yamaguchi et al., 2007). O problema destes métodos é que a definição do que é um módulo não é bem estabelecida, mudando de artigo para 
artigo. Não é claro também como "traduzir" as redes módulo-módulo encontradas para redes gene-gene.

Nas seções seguintes, apresentamos uma introdução do modelo vetor autoregressivo clássico (VAR - Vector Autoregressive), e posteriormente, descrevemos nossas duas propostas como soluções dos problemas apontados: o modelo vetor autoregressivo dinâmico (DVAR - Dynamic Vector Autoregressive) e vetor autoregressivo esparso (SVAR - SparseVector Autoregressive).

\subsection{Vetor autoregressivo (VAR)}

Granger (1969) definiu o conceito de causalidade que é fácil de ser tratado no contexto de modelos de Vetores Autoregressivos. Assim, este conceito de causalidade se tornou bem popular nos últimos anos. A idéia principal da causalidade de Granger consiste no fato do efeito não poder ocorrer antes da causa. No caso do modelo VAR(1), ou seja, modelo VAR de ordem 1 , se um gene $i$ no tempo $t-1$ afeta outro gene $j$ no tempo $t$, o gene $i$ deve ajudar a prever o nível de expressão do gene alvo.

O modelo VAR(1) pode ser descrito como (Lütkepohl, 1993):

$$
y_{t}=A_{1} y_{t-1}+\varepsilon_{t} \quad t=2, \ldots, T
$$

onde $y_{t}$ é um vetor de expressão gênica $n \times 1$, $\varepsilon_{t}$ é também um vetor $n \times 1$ com média zero e matriz de precisão $\Sigma^{-1}$, e $A_{1}$ é uma matriz $n \times n$ de parâmetros. Os distúrbios são serialmente não-correlacionados, mas podem ser correlacionados no mesmo tempo. Assim, $E\left(\varepsilon_{t} \varepsilon_{t}^{\prime}\right)=\Sigma$, onde $\Sigma$ é uma matriz $n \times n$. É importante ressaltar que, no modelo multivariado, cada gene pode depender não somente dos valores do seu próprio passado, mas, também, do passado dos valores de outros genes. Assim, se $y_{i t}$ é o $i$-ésimo elemento de $y_{t}$, a $i$-ésima linha é

$$
y_{i t}=a_{i 1} y_{1, t-1}+a_{i 2} y_{2, t-1}+\ldots+a_{i N} y_{N, t-1}+\varepsilon_{i t}, \quad i=1, \ldots, n
$$

Este modelo pode ser estimado pelo estimador de Mínimos Quadrados Ordinário, simplesmente realizando a regressão em cada uma das variáveis nas defasagens de cada uma delas e de outras variáveis.

Assim, pode-se re-escrever o modelo como

$$
Z=X \beta+E \quad E_{i} \sim N(0, \Sigma) \quad i=1, \ldots, n
$$


onde define-se $m=T-1$ e introduz-se a notação:

$Z_{(m \times n)}=\left[y_{2}, \ldots, y_{t}, \ldots, y_{T}\right]^{\prime}=\left[z_{1}, \ldots, z_{i}, \ldots, z_{n}\right] ;$

$\beta_{(n \times n)}=A_{1}^{\prime}=\left[\beta_{1}, \ldots, \beta_{n}\right]^{\prime}$;

$X_{(m \times n)}=\left[y_{1} \ldots y_{m}\right]^{\prime}$;

$E_{(m \times n)}=\left[\varepsilon_{2}, \ldots, \varepsilon_{t}, \ldots, \varepsilon_{T}\right]^{\prime}$

A solução explícita do estimador de mínimos quadrados é

$$
\hat{\beta}_{i}=\left(X^{\prime} X\right)^{-1} X^{\prime} z_{i} \quad i=1, \ldots, n
$$

onde $z_{i}$ é a $i$-ésima coluna de $Z$.

A fim de especificar a distribuição do $j$-ésimo elemento de $\hat{\beta}$, vamos denotar o $j$-ésimo elemento da diagonal $\left(X^{\prime} X\right)^{-1}$ por $w_{j j}$. Então, pode-se realizar o seguinte teste estatístico

$$
\frac{\hat{\beta}_{i j}}{\sqrt{\hat{\sigma}^{2} w_{j j}}} \sim t(m-n) \quad i=1, \ldots, n
$$

sob a hipótese nula, onde $t(m-n)$ denota uma distribuição $t$ com $(m-n)$ graus de liberdade e

$$
\hat{\sigma}^{2}=\frac{1}{m-n}(Z-X \hat{\beta})^{\prime}(Z-X \hat{\beta})=\frac{E^{\prime} E}{m-n}
$$

É importante notar que no modelo Vetor Autoregressivo é possível inferir causalidades de Granger sem nenhuma informação biológica a priori. Por outro lado, assume-se estacionaridade e, também, que o número de observações deve ser muito maior que o número de variáveis $(m>n)$.

\subsection{Vetor autoregressivo dinâmico (DVAR)}

Baseado no modelo VAR, apresentamos o DVAR, uma forma de modelagem de conectividade que varia com o tempo, com o própósito de modelar a dinâmica das redes ao longo do ciclo celular. O modelo DVAR (Dynamic Vector Autoregressive) é definido por:

$$
y_{t}=v(t)+A_{1}(t) y_{t-1}+A_{2}(t) y_{t-2}+\ldots+A_{p}(t) y_{t-p}+\varepsilon_{t}
$$


onde $\varepsilon_{t}$ é um vetor de variáveis aleatórias com média zero e matriz de covariância $\Sigma(t)$ dado por:

$$
\boldsymbol{\Sigma}(\mathbf{t})=\left(\begin{array}{cccc}
\sigma_{11}^{2}(t) & \sigma_{21}(t) & \ldots & \sigma_{k 1}(t) \\
\sigma_{12}(t) & \sigma_{22}^{2}(t) & \ldots & \sigma_{k 2}(t) \\
\sigma_{13}(t) & \sigma_{23}(t) & \ldots & \sigma_{k 3}(t) \\
\vdots & \vdots & \ddots & \vdots \\
\sigma_{1 k}(t) & \sigma_{2 k}(t) & \ldots & \sigma_{k k}^{2}(t)
\end{array}\right)
$$

e $v(t)$ e $A_{i}(t)(i=1,2, \ldots, p)$ são um vetor e a matriz de coeficientes respectivamente, dados por:

$$
\begin{gathered}
\mathbf{v}(\mathbf{t})=\left(\begin{array}{c}
v_{1}(t) \\
v_{2}(t) \\
\vdots \\
v_{k}(t)
\end{array}\right) \\
\mathbf{A}_{\mathbf{i}}(\mathbf{t})=\left(\begin{array}{cccc}
a_{11 i}(t) & a_{21 i}(t) & \ldots & a_{k 1 i}(t) \\
a_{12 i}(t) & a_{22 i}(t) & \ldots & a_{k 2 i}(t) \\
a_{13 i}(t) & a_{23 i}(t) & \ldots & a_{k 3 i}(t) \\
\vdots & \vdots & \ddots & \vdots \\
a_{1 k i}(t) & a_{2 k i}(t) & \ldots & a_{k k i}(t)
\end{array}\right)
\end{gathered}
$$

Usando esta estrutura variante no tempo para o intercepto (o intercepto está relacionado com o valor médio variante no tempo da expressão gênica), coeficientes autoregressivos e matrizes de covariância, é possível modelar a rede regulatória de um modo dinâmico para analisar o fluxo de informação ao longo do ciclo celular.

Como proposto por Sato et al. (2006), é possível considerar a função de expansão wavelet para estimar as funções variantes no tempo em $v(t), A_{i}(t)$ e $\Sigma(t)$. A idéia é que qualquer função $f(t) \operatorname{com} \int_{-\infty}^{\infty} f^{2}(t) d t<\infty$ pode ser expandida como:

$$
f(t)=\sum_{j=-\infty}^{\infty} \sum_{k=-\infty}^{\infty} c_{j, k} \psi_{j, k}(t)
$$

Portanto, a função $f(t)$ pode ser representada por uma combinação linear de funções wavelet $\psi_{j, k}(t)$, onde os índices $j$ e $k$ estão relacionados à escala e localização temporal, respectivamente. Assim, considerando a expansão wavelet, as funções coeficientes 
autoregressivos $a_{l m i}(t)$ podem ser escritas como:

$$
a_{l m i}(t)=\sum_{j=k-1}^{J} \sum_{k=0}^{2^{j}-1} c_{j, k}^{(i)} \psi_{j, k}(t)
$$

onde a extensão da série temporal $T$ e $c_{j, k}^{(i)}\left(j=-1,0,1, \ldots, T-1 ; k=0,1, \ldots, 2^{j}-1\right.$; $i=1,2, \ldots, p)$ são os coeficientes wavelet para o $i$-ésimo coeficiente da função autoregressivo $a_{l m i}(t)$. Basicamente, a estimativa dos parâmetros do vetor autoregressivo é efetuada pela estimativa de cada coeficiente wavelet $c_{j, k}^{(i)}$ para todas as funções autoregressivas da matriz $A_{i}(t), i=1,2, \ldots, p$, as funções $v(t)$ e as funções de covariância em $\Sigma(t)$.

Um ponto a ser analisado aqui é de como determinar a resolução máxima do parâmetro $J$ que controla o truncamento da expansão wavelet.

Quanto maior o valor de $J$, maior o ruído que a curva estimada terá. A redução do viés implica em aumento da variância, e o contrário também, ou seja, o aumento da variância implica na redução do viés. Um critério objetivo para a escolha do melhor $J$ pode ser obtido por validação-cruzada. Por outro lado, a escolha do grau de suavidade pode ser baseada em mudanças esperadas de acordo com informações biológicas a priori ou no nível de detalhe desejado. Em nossas análises, definimos o valor de $J$ como sendo igual a quatro porque temos a informação biológica a priori de que a conectividade variante no tempo varia ao longo das quatro diferentes fases do ciclo celular (S, G2, M, G1).

Sato et al. (2006) propôs uma regressão por mínimos quadrados generalizado iterativo composto por um loop de dois estágios. O primeiro estágio consiste em estimar os coeficientes de expansões wavelets em $A_{i}(t)$ e $v(t)$ usando a regressão por mínimos quadrados generalizados. No segundo estágio, o quadrado dos resíduos, obtido no passo anterior, é usado para estimar as funções de expansão na matriz de covariância $\Sigma(t)$.

\subsubsection{Algoritmo}

Considere as seguinte matrizes:

$$
\mathbf{Y}_{\mathbf{t}-\mathbf{l}}=\left(\begin{array}{cccc}
y_{1,(p-l+1)} & y_{2,(p-l+1)} & \ldots & y_{k,(p-l+1)} \\
y_{1,(p-l+1)} & y_{2,(p-l+2)} & \ldots & y_{k,(p-l+2)} \\
\vdots & \vdots & \ddots & \vdots \\
y_{1,(T-1)} & y_{2,(T-l)} & \ldots & y_{k,(T-l)}
\end{array}\right)
$$




$$
\begin{gathered}
\varepsilon=\left(\begin{array}{cccc}
\varepsilon_{1,(p+1)} & \varepsilon_{2,(p+1)} & \ldots & \varepsilon_{k,(p+1)} \\
\varepsilon_{1,(p+1)} & \varepsilon_{2,(p+2)} & \ldots & \varepsilon_{k,(p+2)} \\
\vdots & \vdots & \ddots & \vdots \\
\varepsilon_{1,(T)} & \varepsilon_{2,(T)} & \ldots & \varepsilon_{k,(T)}
\end{array}\right) \\
\pi=\left(\begin{array}{cccc}
\psi_{-1,0}(p+1) & \psi_{0,0}(p+1) & \ldots & \psi_{J, 2^{J}-1}(p+1) \\
\psi_{-1,0}(p+2) & \psi_{0,0}(p+2) & \ldots & \psi_{J, 2^{J}-1}(p+2) \\
\vdots & \vdots & \ddots & \vdots \\
\psi_{-1,0}(T) & \psi_{0,0}(T) & \ldots & \psi_{J, 2^{J}-1}(T)
\end{array}\right)
\end{gathered}
$$

onde a matriz $Y$ é dado do problema.

O produto linha de Kronecker é definido por

$$
\left(\begin{array}{c}
a_{1} \\
a_{2} \\
\vdots \\
a_{n}
\end{array}\right) \otimes^{L}\left(\begin{array}{c}
b_{1} \\
b_{2} \\
\vdots \\
b_{n}
\end{array}\right)=\left(\begin{array}{c}
a_{1} \otimes b_{1} \\
a_{2} \otimes b_{2} \\
\vdots \\
a_{n} \otimes b_{n}
\end{array}\right)
$$

sendo

$$
\begin{gathered}
W=\left[1_{T-p} \otimes^{L} \pi_{t-1} \otimes^{L} \pi \ldots Y_{t-1} \otimes^{L} \pi\right] \\
M=I_{K} \otimes W
\end{gathered}
$$

onde $1_{T-p}$ é o vetor coluna de cardinalidade $(T-p)$ composto por $1 \mathrm{~s}$, e $I_{k}$ é a matriz identidade de $k$ linhas.

Seja o vetor $Z=\operatorname{vec}\left(Y_{t}\right)$, onde o operador vec concatena todas as colunas da matriz. O modelo DVAR pode ser re-escrito como:

$$
Z=M \beta+E
$$

Um vetor de parâmetros $\beta$ contem os coeficientes $c_{j, k}^{(i)}$ da wavelet para todas as funções de conectividade. Seja a matriz de covariâncias de $E$ denotado por $\tau$.

O estimador de mínimos quadrados generalizados para os parâmetros do modelo é dado por:

$$
\hat{\beta}=\left(M^{\prime} \tau^{-1} M\right)^{-1} M^{\prime} \tau^{-1} Z
$$

Um estimador para $\tau$ pode ser obtido considerando-se a suavização de wavelets do quadrado dos resíduos $\left(r_{i t}^{2}, i=1, \ldots, k\right)$ 
A hipótese de conectividade significante ou qualquer combinação linear dos parâmetros em $\beta$ pode ser feito simplesmente aplicando-se o teste de Wald. Detalhes sobre o teste de Wald podem ser encontrados em Graybill (1976).

\subsubsection{Aplicação em dados reais}

Aplicamos o método proposto nos dados de expressão gênica do ciclo celular de células HeLa, coletados por Whitfield et al. (2002). Esses dados contêm três ciclos completos, i.e., 48 pontos distribuídos em intervalos de uma hora, onde o ciclo celular das células HeLa é de 16 horas. Assim, foram usados todos os 48 pontos e os assumimos como triplicatas , i.e., cada ponto do tempo foi representado por três pontos. Esses dados foram obtidos na Internet na seguinte página: http://genome-www.stanford.edu/Human-CellCycle/HeLa/ (acessado em 25 de janeiro de 2006).

Para aplicação do DVAR, os dados de expressão de cada gene foram normalizados para terem média zero e variância igual a um.

Em nossas análises, modelamos três redes, sendo uma composta pelos genes p53, gadd45a e $p 21$; a segunda pelos genes $N F-\kappa B$, $i k k \alpha$, nemo e nik e a terceira por $c-m y c$, reck, src e timp-2, pois essas redes possuem importantes papéis na regulação gênica e na progressão de diversos tipos de tumores.

\subsubsection{Resultados e Discussões}

A fim de medir o desempenho do proposto método (DVAR) e identificar as causalidades de Granger variantes no tempo, o DVAR foi aplicado em conjuntos de dados biológicos reais.

As Figuras 3.1, 3.3 e 3.5 ilustram as redes estimadas usando o método proposto (DVAR) e o método clássico (VAR) o qual acreditamos ser o mais apropriado para modelar redes baseadas em séries temporais.

Para validarmos nossa abordagem, analisamos 3 módulos de genes, que são regulados por 3 fatores de transcrição, chamados: p53, NF- $\kappa$ B e c-Myc no contexto da progressão do ciclo celular em células tumorais HeLa.

Os resultados obtidos com a aplicação do nosso método no conjunto de 3 genes ( $p 53$, p21 e gadd45a) estão ilustrados na Figura 3.1. Na Figura 3.3 é ilustrada a rede composta 
por NF- $\kappa \mathrm{B}, \mathrm{IKK} \alpha, \mathrm{NEMO}$ e NIK. Na Figura 3.5, apresentamos o conjunto de genes composto por c-myc, reck, src e timp2. Como nós estamos interessados em analisar conexões reais, consideramos três ou quatro como um número adequado de genes para o tamanho da nossa série temporal, para que não perdêssemos o poder do teste. Acima de sete genes, começam a ocorrer problemas computacionais numéricos de singularidade. Assim, se o interesse é de construir redes "grandes", uma possível solução seria realizar comparações dois a dois e controlar a taxa de falsos positivos através da correção por Bonferroni ou FDR (False Discovery Rate) (Benjamini e Hochberg, 1995). Como a correção por Bonferroni é muito conservadora, sugere-se o uso do FDR. É importante notar que, nesse caso, as causalidades inferidas não são parciais. Nós aplicamos o DVAR de ordem um devido ao pequeno número de pontos na série temporal. É necessário ressaltar que quanto maior o número de genes a ser analisado e/ou maior a ordem do DVAR, menor é o poder do teste, já que o número de parâmetros a ser estimado aumenta.

p53 é uma proteína supressora de tumor que age numa via crítica do ciclo celular e no controle da apoptose. p53 se liga aos elementos enhancer ou promotores dos genesalvos, regulando sua transcrição, e ativando programas celulares que estão envolvidos com grande parte das funções supressoras de tumor. Dois desses genes-alvo são o p21 e o gadd45a, que são transcricionalmente ativados por p53 nas transições G1-S e G2-M do ciclo celular, respectivamente, induzindo a inibição do crescimento e/ou apoptose. Mas estudos recentes demonstraram que GADD45A é capaz de gerar um feedback positivo dependente da quinase p38, que é essencial para manter a estabilidade da proteína p53 e sua atividade transcricional (Jin et al., 2006). De fato, foi observado que GADD45A pode funcionar como um efetor upstream da proteína p53, já que a indução de p53 é diminuída em células knock-out de gadd45a (Hildesheim et al., 2002).

Nossa análise de expressão gênica in silico (Figura 3.1) sugere que, em células Hela, p53 também está sendo regulado transcricionalmente de modo GADD45A-dependente, aumentando a conectividade na fase G1 do ciclo celular. Consistentemente, a auto-regulação de GADD45A na fase G2 pode ser resultado de uma ativação p53-independente, como pode ser observado em células HeLa tratadas com quercetina (Yoshida et al., 2005). Esta regulação pode envolver outros reguladores bem conhecidos de GADD45, como BRCA1 (Jin et al., 2000), oct-1 (Takahashi et al., 2001) e NF-YA (Jin et al., 2001).

Em nossos experimentos, não foi possível observar a regulação de GADD45A por p53. Diversas explicações podem ser oferecidas para a ausência da causalidade de Granger de 

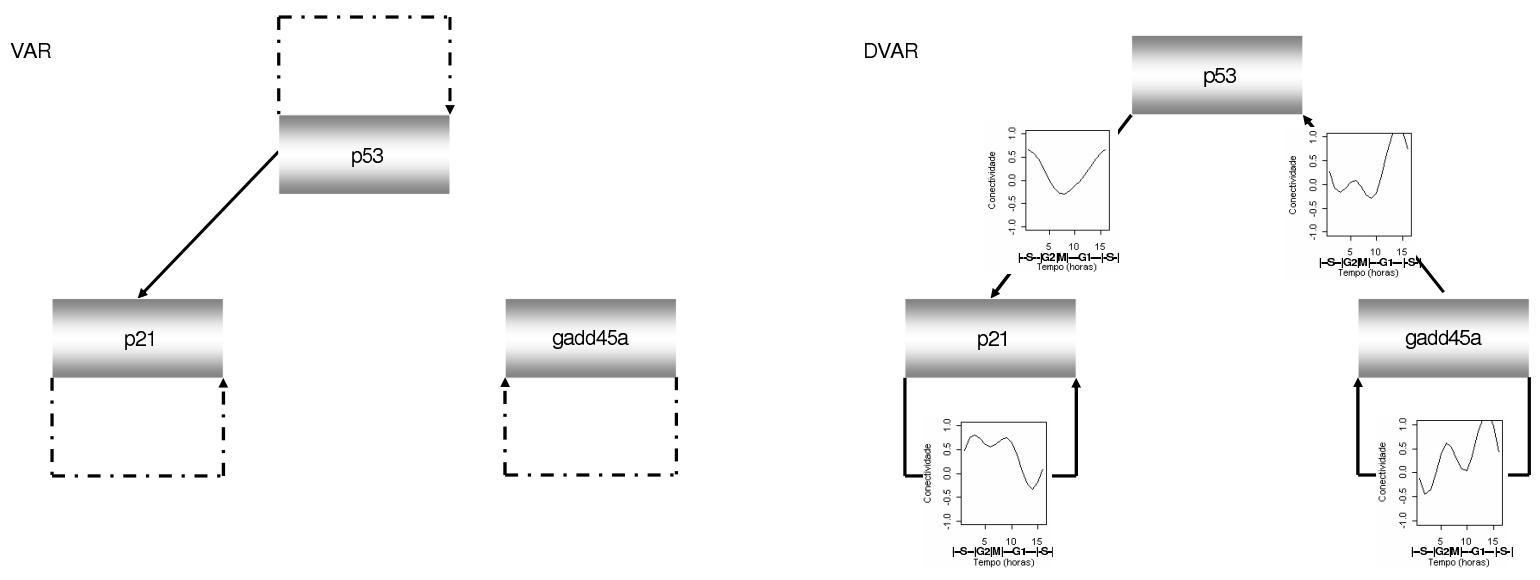

Figura 3.1: Aplicação dos modelos VAR e DVAR na rede composta pelos genes p53, gadd45a e p21. VAR: arestas pontilhadas são as conectividades significativas (p valor $<0.1$ ) e arestas cheias são as conectividades significativas (p valor $<0.05$ ). DVAR: conectividades significativas ( $\mathrm{p}$ valor $<0.05$ ). As funções de conectividade estão ilustradas em cada aresta.
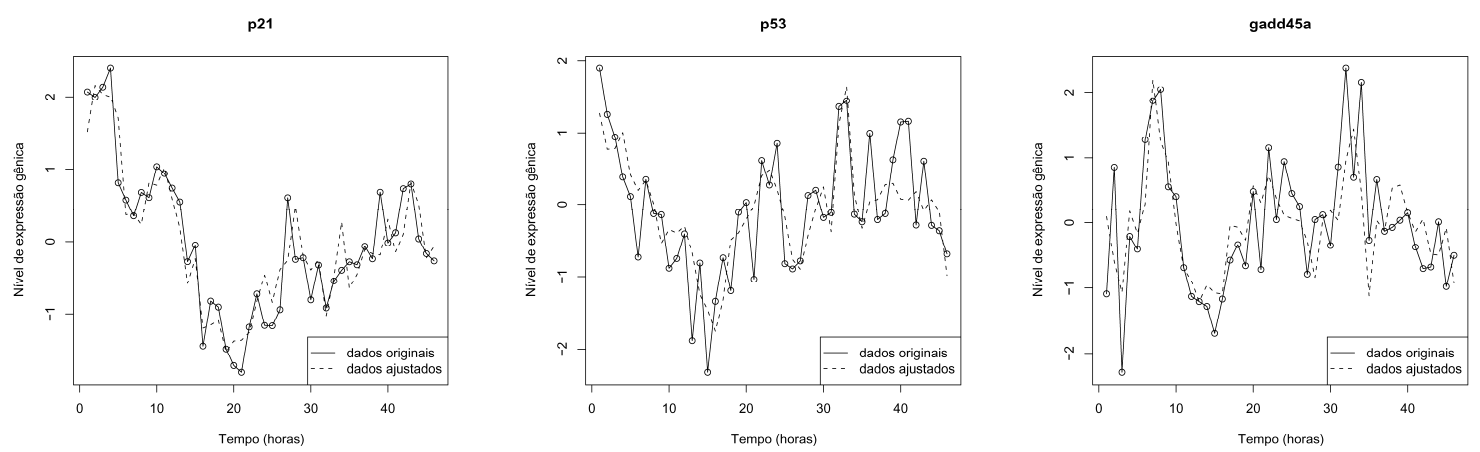

Figura 3.2: Perfil da expressão gênica com dados reais e com dados ajustados pelo método DVAR para os genes p21, p53 e gadd45a. 
p53 para GADD45A, como: a) o comprimento da série temporal não é longa o suficiente; b) ou a causalidade de Granger pode estar ocorrendo em uma ordem diferente de um; c) as células HeLa não possuem essa regulação; d) a regulação não ocorre no nível transcricional. Por outro lado, o método DVAR inferiu uma conexão positiva entre p21 e p53 na transição G1-S do ciclo celular, estando de acordo com evidências experimentais do aumento da expressão do gene p21 dependente de p53 nesta fase do ciclo, induzindo interrupção do ciclo celular e restringindo o crescimento celular aberrante em resposta a danos no DNA, ativação de oncogenes, hipóxia e perda de contatos de células normais (el-Deiry et al., 1993; Lohrum e Vousden, 1999). Mas ao mesmo tempo, um feedback negativo parece estar presente nas células Hela, já que uma auto-regulação negativa de p21 é também evidente na fase G1 do ciclo celular, numa regulação aparentemente independente e contraditória mediada por p53. Como a linhagem celular Hela é transformada, isto pode ser uma das vias de sinalização próprias da tumorigênese e/ou da progressão do tumor. A Figure 3.2 mostra o perfil da expressão gênica dos dados reais compostos por p21, p53 e gadd45a e os valores ajustados pelo DVAR.

$\mathrm{O}$ fator $\kappa \mathrm{B}$ nuclear $(\mathrm{NF}-\kappa \mathrm{B})$, um fator de transcrição regulado pelo stress, pertencente a família Rel, participa essencialmente do controle inflamatório e da resposta imune inata. Uma vez ativado, na maioria das vezes por fosforilação e subseqüente degradação de seu inibidor, a proteína $\mathrm{I} \kappa \mathrm{B}, \mathrm{NF}-\kappa \mathrm{B}$ transloca para o núcleo, onde este modula a expressão de uma variedade de genes, incluindo aqueles que codificam citoquinas, fatores de crescimento, proteínas de resposta de fase aguda, moléculas de adesão celular e uma série de reguladores de apoptose celular. Mais recentemente, a ativação de NF- $\kappa \mathrm{B}$ tem sido relacionada a múltiplos aspectos de tumorigênese, incluindo o controle da proliferação celular e migração, progressão do ciclo celular e apoptose.

Apesar de estarem disponíveis somente informações limitadas sobre o envolvimento de $\mathrm{NF}-\kappa \mathrm{B}$ na regulação do ciclo celular, foi encontrado que níveis de ativação de NF- $\kappa \mathrm{B}$ estão ligados aos controles de sinalização da progressão do ciclo celular em células HeLa. Mas há observações controversas da conseqüência funcional desta regulação. Alguns autores sugerem que a inibição de NF- $\kappa \mathrm{B}$ causa bloqueio da progressão do ciclo celular e atraso na transição G1/S (Kaltschmidt et al., 1999). Outros afirmam que a superexpressão de NF- $\kappa$ B impede a transição de G1/S em células Hela (Bash et al., 1997). A nossa análise in silico (Figura 3.3) indica que este aumento na ativação de $\mathrm{NF}-\kappa \mathrm{B}$ na transição G1/S correlaciona com o aumento da atividade de IKK $\alpha$, um repressor natural da inibição de 
$\mathrm{NF}-\kappa \mathrm{B}$ dependente de $\mathrm{I} \kappa \mathrm{B}$. Como observado em nossos resultados, a atividade de IKK $\alpha$ é positivamente conectada com NEMO, afetando simultaneamente a regulação negativa de $\mathrm{I} \kappa \mathrm{B}$ mediada por NEMO, aparentemente para ativar $\mathrm{NF}-\kappa \mathrm{B}$, e, promovendo, assim a progressão do ciclo celular na transição G1/S. Estes mecanismos proliferativos são aumentados por uma regulação negativa de $\mathrm{I} \kappa \mathrm{B}$ mediada por NF- $\kappa \mathrm{B}$ na transição G0/G1, que é reforçada pela própria regulação negativa de $\mathrm{I} \kappa \mathrm{B}$ na fase de transição G1/S. Mas, também há indicações de uma regulação negativa de $\mathrm{NF}-\kappa \mathrm{B}$ por $\mathrm{I} \kappa \mathrm{B}$ neste ponto, podendo estar operando como um feedback negativo em direção ao defeito da atividade transcricional de NF- $\kappa$ B na transição G1/S. Assim, está claro que o balanço entre a ativação de NF$\kappa \mathrm{B}$ e o estímulo pró/anti-proliferativo pode estar determinando o destino da célula em direção à progressão/parada do ciclo ou ativando programas de morte celular. Juntos, como descrito em dados experimentais, nossos resultados in silico indicam que o fator de transcrição NF- $\kappa \mathrm{B}$ participa (diretamente ou indiretamente) do controle de um complexo padrão dos reguladores do ciclo celular de um modo bi-direcional. A Figure 3.4 mostra o perfil da expressão gênica dos dados reais compostos por nf- $\kappa \mathrm{B}$, ikk $\alpha$, nemo e nik, e os valores ajustados pelo DVAR.

VAR

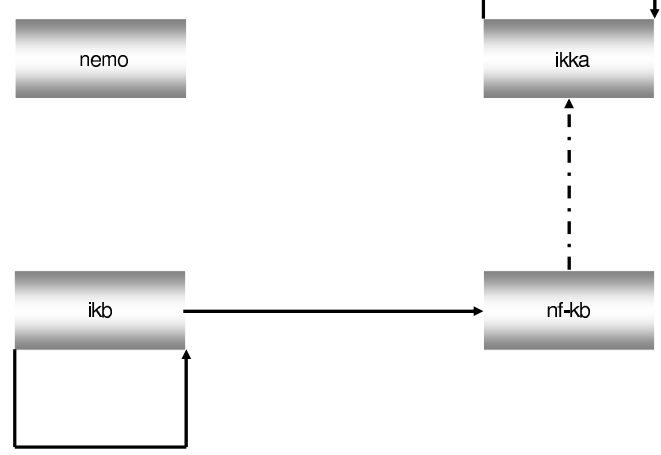

DVAR

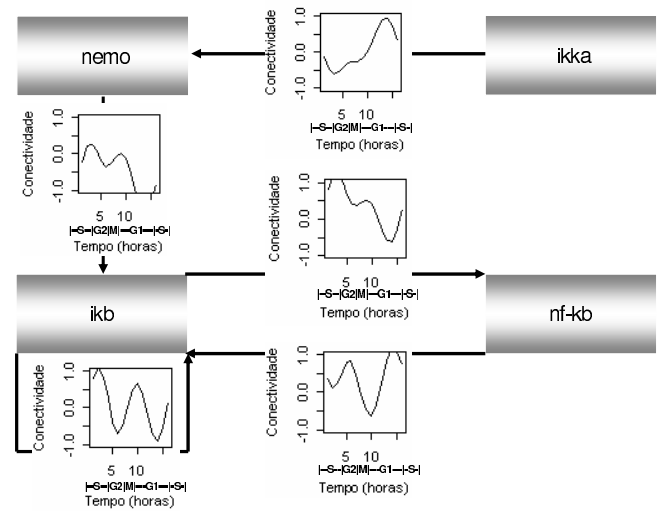

Figura 3.3: Aplicação dos modelos VAR e DVAR na rede composta pelos genes $n f-\kappa b, i k k \alpha$, nemo e nik. VAR: arestas pontilhadas são as conectividades significativas ( $\mathrm{p}$ valor $<0.1$ ) e arestas cheias são as conectividades significativas ( $\mathrm{p}$ valor $<0.05$ ). DVAR: conectividades significativas $(\mathrm{p}$ valor $<0.05$ ). As funções de conectividade estão ilustradas em cada aresta. 

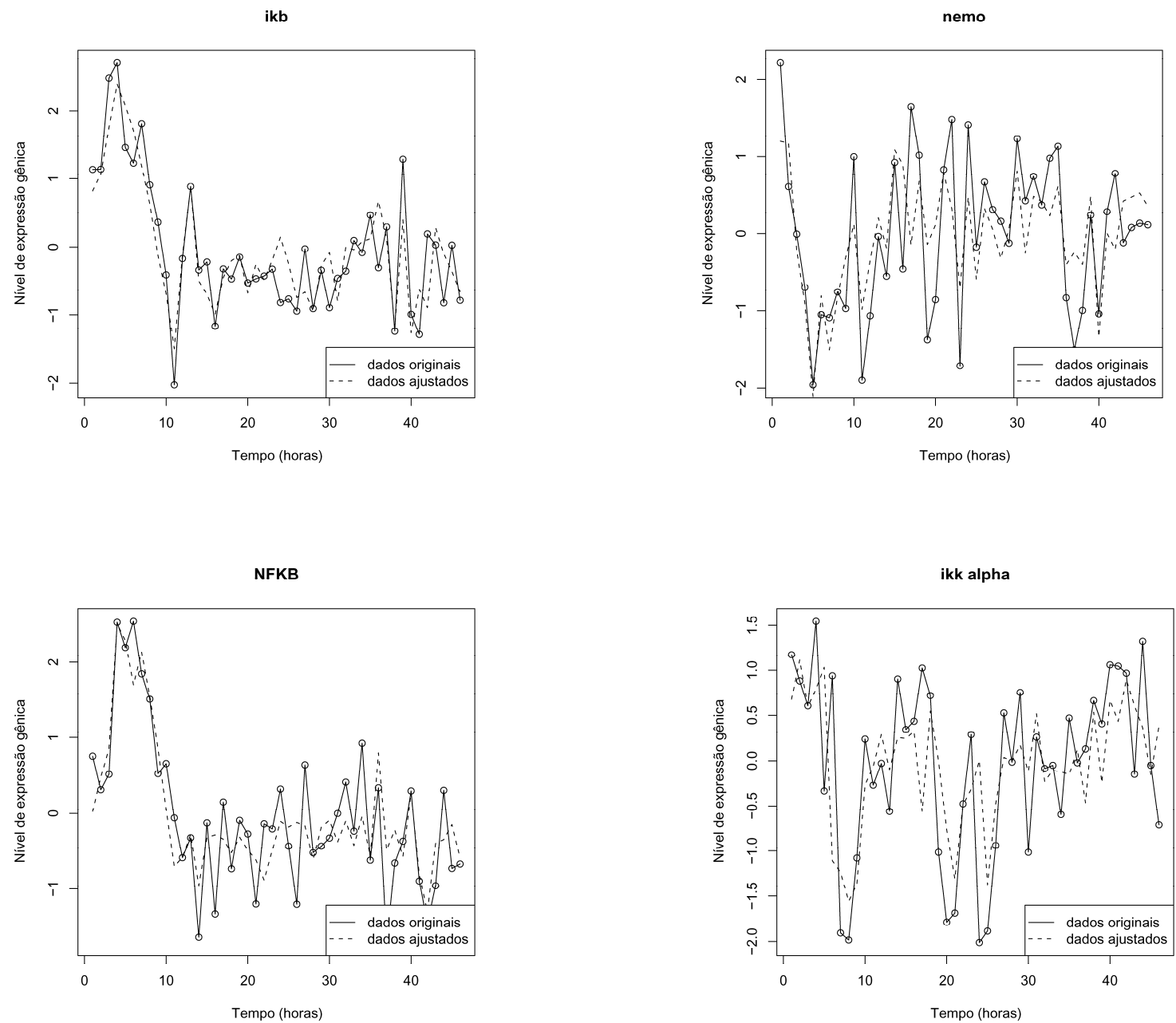

Figura 3.4: Perfil da expressão gênica dos dados reais e dos dados ajustados pelo método DVAR para os genes $n f-\kappa b$, ikk $\alpha$, nemo e nik. 
O oncogene c-myc atua como um potente modulador da transcrição durante a proliferação normal da célula. A atividade desregulada de c-myc no câncer leva à ativação excessiva das vias downstream, e pode, também, estimular mudanças na expressão dos genes e sinalizações celulares que não são observadas em condições não-patológicas (Wade et al., 2006). c-Myc participa essencialmente da transição G1/S, induzindo diversos genes que estão envolvidos no controle do ciclo celular (Matsumura et al., 2003).

Os inibidores de metaloproteinases (TIMPs e RECK) mantêm o balanço entre a destruição e a formação da matriz. TIMPs são capazes de inibir a proliferação de células endoteliais em resposta a estímulos angiogênicos. Aparentemente, TIMPs e RECK participam de funções importantes, controlando o fenótipo invasivo de tumores malignos.

Até o momento, a relação entre $c-M y c$ e os inibidores de metaloproteinases durante a progressão no ciclo celular é pouco conhecida. A regulação negativa da expressão de reck foi observada em células NIH-3T3 transformadas pelos oncogenes c-myc e src, sugerindo que o gene reck é um alvo comum para sinais oncogênicos (Takahashi et al., 1998). De fato, em diversos tipos de tumores, uma correlação inversa entre os níveis de expressão de reck e o grau de malignidade dos tumores (como invasão, metástase, recorrência e baixas taxas de sobrevivência) são observados. Mas o DVAR prediz (Figura 3.5) uma ativação de RECK mediada por $c$-myc na transição M/G1 no ciclo celular de células Hela, na fase imediatamente fase anterior à auto-regulação de $c$-myc. Isto está de acordo com a análise da expressão gênica em hepatomas, no qual a expressão de reck é maior no tumor quando comparado a tecidos subjacentes (Noda et al., 2003). Adicionalmente, dados obtidos no nosso laboratório, utilizando análise de expressão gênica por RT-PCR em tempo real de astrocitomas em 50 pacientes, revelaram uma correlação positiva entre a expressão de c-myc e reck (Figura 3.7). De fato, como aparentemente não há um controle da expressão de $c$-myc por reck, não foi possível estabelecer uma relação de direcionalidade entre as expressões de $c$-myc e reck no controle do ciclo celular de células Hela.

Por outro lado, nossos resutlados também mostraram uma regulação positiva de TIMP2 mediada por RECK e, simultaneamente, uma regulação negativa da quinase Src na transição G2/M, em contraste com dados experimentais obtidos em células de cultura primária (Oh et al., 2003). Considerando que o oncogene src está envolvido na progressão tumoral e que TIMP-2 é um inibidor da proliferação celular, reck pode ser um alvo para a regulação da indução da apoptose regulada por $c-m y c$, como descrito na literatura (Wade e Wahl, 2006; Matsumura et al., 2003). A Figure 3.6 mostra o perfil da expressão gênica 
dos dados reais compostos por reck, c-myc, src e timp-2, e os valores ajustados pelo DVAR.
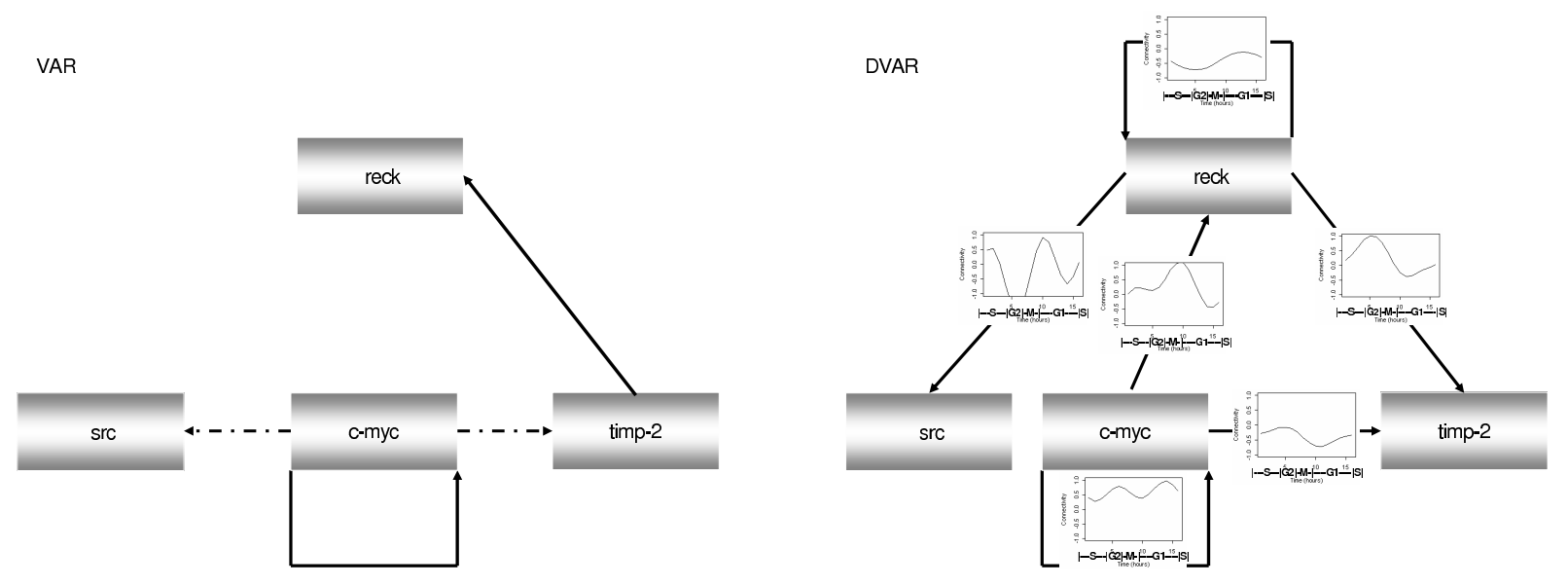

Figura 3.5: Aplicação dos modelos VAR e DVAR na rede composta pelos genes reck, c-myc, src e timp-2. VAR: arestas pontilhadas são as conectividades significativas (p valor $<0.1$ ) e arestas cheias são as conectividades significativas (p valor $<0.05$ ). DVAR: conectividades significativas ( $\mathrm{p}$ valor $<0.05$ ). As funções de conectividade estão ilustradas em cada aresta.

Estes resultados revelaram evidências in silico para apoiar a hipótese de que o lugar, o tempo e o nível de expressão de reck estão sob o controle fino de programas de desenvolvimento e, também, das condições ambientais.

Em geral, no nível molecular, a causalidade ocorre em um determinado intervalo de tempo, e mais precisamente, numa fase específica do ciclo celular. É interessante que o poder do teste usando DVAR é maior que o do VAR. Isto ocorre devido ao estreito intervalo de tempo em que as causalidades ocorrem, os quais podem ser observados na Figura 3.1 , entre gadd45a $\rightarrow$ p53, na Figura 3.3 , entre $i k k \alpha \rightarrow$ nemo, nemo $\rightarrow i \kappa b$ e $n f-\kappa b \rightarrow i \kappa b$ e na Figura 3.5 entre reck $\rightarrow$ src, $c-m y c \rightarrow$ reck, e no feedback para reck, indicando que essas conectividades são variantes no tempo.

Simulamos também uma grande rede regulatória composta por 1.000 genes e inferimos uma rede de genes dois a dois aplicando o DVAR. O tempo computacional foi de 8 horas em um Pentium IV $3.06 \mathrm{GHz}$, mostrando que essa abordagem também é computacionalmente viável para redes de grande porte.

A principal vantagem do vetor autoregressivo dinâmico baseado em wavelets (DVAR), 

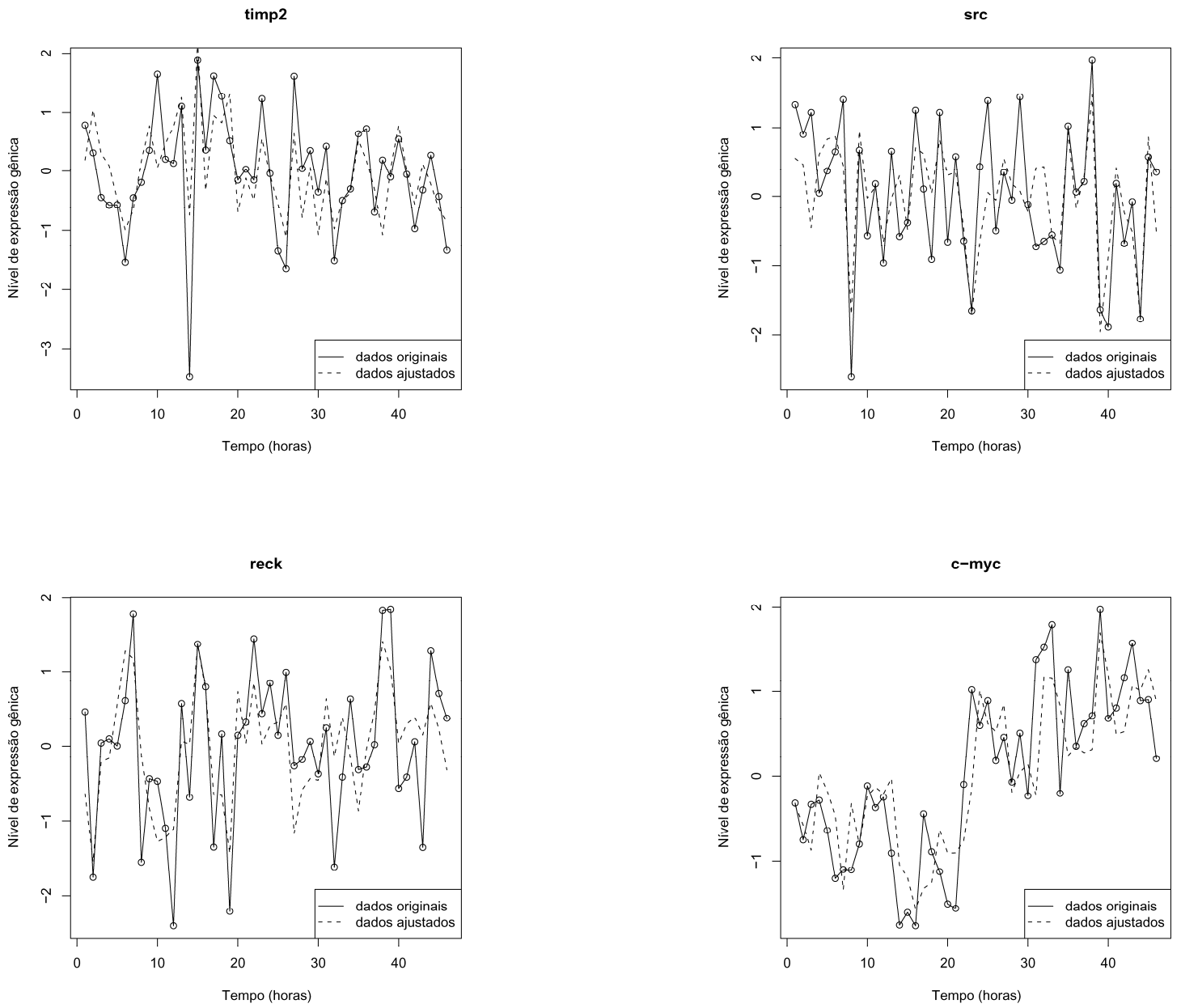

Figura 3.6: Perfil de expressão gênica com dados reais e com dados ajustados pelo método DVAR para os genes reck, c-myc, src e timp-2. 
quando comparado aos outros modelos de conectividade, é que este método não assume estacionaridade.

É sabido que em diferentes fases do ciclo celular ou em diferentes condições, estão envolvidos diferentes circuitos, sendo largamente aceita a idéia de que a célula sofre alterações dinâmicas em sua conectividade. Assim, a suposição de estacionaridade pode eventualmente nos levar a resultados espúrios. Além disso, o DVAR não necessita de uma pré-especificação, diferentemente da modelagem por equações estruturais (Xiong et al., 2004).

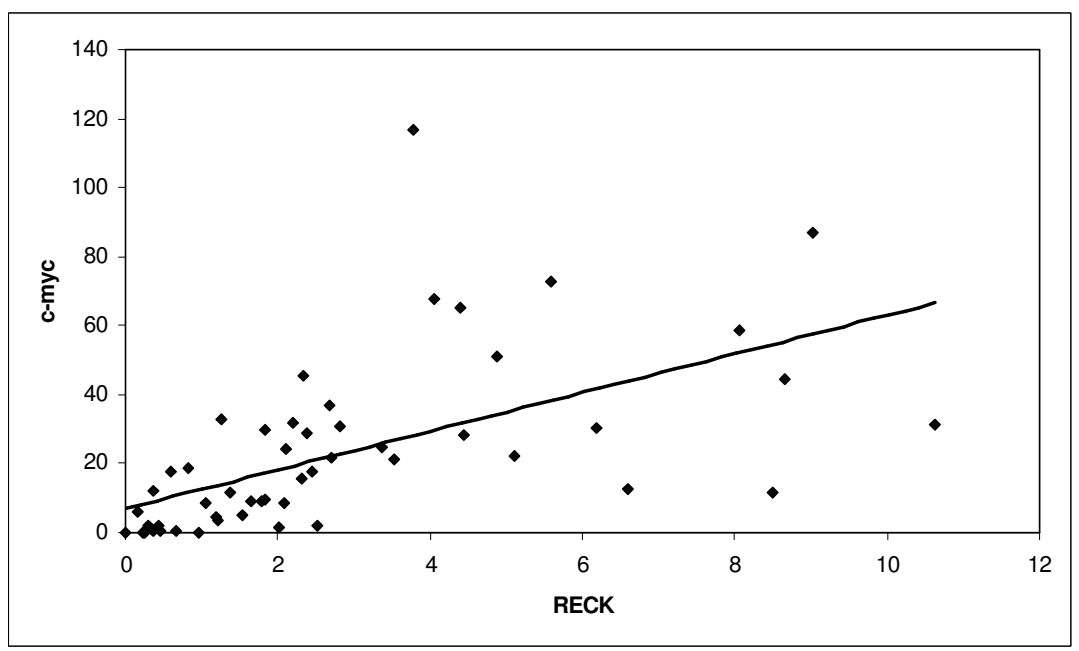

Figura 3.7: Representação dos dados de expressão gênica dos genes reck e c-myc derivados de 50 astrocitomas humanos. A linha representa a curva de regressão linear entre estes genes ( $\mathrm{p}$ valor $<0.001)$.

Assim, o DVAR é não-viesado quando comparado com modelos que requerem conhecimento da conectividade a priori, contribuindo para inferir novas conectividades e sendo útil para o desenho de novos experimentos e novos alvos para um dado gene específico. Diferentemente dos modelos gráficos gaussianos, que funcionam com correlações parciais, i.e., sem direcionalidade nas arestas, aqui é possível inferir causalidades baseadas na causalidade de Granger. Outra vantagem, quando comparado com modelos clássicos, como a rede Booleana, é o fato que a discretização da expressão dos genes para variáveis booleanas não é necessária no DVAR. A necessidade de usar-se limiares para tais discretizações pode levar a perda de informação, o que não ocorre no DVAR. Ademais, o método pode ser naturalmente aplicado a redes contendo ciclos, uma vantagem sobre modelos baseados em DAGs (Directed Acyclic Graphs), já que é bem sabido que as redes regulatórias mantêm 
sua regulação através de feedbacks positivos e negativos. DVAR é sempre identificável quando o número de observações é maior que o número de parâmetros a serem estimados porque este método utiliza as defasagem nas regressões, diferentemente do SEM que usa os dados simultâneos.

Modelos dinâmicos clássicos são baseados em uma janela móvel, mas a detecção das mudanças dinâmicas através dessa abordagem pode ter mais baixa resolução e flexibilidade que o método DVAR que é baseado em wavelets.

Nos nossos dados, as tomadas de tempo da série temporal eram igualmente espaçadas, por isso, utilizamos as wavelets de Daubechies Extreme Phase 16 que, devido às propriedades de ortogonalidade, reduz a multicolinearidade dos dados e, conseqüentemente, reduz a variância dos estimadores. Infelizmente, isto não é um caso geral. Quando a série temporal não está igualmente espaçada, pode-se resolver esse problema usando warped wavelets ou funções explícitas como Haar, Morlet, Shannon ou chapéu mexicano (Meyer, 1993; Chui, 1992) que não requerem dados em série temporal igualmente espaçados.

\subsection{Vetor autoregressivo esparso (SVAR)}

Como mostrado na seção 3.3, o método DVAR é útil para inferir causalidades de Granger variantes no tempo, porém, não é possível inferir causalidades quando o número de observações é menor que o número de parâmetros a ser estimado, como na maior parte dos modelos de redes regulatórias. A fim de resolver o problema da dimensionalidade, apresentamos o SVAR (Sparse Vector Autoregressive). Porém, o SVAR não é capaz de inferir causalidades de Granger variantes no tempo como o DVAR, e sim, somente causalidades de Granger lineares e estacionárias. Aqui é necessário ressaltar que as definições acima mencionadas no caso do Vetor Autoregressivo só funcionam para $m>n$ (onde $m$ é o número de observações e $n$ é o número de parâmetros). Além disso, é sabido que o estimador de mínimos quadrados não assume esparsidade na conectividade da matriz $A$.

Os resultados desta seção estão presentes no artigo submetido: Fujita A, Sato JR, Garay-Malpartida, Yamaguchi R, Miyano S, Sogayar MC, Ferreira CE. Modeling large gene expression regulatory networks with the sparse vector autoregressive model. Este trabalho foi realizado em colaboração com os Professores Dr. Satoru Miyano e Dr. Rui Yamaguchi, ambos do Laboratory of DNA information analysis, durante o estágio sanduíche 
na Universidade de Tóquio.

Considere $Z, \beta, X$ e $E$ como descritos na seção 3.2.

Por Fan e Li (2001), Fan e Peng (2004), Hunter (2004) e Hunter e Lange (2004), a regressão LASSO (Least Absolute Shrinkage and Selection Operator) (Tibshirani, 1996) pode ser descrita por um procedimento iterativo:

$$
\hat{\beta}_{i}^{k+1}=\left(X^{\prime} X+\lambda^{2} D\left(\hat{\beta}_{i}^{k}\right)\right)^{-1} X^{\prime} z_{i} \quad i=1, \ldots, n \text { e } k=1, \ldots, N_{i t}
$$

onde $N_{i t}$ é o número de iterações (definimos $N_{i t}=30$ nas nossas análises), $\lambda$ é o parâmetro que determina quanto de penalização deve ser atribuído, $D\left(\hat{\beta}_{i}^{k}\right)$ é a diagonal da matriz definida por $D(\theta)=\operatorname{diag}\left(p_{\lambda}^{\prime}(\theta) / \theta\right) k=1, \ldots, n$ e $p_{\lambda}^{\prime}(\theta)=\lambda \operatorname{sinal}(\theta)$.

A cada iteração, os coeficientes da regressão $\beta$ de cada gene, ponderados em relação ao seu atual tamanho, são sucessivamente diminuídos de peso até atingirem o valor zero.

A matriz de covariância pode ser aproximada por

$$
\left(X^{\prime} X+\lambda^{2} D(\hat{\beta})\right)^{-1} X^{\prime} X\left(X^{\prime} X+\lambda^{2} D(\hat{\beta})\right)^{-1} \hat{\sigma}^{2},
$$

onde $\hat{\sigma}^{2}$ é a variância estimada

$$
\hat{\sigma}^{2}=\frac{1}{m-n-c}(Z-X \hat{\beta})(Z-X \hat{\beta})=\frac{E^{\prime} E}{m-n-c}
$$

onde $c$ é o número de variáveis $\beta$ postas como zero pela regressão LASSO.

Quando $\hat{\sigma}^{2}$ é substituído por $\sigma^{2}$, obtem-se como resultado, o teste estatístico

$$
\frac{\hat{\beta}_{i j}}{\sqrt{\hat{\sigma}^{2}} w_{j j}} \sim t(m-n-c) \quad i=1, \ldots, n
$$

sob a hipótese nula, onde $t(m-n-c)$ denota a distribuição $t$ com $(m-n-c)$ graus de liberdade e $w_{j j}$ é o $j$-ésimo elemento da diagonal de:

$$
\left(X^{\prime} X+\lambda^{2} D(\hat{\beta})\right)^{-1} X^{\prime} X\left(X^{\prime} X+\lambda^{2} D(\hat{\beta})\right)^{-1}
$$

\subsubsection{Ajuste da variável $\lambda$}

É necessário enfatizar que o número de variáveis marcadas como zero pelo método é dependente do valor atribuído ao parâmetro $\lambda$. Quanto mais alto o valor de $\lambda$, mais variáveis são marcadas como zero. 
Em nosso trabalho, o valor de $\lambda$ foi selecionado como o valor que minimiza o valor do critério da validação cruzada generalizada (GCV, Generalized Cross-Validation).

Seja $q(\lambda)=\operatorname{tr}\left\{X\left(X^{\prime} X+\lambda^{2} D(\beta)\right)^{-1}\right\}$ e $r s s(\lambda)$ o resíduo da soma dos quadrados com constante $\lambda$, o valor da GCV pode ser calculado como

$$
G C V(\lambda)=\frac{1}{m} \frac{r s s(\lambda)}{\{1-q(\lambda) / m\}^{2}}
$$

O valor mínimo do GCV foi atingido com o uso do algoritmo L-BFGS-B (Bryd et al., 1995), implementado na função optim do pacote estatístico R.

\subsubsection{Controle da taxa de falso-positivos}

Para controlar o aumento da taxa do erro tipo I (falsos-positivos) quando testamos simultaneamente centenas de arestas, aplicou-se o método FDR (Benjamini e Hochberg, 1995).

Primeiramente, assume-se que as $n$ hipóteses testadas $\left\{H_{1}^{0}, H_{2}^{0}, \ldots, H_{n}^{0}\right\}$, onde $H_{j}^{0}$ é a hipótese nula do $j$-ésimo teste e $\{p(1), p(2), \ldots, p(n)\}$ seus correspondentes $p$-valores, $n_{0}$ é o número de verdadeiras hipóteses nulas e os outros $n-n_{0}$ são as hipóteses falsas.

Sejam $p(1) \leq p(2) \leq \ldots p(n)$ os valores dos $p$-valores observados. Define-se

$$
l=\max \left\{i: p(i) \leq \frac{i}{n} q\right\}
$$

e rejeita-se $H_{(1)}^{0} \ldots H_{(l)}^{0}$. Se não existe $i$, não se rejeita hipótese alguma.

Assim, o FDR controla a proporção esperada $(q)$ de hipóteses incorretamente rejeitadas (erro tipo I) de uma lista de hipóteses rejeitadas.

\subsubsection{Simulações}

Para testar o método proposto SVAR, realizamos várias simulações. Para tal finalidade, construímos redes regulatórias artificiais baseadas em grafos livres de escala, já que é bem sabido que redes metabólicas são deste tipo (Jeong et al, 2000).

\section{Redes regulatórias artificiais}

A descrição de que na natureza muitas redes têm uma distribuição em potência nos graus dos nós foi primeiramente descrita por Barabási e Albert (1999). Em seu modelo 
de grafo aleatório, chamado de grafo livre de escala, o crescimento da rede é baseado em dois mecanismos comuns a diversas redes do mundo real. Estas redes começam com um pequeno número de nós e crescem continuamente com a adição de novos nós; assim, o número de nós aumenta conforme o tempo de vida da rede. Quando um novo nó é adicionado à rede, sua conexão é preferencial, i.e., a probabilidade com a qual um novo nó se conecta a um nó já existente não é uniforme como no grafo aleatório (Erdös e Rényi, 1959), mas há uma probabilidade maior de se ligar em um nó que possui um número de conexões maior, resultando em uma distribuição em potência nos graus dos nós. Em outras palavras, a probabilidade $P(k)$ que um nó da rede se conecte a $k$ outros nós decai em potência. Assim, o grau de distribuição tem uma cauda em potência $P(k) \sim k^{-\gamma}$, onde $\gamma$ é um número escalar que representa o quanto a distribuição do grau decai. No nosso caso, os nós representam os genes e as conexões as relações de Granger causalidades.

Um grafo livre de escala pode ser construído da seguinte maneira:

1. Crescimento: comece com uma pequeno número $z_{0}$ de genes e, a cada iteração, um novo gene com $z \leq z_{0}$ arestas é adicionado. Este novo gene é conectado com conexão preferencial aos genes já existentes na rede.

2. Conectividade preferencial: o gene com o qual o novo gene irá se conectar é selecionado de uma forma não-determinística. Assuma como $\phi$ a probabilidade de um novo gene se conectar ao gene $i$, e que essa probabilidade depende do grau $d_{i}$ do gene que já está presente na rede. Assim

$$
\phi\left(d_{i}\right)=\frac{d_{i}}{\sum_{j} d_{j}}
$$

Como estamos interessados em relações de causalidade, foi necessário definir a direção da aresta. Assim, há um terceiro passo na nossa construção. Nas nossas simulações, a probabilidade atribuída para adicionar uma aresta do gene $i$ para o gene $j$ é o mesmo que de $j$ para $i$, i.e., 0.5 .

Após $T_{\text {passos }}$ iterações, a construção do grafo aleatório é composta com $n=T_{\text {passos }}+z_{0}$ genes e $z * T_{\text {passos }}+z_{\text {arestas }}$ relações de Granger causalidades, onde $z_{\text {arestas }}$ é o número inicial de arestas.

O grafo construído usando o algoritmo acima pode ser representado por sua matriz de adjacências $A$, i.e., onde existir uma aresta do gene $i$ para o gene $j$, a matriz é definida 
como $A[i, j]=0.8$, e 0 caso contrário (definimos como 0.8 o peso de cada aresta). A matriz de adjacências $A$ corresponde a matriz $A$ descrita na equação 3.1. A defasagem das séries temporais foi definida como uma, assim, defina $m=T-1$.

Para construir as séries temporais para cada gene, gere números aleatórios com distribuição normal para cada gene $i=1, \ldots, n$ no tempo $t=1, y_{i 1}=\varepsilon_{i}$. Depois, aplique a equação 3.2 para gerar as séries temporais para cada gene $i=1, \ldots, n$ e tempos $t=2, \ldots, T$.

\section{Aplicação em dados reais}

O SVAR foi aplicado nos dados descritos na seção 3.3.2.

\subsubsection{Resultados e Discussão}

A fim de medir o desempenho do SVAR, simulações intensas foram realizadas. Para este propósito, simulamos centenas de redes com topologias livres de escala como descrito acima. Para cada grafo simulado, a matriz de adjacências $A$ foi construída, i.e., a aresta do gene $i$ para o gene $j$ está representada em $A[i, j]$. Esta matriz de adjacências é a matriz $A$ descrita em 3.1. As séries temporais têm defasagens iguais a um em nossas simulações.

O número de genes para cada rede gerada foi de $n=100$ e o tamanho da observações foi variado, i.e., o tamanho da série temporal $(T=25,20,75,100,125,150$ e 200 para o SVAR e $T=110,125,150,175$ e 200 para o VAR). Note que, para o VAR, $T$ necessariamente deve ser maior que $n$. Para cada tamanho $T$ da série temporal, realizamos 100 simulações, i.e., geramos 100 diferentes grafos livres de escala. Os grafos livres de escala foram inicialmente gerados a partir de 2 genes fortemente conexos $\left(z_{0}=2, z_{\text {arestas }}=2\right.$, onde $z_{0}$ é o número inicial de genes $z_{\text {arestas }}$ é o número inicial de arestas), ou seja, dois nós com duas arestas, um apontando para o outro. O número de genes adicionados para cada instante $T$ é $z=1$, assim, cada rede é composta por 100 genes e 100 arestas dentro das 10.000 possíveis arestas (o máximo possível de arestas é de $n^{2}$ ). Na Figura 3.8, está ilustrado um exemplo de uma rede de expressão gênica artificialmente gerada pelo nosso procedimento.

É importante ressaltar que o SVAR foi capaz de identificar verdadeiros positivos mesmo quando o tamanho da série temporal foi menor que o número de genes. Figuras 


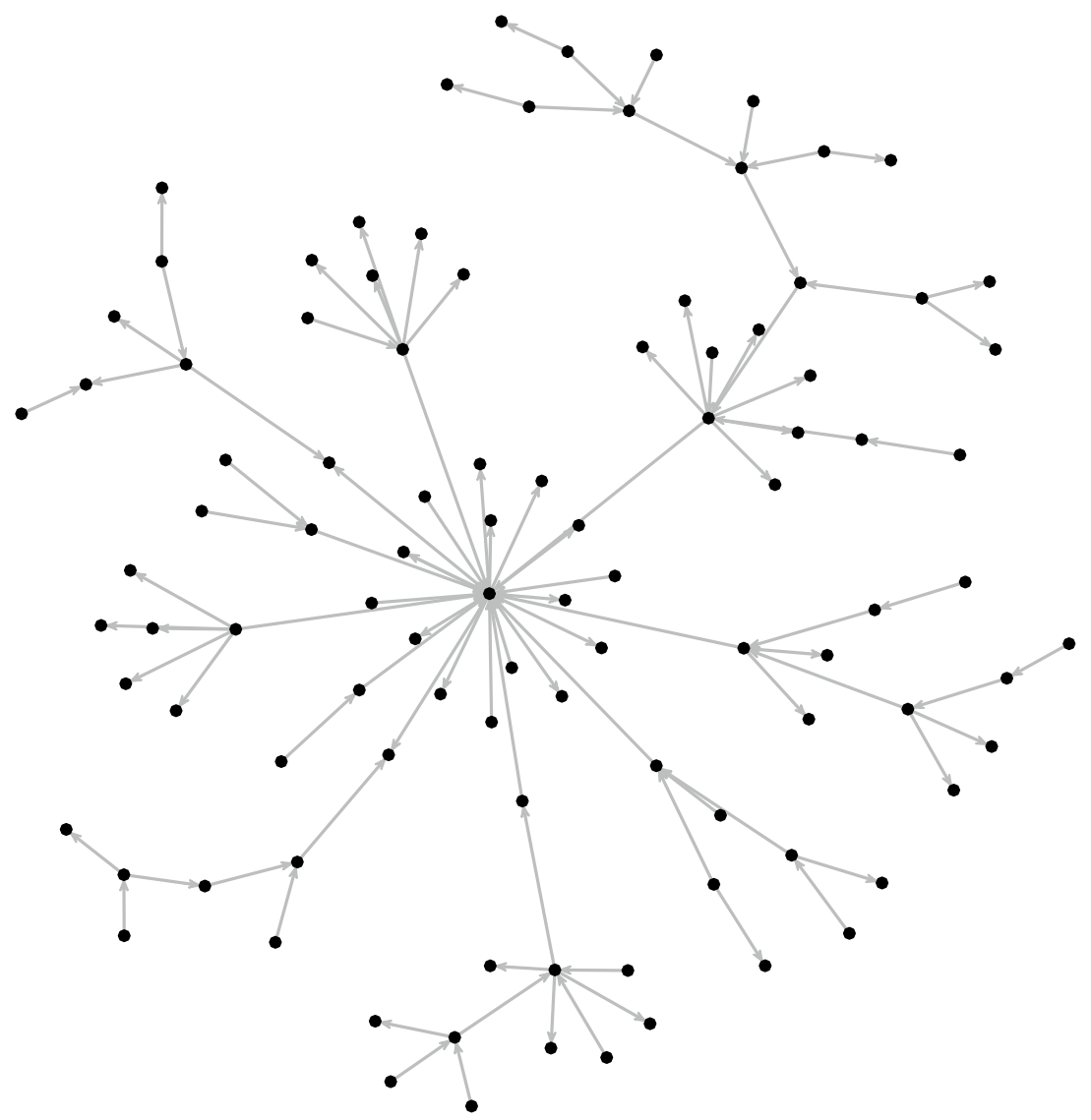

Figura 3.8: Exemplo de uma rede regulatória esparsa de genes simulada com $n=100$ genes e 100 arestas. As arestas direcionadas indicam as relações de causalidade de Granger. 
3.9, 3.10 e 3.11 mostram, respectivamente, o número de verdadeiros positivos inferidos pelos métodos VAR e DVAR para os valores de q-valores menores que 0.01, 0.05 e 0.10.

Analisando as Figuras 3.9, 3.10 e 3.11, obtivemos os seguintes resultados:

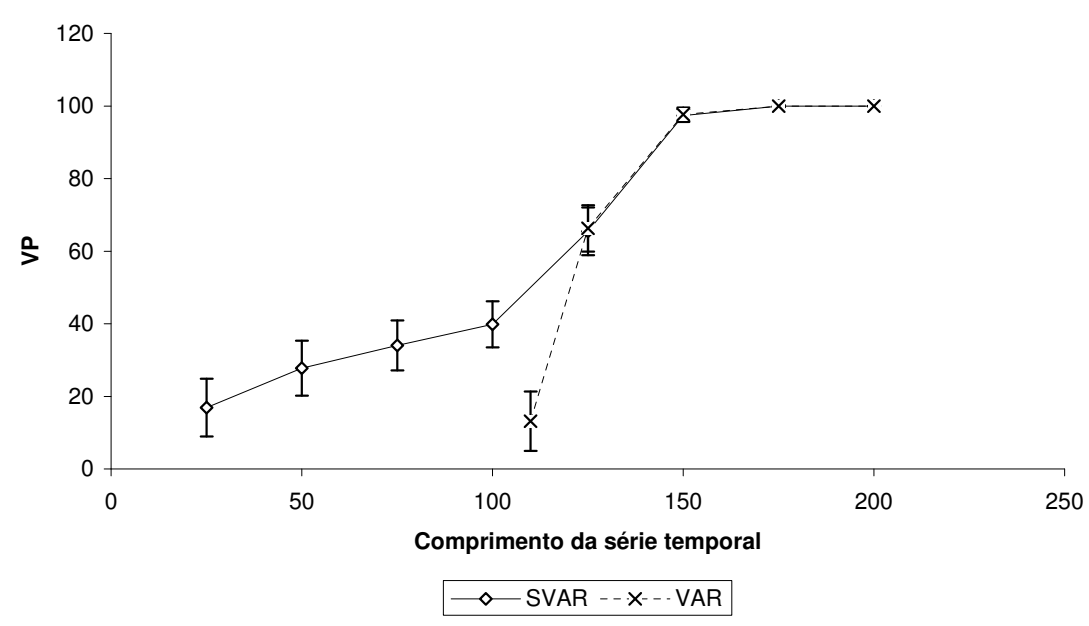

Figura 3.9: Comparação entre os métodos SVAR e VAR. As simulações foram realizadas em uma rede livre de escala composta por 100 nós e 100 arestas. O VAR foi utilizado somente para experimentos com séries temporais de comprimento maior que 110. VP: Verdadeiros Positivos. q-valor $<0.01$. A barra de erros representa um erro padrão $=$ $\sqrt{\frac{\text { variância }}{\text { núm. de simulações }}}$.

1. A capacidade do SVAR de identificar os verdadeiros positivos, mesmo quando o número de observações é menor que o número de genes, é muito alta. Isto pode ser notado comparando o desempenho entre SVAR quando o tamanho da série temporal é igual a 50 e o VAR com tamanho da série temporal igual a 110. Mesmo nesse caso, SVAR conseguiu identificar mais arestas verdadeiros positivas que o VAR.

2. Comparando SVAR e VAR quando o número de genes é menor que o número de microarrays, em geral, SVAR foi levemente mais poderoso que o VAR.

3. Quando $m>n$, não foi possível observar diferenças entre eles. Isto pode ser explicado, nesse contexto, porque o melhor $\lambda$ que minimiza o GCV é próximo de zero. Quando $\lambda=0$, o modelo SVAR se torna o tradicional modelo VAR. 


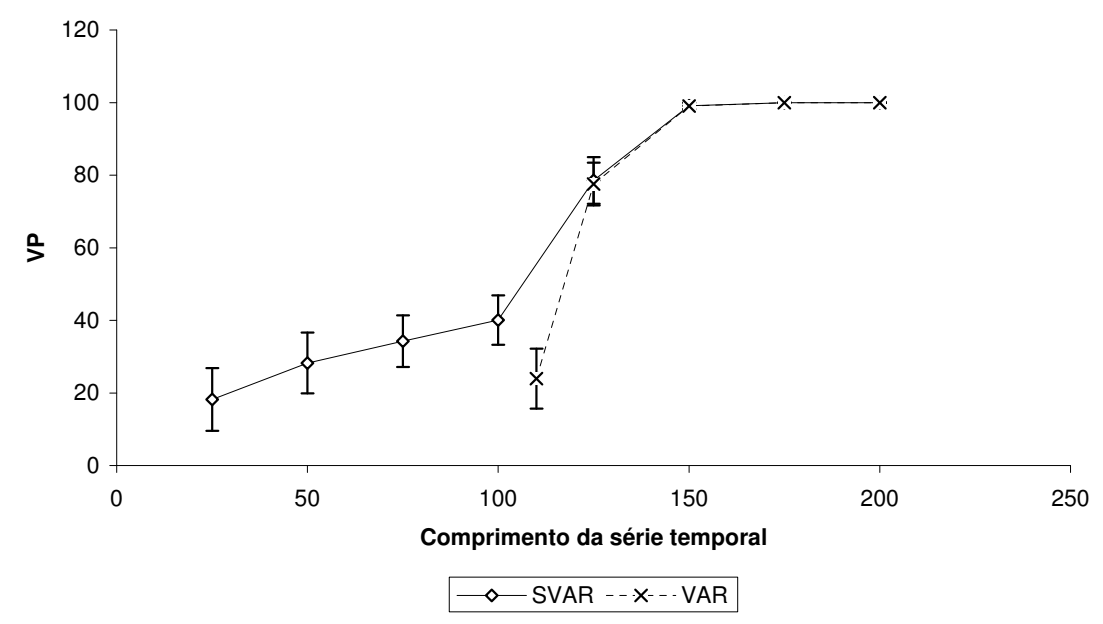

Figura 3.10: Comparação entre os métodos SVAR e VAR. As simulações foram realizadas em uma rede livre de escala composta por 100 nós e 100 arestas. O VAR foi utilizado somente para experimentos com séries temporais de comprimento maior que 110. VP: Verdadeiros Positivos. q-valor $<0.05$. A barra de erros representa um erro padrão $=$ $\sqrt{\frac{\text { variância }}{\text { núm. de simulações }}}$.

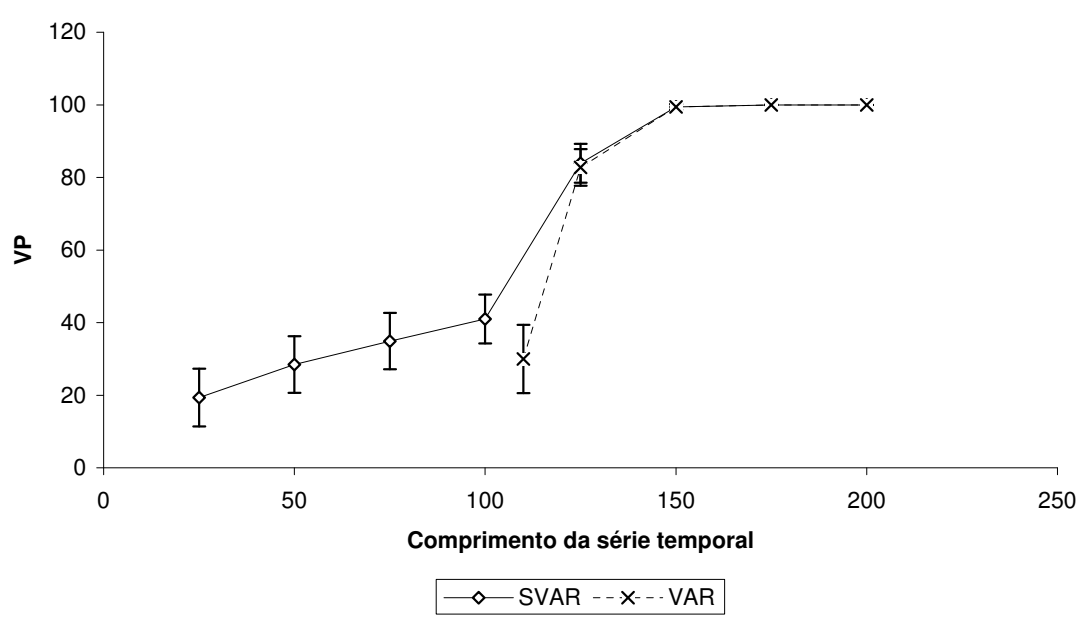

Figura 3.11: Comparação entre os métodos SVAR e VAR. As simulações foram realizadas em uma rede livre de escala composta por 100 nós e 100 arestas. O VAR foi utilizado somente para experimentos com séries temporais de comprimento maior que 110. VP: Verdadeiros Positivos. q-valor $<0.10$. A barra de erros representa um erro padrão $=$ $\sqrt{\frac{\text { variância }}{\text { núm. de simulações }}}$. 
Nós também analisamos o perfil de expressão de um conjunto de 94 genes regulados no ciclo celular, representado por 48 microarrays, i.e., o número de genes $n$ é aproximadamente duas vezes maior que o tamanho da série temporal T. A Figura 3.12 ilustra os genes presentes com alguma conectividade. Genes sem conectividade alguma foram excluídos da figura.

O método SVAR revelou no mínimo três redes regulatórias de genes: os módulos

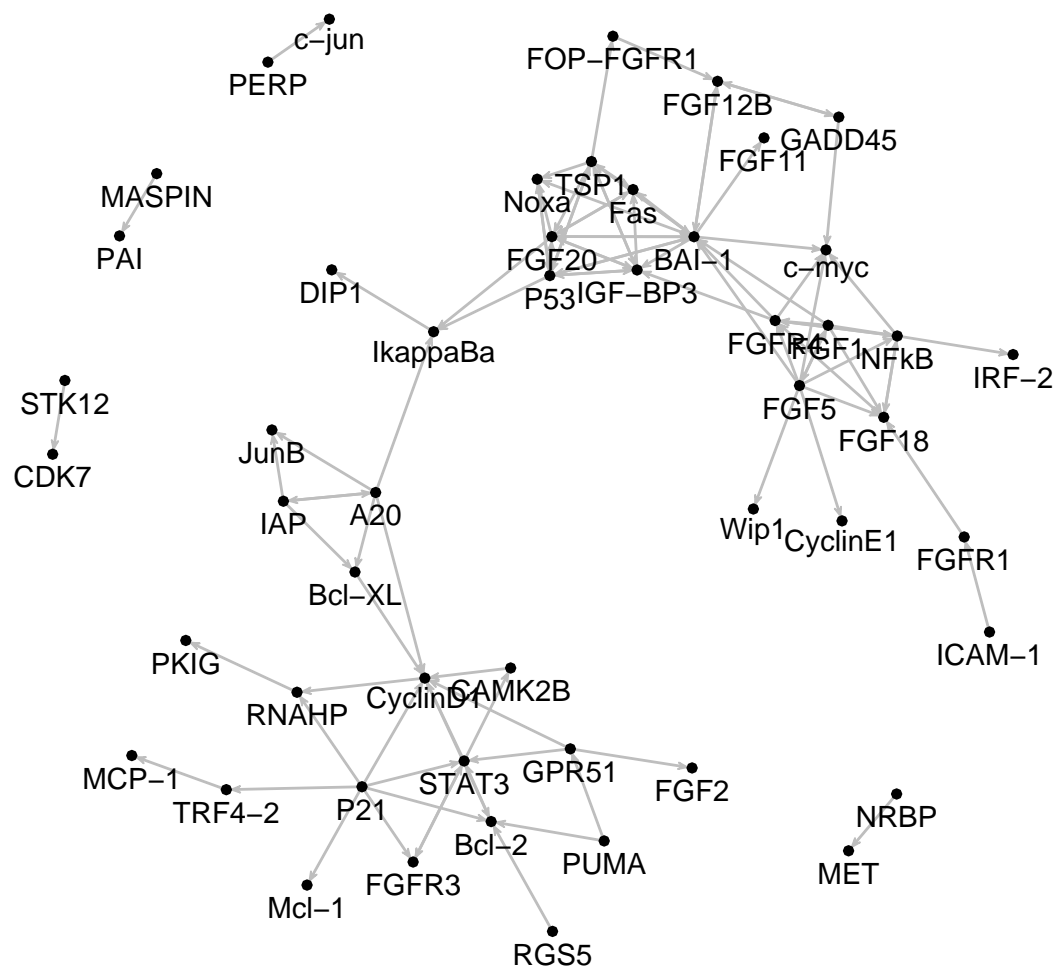

Figura 3.12: Rede regulatória inferida à partir de dados de expressão gênica da HeLa no ciclo celular. As arestas representam as causalidades de Granger com q-valor $<0.05$. Genes que não tiveram causalidades de Granger identificadas pelo SVAR foram retirados da figura. 
transcricionais de NF- $\kappa$ B, p53 e STAT3 (Inoue et al., 2007; Soussi et al., 2007; Yu et al, 2007) que estão de acordo com as vias já bem conhecidas em diversos modelos celulares e também na própria Hela.

É importante ressaltar que o grau de saída (número de arestas que saem do vértice) dos genes que codificam proteínas que atuam como fatores de transcrição (p53, NF- $\kappa \mathrm{B}$ e STAT3) ou genes importantes para o controle da proliferação celular (p21, bai1, tsp1, a20) é maior que os outros genes. Numa análise similar, o grau de entrada (número de arestas que entram no vértice) do FGFs (fgf18, fgf20, fgfr4) e genes envolvidos na regulação do ciclo celular e apoptose (cyclin d1, c-myc, bcl-2, noxa, fas) são também altos, demonstrando a associação entre sua importância na homeostase da célula e seu grau de entrada e saída (Albert et al., 2000).

NF- $\kappa \mathrm{B}$ é um complexo fator de transcrição indutível formado pela associação heterodimérica entre os produtos dos genes relA e $c$-rel, cuja atividade transcricional é regulada pela interação com a proteína inibidora $\mathrm{I} \kappa \mathrm{B} \alpha$. Já foi demonstrado que a ativação de NF$\kappa \mathrm{B}$ controla a progressão do ciclo celular nas células Hela por diversos mecanismos (Chen et al., 2001). O método SVAR não foi capaz de identificar as relações entre NF- $\kappa \mathrm{B}$ e seus alvos naturais como os genes $A 20$, iap, bclx e $i \kappa B \alpha$. Mas, SVAR mostra que NF- $\kappa \mathrm{B}$ regula diretamente diversos FGFs e a proteína c-Myc, que são reguladores chave da proliferação celular. De fato, pode-se notar que a maior parte da atividade transcricional de NF- $\kappa \mathrm{B}$ é regulada ou regula a atividade dos FGFs. Esses resultados apóiam a hipótese de que alguns dos múltiplos aspectos da tumorigênese nas células Hela podem estar relacionados com a transcrição de genes relacionados com os FGFs mediada por NF- $\kappa$ B.

Como discutido anteriormente, não foi possível a identificação da regulação positiva de diversos alvos bem conhecidos de NF- $\kappa$ B. Mas estes processos regulatórios parecem estar presentes, mesmo na ausência de evidências de arestas diretas com NF- $\kappa \mathrm{B}$, já que todos esses genes transcricionalmente regulados estão altamente relacionados em uma rede (Figura 3.12). A20, uma proteína contendo domínios de dedo de zinco, que é regulado no nível transcricional por NF- $\kappa \mathrm{B}$ em diversos tipos celulares (Krikos et al., 1992), parece orquestrar a relação dos genes nessa rede, ativando a transcrição de genes anti-apoptóticos muito bem conhecidos, como iap, bclx e junB, que são alvos de NF- $\kappa$ B (You et al., 1997; Chen e Gosh, 1999; Brown et al., 1995). A proteína A20 está também envolvida na regulação de NF- $\kappa \mathrm{B}$, bloqueando sua atividade, num mecanismo de feedback negativo (Storz et al., 2005). Apesar desse controle ser operado em um nível pós-transcricional, os resul- 
tados do SVAR estão mostrando que este processo pode ser controlado também por uma regulação positiva de $i \kappa B \alpha$, mediada por A20 (Figura 3.12). Estes resultados confirmam a confiabilidade do SVAR para predizer relações regulatórias, já que $i \kappa B \alpha$, um inibidor natural de $\mathrm{NF}-\kappa \mathrm{B}$ tem um papel-chave no controle de eventos que ocorrem no ciclo celular das células Hela, os quais são regulados por $\mathrm{NF}-\kappa \mathrm{B}$, como descrito na literatura (Chen et al., 2001). Além disso, SVAR mostrou que o papel de $i \kappa B \alpha$ na progressão do ciclo celular das células Hela parece ser também regulado através da ativação de $i \kappa B \alpha$, num processo mediado por p53 (Figura 3.12), estando de acordo com dados mostrados na literatura (Dreyfus et al., 2005). Em resumo, estes dados apóiam a hipótese de que este gene pode estar envolvido na atenuação dos mecanismos de progressão tumoral e no baixo potencial invasivo, que é comumente observado em células Hela.

A proteína p53 é um fator de transcrição que se liga aos elementos enhancer/promotor dos genes-alvos, regulando, assim, sua transcrição, e iniciando programas celulares que estão relacionados com funções de supressão tumoral como: parada do ciclo celular, inibição da angiogênese e metástase, indução da apoptose e reparo do DNA (Jin e Levine, 2001). O SVAR foi capaz de identificar a interação de diversos membros da rede de p53 como IGF-BP3, NOXA e BCL-2, que são transcricionalmente ativados por p53 na ativação da apoptose em diversos tipos celulares (Buckbinder et al., 1997); Yakovlev et al., 2004). Os nossos resultados in silico mostraram que a regulação está também presente nas células Hela. Apesar do gene fas não ser um alvo conhecido de p53, sua ativação pode ser mediada por outros alvos de p53, levando ao aumento da taxa de apoptose e controle da proliferação celular. Por outro lado, nossos resultados mostraram que os genes bai-1 e tsp1 são induzidos pelo gene $p 53$ em células HeLa. É sabido que o gene bai-1 codifica para um membro da família de receptores de secretina, contendo pelo menos um sítio funcional de ligação de p53, sendo postulado como um inibidor da angiogênese e um supressor de crescimento tumoral (Fukushima et al., 1998). Similarmente, o gene tsp-1 codifica para uma glicoproteína adesiva que medeia interações célula-célula e célula-matriz, e que tem sido descrita como tendo uma participação chave na agregação de plaquetas, angiogênese e tumorigênese (Dameron et al., 1994). Juntos, a regulação positiva de bai-1 e tsp-1, mediada por p53, pode ser um mecanismo de evasão da migração celular e angiogênese, características que estão comumente ausentes nas células Hela. Percebemos que alvos clássicos de p53, como gadd45a e p21, não apareceram como sendo diretamente regulados por p53 na análise por SVAR (Figura 3.12). Isto pode ter ocorrido devido ao fato da série 
temporal não ser suficientemente longa e/ou o fato da regulação ocorrer em um intervalo de tempo muito curto. Assim, essas conectividades não podem ser detectadas pelo método SVAR, que assume estacionaridade. É importante ressaltar que o DVAR (Fujita et al., 2007a), segundo nosso conhecimento, é o único método que não assume estacionaridade e, conseqüentemente, é o único capaz de identificar causalidades de Granger na ausência de estacionaridade. As regulações transcricionais independentes de p53 observadas no gene p21 (Figura 3.12) parecem não estar relacionadas com a parada do ciclo celular, como descrito mais abaixo.

A proteína STAT3 é um membro da família das proteínas STAT. Em resposta à citocinas e fatores de transcrição, forma homo ou heterodímeros com outras proteínas STAT e transloca para o núcleo, onde atuam como ativadores transcricionais. As STATs medeiam a resposta da célula a diferentes estímulos, e assim, participam significativamente em diversos processos celulares, como crescimento celular e apoptose (Jing e Tweardy, 2005). Como mostrado, utilizando o método SVAR (Figura 3.12), STAT3 regula a expressão do regulador positivo do ciclo celular Ciclina D1 e da proteína anti-apoptótica Bcl-2. Já foi mostrado na literatura que a ativação constitutiva de STAT3 correlaciona com a superexpressão dos genes ciclina $d 1$ e bcl-2, proporcionando assim, um novo marcador de prognóstico de células de carcinoma de cabeça e pescoço (Masuda et al., 2002). Além disso, a repressão da expressão do gene p53 por STAT3 pode ter um importante papel no desenvolvimento de tumores (Niu et al., 2005). Estas evidências apontam para o envolvimento de STAT3 na progressão do ciclo celular e transformação das células HeLa.

A nossa análise in silico também mostra um comportamento inesperado do gene $p 21$, independente da regulação por p53. Esta regulação alternativa já foi descrita em outros tipos celulares (Roninson, 2002), mas ainda continua desconhecida no caso das células HeLa. Apesar de p21 não ser um fator de transcrição, é concebível que efeitos indiretos de p21 na expressão gênica de promotores de progressão do ciclo celular, como Ciclina D1 e inibidores apoptóticos, como Bcl-2 podem mediar algumas funções inesperadas em células Hela. Estas funções parecem não estar relacionadas com a inibição do crescimento e parada do ciclo celular, apoiando a hipótese de que a regulação de p21, independente de p53 pode ser uma das vias de sinalização ativadas em direção à tumorigênese e/ou progressão tumoral em células HeLa, assim como em outros tipos de tumores (Gartel, 2006. De la Cueva et al., 2006).

É interessante que, mesmo utilizando um conjunto pequeno de dados, o método SVAR 
permitiu a identificação de regulações já conhecidas na literatura, como descrito acima, ilustrando o poder desta técnica. Em geral, os métodos apresentados na literatura não apresentam teste estatístico devido às dificuldades geradas pelo fato do número de observações ser muito menor que o número de parâmetros a ser estimado, conseqüentemente, não apresentando o controle dos falsos positivos.

A grande vantagem do vetor autoregressivo esparso (SVAR), quando comparado aos outros modelos de conectividade, é que este permite modelar redes com causalidades de Granger com um número de genes muito maior que o número de observações. Além disso, o SVAR fornece um teste estatístico para controlar os falsos-positivos. Segundo nosso conhecimento, este é o único método que oferece a combinação dessas duas vantagens, pois outros métodos que modelam "grandes" redes, no geral, não apresentam testes estatísticos. Além do mais, "grandes" redes gene-gene geralmente realizam comparações dois a dois dos genes. Utilizando SVAR, é possível inferir causalidades parciais, resultando, assim, em um menor número de arestas espúrias que as comparações dois a dois.

Modelos Gráficos Gaussianos apresentados por Schäfer e Strimmer, que aplicam correlações parciais no mesmo contexto $(n>m)$ é o mais semelhante ao SVAR, apresentando um teste estatístico. Contudo, as arestas obtidas por esta abordagem representam associações instantâneas (correlações), não fornecendo uma noção de causalidade, i.e., as arestas não possuem direção.

Diferentemente de funções de score, que possuem interpretações difíceis e algumas vezes, a escolha do limiar para determinar onde há uma aresta ou não é subjetiva, um teste estatístico é uma forma objetiva de determinar onde há uma aresta e com qual probabilidade nós estamos olhando para um falso positivo.

A complexidade computacional do procedimento de inferência proposto é linear no número de genes $n$, pois somente uma regressão é realizada para cada gene.

Existem outros métodos de seleção de variáveis baseados em métodos stepwise. Infelizmente, métodos stepwise não são consistentes (Hastie et al., 2001), i.e., mesmo aumentando o tamanho da amostra $(T \rightarrow \infty)$, não há garantia que os coeficientes que se tornaram zero são realmente os corretos. Este resultado não se altera mesmo se todos os subconjuntos de variáveis forem explorados.

Ao invés de se usar o LASSO, alguém poderia querer usar outro método de regressão com penalidades, como o mais popular Ridge (Hoerl e Kennard, 1970) ou o Garrote não-negativo (Breiman, 1995). Ridge não torna as variáveis iguais a zero, resultando em 
modelos com interpretações difíceis. Comparando LASSO com o Garrote não-negativo, este último é pior que o LASSO quando há a presença da multicolinearidade (Tibshirani, 1996). Assim, para identificar redes regulatórias, o LASSO parece ser o mais apropriado.

Outras vantagens do SVAR são o fato de que ele não requer um modelo pré-especificado. Assim, o SVAR é não viesado e possibilita inferir novas conexões, não somente modelando redes com arestas já conhecidas. Diferentemente dos modelos Gráficos Gaussianos apresentado por Schäfer e Strimmer, que aplicam correlações parciais no mesmo contexto que o SVAR $(m>n)$, no SVAR é possível inferir causalidades baseadas no conceito da causalidades de Granger e não somente correlações. Outra vantagem é que não é necessário discretizar o valor da expressão do gene para variáveis Booleanas, como pela modelagem de redes Booleanas, portanto, não há perda de informação. Além disso, não há a necessidade de assumir uma rede DAG (Directed Acyclic Graph) a priori, ou seja, o método pode modelar redes com ciclos também. É importante que o método seja capaz de modelar redes com ciclos já que é sabido que as redes regulatórias de genes mantém seu balanço e controle através de feedbacks positivos e negativos.

Nesta abordagem, para tornar viável a construção de uma estimativa para o número de falsos-positivos quando $m>n$, usamos o fato que a rede metabólica é esparsamente conectada como parte da solução. Assim, o número de variáveis a serem analisadas decresce significativamente, resultando somente nas variáveis que são grandes o suficiente para serem testadas e rejeitadas como sendo diferentes de zero. 
Capítulo 4

\section{Pacote de ferramentas}

Nos últimos anos, diversos métodos avançados para análise dos dados de expressão gênica foram publicados, mas infelizmente, em geral, esses métodos não estão implementados em programas com interfaces amigáveis e não são facilmente acessíveis, não estando disponíveis para pesquisadores que não possuem formação em Ciências Exatas. Isto faz com que somente métodos clássicos sejam utilizados, sendo que os métodos mais avançados, que podem apresentar resultados superiores a estes, se tornem menos usados. Neste capítulo, apresentaremos o pacote de ferramentas GEDI (Gene Expression Data Interpreter) (Fujita et al., 2007), um pacote de código aberto implementado em R, que visa a auxiliar biólogos na análise dos dados gerados através de microarrays de DNA ou qualquer outro dado de expressão gênica.

\section{$4.1 \quad G E D I$}

O principal objetivo do GEDI é ajudar o pesquisador a analisar os dados de $m i$ croarrays de DNA, disponibilizando tanto ferramentas básicas quanto avançadas de visualização e normalização dos dados, determinação dos genes diferencialmente expressos, clusterização e identificação de marcadores moleculares e construção de redes regulatórias. O GEDI permite que pesquisadores que não estejam familiarizados com programação computacional possam escolher a análise mais adequada para o seu conjunto de dados, encontrando-se disponível gratuitamente na página (http://mariwork.iq.usp.br/gedi/) na versão em Inglês. 


\subsection{Funcionalidades}

O GEDI possui a implementação de todos os algoritmos apresentados nos capítulos anteriores. Este pacote de ferramentas está dividido, basicamente, em quatro partes: (i) normalização de microarrays; (ii) identificação de genes diferencialmente expressos, (iii) classificadores de amostras e (iv) modelagem de redes regulatórias de genes.

O pipeline comumente utilizado para análise dos dados de microarrays de DNA pode ser esquematizado da seguinte forma:

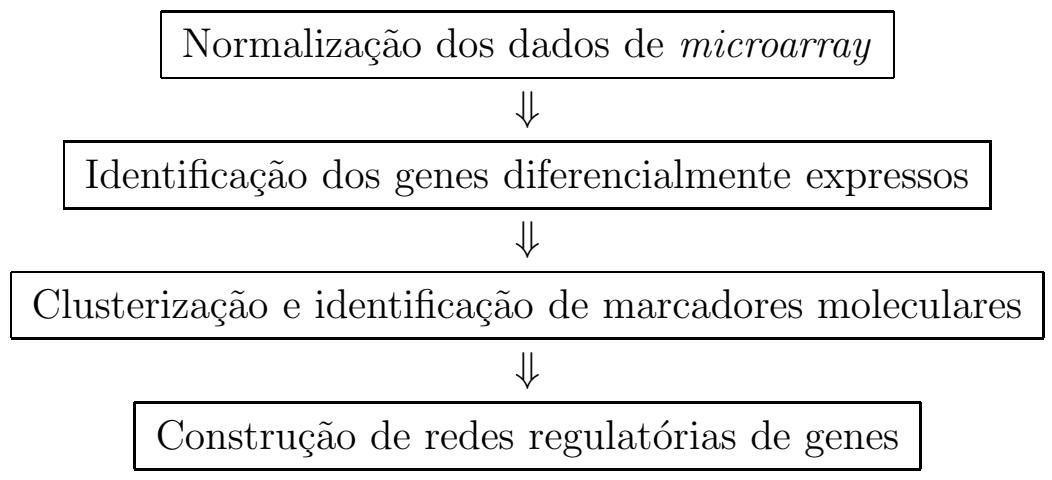

Na seção normalização de microarrays de DNA, estão à disposição tanto os métodos baseados no popular método de Loess, como os demais métodos mais avançados, como Splines, Wavelets e o método proposto nesta tese, o SVR. Além destes, também adicionamos os métodos baseados em normalização por intensidade global, centralizados na média e mediana e também a normalização por quantis (função normalize.quantiles\{affy\} do R).

Na segunda seção, identificação de genes diferencialmente expressos, o clássico teste $\mathrm{t}$ e teste $\mathrm{t}$ com permutação, que permitem testar se duas médias são iguais, o teste não-paramétrico de Wilcoxon e o SAM (Significance Analysis of Microarray) (função samr\{samr\} do R) (Tusher e Tibshirani, 2001) estão implementados.

Na terceira seção, classificadores de amostras, estão implementados os métodos de clusterização e classificação de amostras, baseados nos algoritmos k-means (função kmeans\{stats\} do R), análise discriminante linear e quadrático (funções lda\{MASS\} e qda\{MASS\} do R) e a Máquina de Suporte Vetorial (função ksvm\{kernlab\} do R).

Por fim, na última seção, modelagem de redes regulatórias de genes, estão implementados diversos métodos de modelagem de redes. Para dados de expressão gênica em séries temporais, pode-se usar o tradicional vetor autoregressivo, vetor autoregressivo 
dinâmico e o vetor autoregressivo esparso. Para dados de expressão que não são séries temporais ou mesmo quando estão em séries temporais, mas se deseja inferir relações instantâneas, pode-se inferir as conectividades através da correlação parcial de Pearson ou

pela correlação parcial de Spearman. Note que, no caso do vetor autoregressivo, é possível inferir a causalidade de Granger. Já nos métodos de correlação parcial, não é possível tal inferência, logo, as arestas da rede não são direcionadas.

Nos modelos baseados no vetor autoregressivo, estão implementados os modelos de ordem um, devido à baixa quantidade de observações (microarrays) disponíveis até o momento.

\subsubsection{Normalização de microarrays de DNA}

\section{Loess}

O mais popular método de normalização, baseado em regressão não-paramétrica. No GEDI, está implementada a função de peso cúbica conforme seção 2.2.1.

\section{Splines}

Normalização baseada em expansão por polinômios. No pacote de ferramentas, está implementado o B-Splines cúbico conforme seção 2.2.2.

\section{Wavelets}

Como o Splines, também é uma expansão por polinômios. Uma vantagem do Wavelets é a multi-resolução. No pacote de ferramentas GEDI está implementada a janela conhecida como chapéu mexicano conforme seção 2.2.3.

\section{Support Vector Regression (SVR)}

Método de normalização superior aos já existentes. Robusto em relação aos outliers, permite a identificação de genes diferencialmente expressos mesmo em genes com altos ou baixos níveis de expressão conforme seção 2.2.5. 


\section{Normalização cíclica}

Para a normalização de mais de dois arrays, é realizada a normalização cíclica. Este método é baseado na idéia do plote $M$ versus $A$, onde $M$ é a diferença do log dos valores das expressões e $A$ é média do log dos valores das expressões (Dudoit et al., 2002). Um plote $M$ versus $A$ para dados normalizados deve mostrar uma nuvem de pontos ao redor do eixo $M=0$.

Para quaisquer dois microarrays $i, j$ com intensidades $x_{k i}$ e $x_{k j}$ onde $k=1, \ldots, p$ representa a sonda, calcula-se $M_{k}=\log _{2}\left(x_{k i} / x_{k j}\right)$ e $A_{k}=\frac{1}{2} \log _{2}\left(x_{k i} x_{k j}\right)$. Uma curva de normalização é ajustada para esse plote $M$ versus $A$ usando um dos métodos citados acima (Loess, Splines, Wavelets, SVR). O ajuste baseado na curva de normalização é o $\hat{M}_{k}$ e assim os ajustes da normalização são $M_{k}^{\prime}=M_{k}-\hat{M}_{k}$. Os valores das intensidades das sondas ajustadas são dadas por $x_{k i}^{\prime}=2^{A_{k}+\frac{M_{k}^{\prime}}{2}}$ e $x_{k j}^{\prime}=2^{A_{k}-\frac{M_{k}^{\prime}}{2}}$.

Para a normalização de mais de dois microarrays, o método é estendido para a análise de todas as combinações dois a dois. A normalização dois a dois é realizada como descrito acima. Guardamos os ajustes para cada um dos dois microarrays de cada par. Então, após a normalização de todos os pares de microarrays para todo $z$ onde $1 \leq z \leq n$, temos ajustes para o chip $k$ relativo aos microarrays $1, \ldots, z-1, z+1, \ldots, n$. A média dos ajustes é então aplicada para o conjunto de microarrays. No geral, de 1 a 2 ciclos completos de iterações para todos os pares é o suficiente para haver convergência (Bolstad et al., 2003).

\subsubsection{Identificação de genes diferencialmente expressos}

\section{Teste $t$}

Compara a média de duas populações com variâncias desiguais e desconhecidas, sendo que as observações devem ser independentes e apresentar distribuição Normal.

Sejam $\left(x_{1}, x_{2}, \ldots, x_{n}\right)$ os $n$ valores dos níveis de expressão do gene $\mathrm{X}$ e $\left(y_{1}, y_{2}, \ldots, y_{m}\right)$ os $m$ valores do gene $Y$.

$$
t=\frac{(\hat{x}-\hat{y})-\left(\mu_{X}-\mu_{Y}\right)}{\sqrt{\frac{\sigma_{X}^{2}}{n}+\frac{\sigma_{Y}^{2}}{m}}}
$$

onde $\sigma_{X}^{2}$ e $\sigma_{Y}^{2}$ são os estimadores não-viesados da variância de $X$ e $Y$ respectivamente. 


\section{Teste de Wilcoxon}

Como o teste $t$, o teste de Wilcoxon realiza comparações entre diferenças entre as medições, mas não requer que as medições tenham algum tipo de distribuição específica.

Seja $Z_{+}$a soma da diferença dos postos positivos. Então, a estatística pode ser calculada como:

$$
W=\frac{Z_{+}-\mu}{\sigma}
$$

onde

$$
\mu=\frac{n(n+1)}{4}
$$

e

$$
\sigma^{2}=\frac{n(n+1)(2 n+1)}{24}
$$

\subsubsection{Classificação}

\section{$k$-médias}

Método iterativo de clusterização, onde o número de clusters $k$ é dado como entrada do algoritmo.

O número de clusters é definido pelo usuário sendo que, cada cluster é representado pelo centróide, ou seja, o centro de cada grupo. O algoritmo minimiza a soma das distâncias de cada objeto (gene ou observação) para o correspondente centróide. Em cada iteração, cada objeto é designado para o centróide mais próximo e novos centróides são computados baseados na nova distribuição. Esses passos são repetidos até que não haja mais mudança na classificação dos objetos para diferentes grupos (MacQueen, 1967).

\section{Análise discriminante}

A análise discriminante linear é usada para encontrar combinações lineares das características que melhor separam duas ou mais classes de objetos, como por exemplo, amostras normais ou tumorais provenientes de pacientes.

Considere o conjunto de observações da expressão dos genes $k$ para cada amostra onde sabemos a classe $z$ de cada uma delas. Este conjunto de amostras é chamado de conjunto de treinamento. O problema consiste em encontrar um bom preditor para a classe $z$ dado 
somente as observações de $k$.

Já a análise discriminante quadrática separa duas ou mais classes de objetos usando uma superfície quadrática. Este método é uma versão mais generalizada da análise discriminante linear.

\section{Máquina de suporte vetorial}

Um outro método de classificação, baseado em uma abordagem de aprendizagem de máquina, é a Máquina de Suporte Vetorial (SVM - Support Vector Machine) (Brown et al., 2000). Esta é uma técnica aplicada para resolver o problema da dimensionalidade dos dados de microarrays.

A Máquina de Suporte Vetorial consiste em uma técnica de classificação supervisionada em que as observações são classificadas com base em observações de treinamento previamente conhecidas. A SVM é utilizada em Bioinformática para resolver o problema da classficação das observações (tecidos) do espaço de expressões gênicas em um espaço de características de maior dimensão, em que a distância é medida usando uma função núcleo (kernel), e então os dados podem ser separados em duas classes, no geral, caso normal e patológico. Vetores de expressão gênica podem ser vistos como pontos em um espaço $n$-dimensional.

A SVM é então treinada para distinguir as observações. Com um espaço de características apropriadamente escolhido de dimensionalidade suficiente, qualquer conjunto de treinamento consistente pode ser separável. SVM é uma técnica linear que usa hiperplanos que separam superfícies entre as observações normais e patológicas. Em outras palavras, a SVM seleciona o hiperplano que provê a maior margem entre as superfícies do plano e os pontos, buscando evitar, ao máximo, a mistura entre os dois conjuntos de dados.

\subsubsection{Modelagem de redes regulatórias}

\section{Vetor Autoregressivo (VAR)}

Neste método, dados os níveis de expressão dos genes medidos ao longo do tempo em intervalos uniformes, é possível inferir relações de causalidades de Granger estacionárias e 
lineares entre eles, ou seja, é possível construir redes com arestas direcionadas. Veja seção 3.2 para maiores detalhes.

\section{Vetor Autoregressivo Dinâmico (DVAR)}

No Vetor Autoregressivo Dinâmico, é possível construir redes regulatórias com causalidades de Granger, mas sem o pressuposto de que a causalidade seja estacionária ou linear como no Vetor Autoregressivo clássico, ou seja, é possível inferir se ocorre uma causalidade de Granger em cada fase do ciclo celular. Veja seção 3.3 para maiores detalhes.

\section{Vetor Autoregressivo Esparso (SVAR)}

Devido ao problema da dimensionalidade, na qual o número de genes é muito maior que o número de experimentos de microarrays, métodos tradicionais não conseguem realizar testes estatísticos para as arestas da rede regulatória. Com o método de Vetor Autoregressivo Esparso, é possível testar cada uma das arestas e encontrar causalidades de Granger lineares e estacionárias mesmo para o caso onde o número de observações é muito maior que o número de parâmetros. Veja seção 3.4 para maiores detalhes.

\section{Correlação simples}

A correlação linear de Pearson e a correlação não-paramétrica de Spearman medem a associação entre duas variáveis quantitativas.

Dados $n$ pares de valores de níveis de expressão $\left(x_{1}, y_{1}\right),\left(x_{2}, y_{2}\right) \ldots\left(x_{n}, y_{n}\right)$, chama-se de coeficiente de correlação linear entre duas variáveis $X$ e $Y$ a

$$
r_{x, y}^{\text {pearson }}=\frac{1}{n} \sum_{n=1}^{n}\left(\frac{x_{i}-\hat{x}}{\sigma_{x}}\right)\left(\frac{y_{i}-\hat{y}}{\sigma_{y}}\right)
$$

onde $\sigma_{x}$ e $\sigma_{y}$ são os desvios padrões de $x$ e $y$, respectivamente.

A correlação não-paramétrica de Spearman é definida como

$$
r_{x, y}^{\text {spearman }}=1-\frac{6 \times \sum d^{2}}{n\left(n^{2}-1\right)}
$$

onde $d$ é o $(\operatorname{posto}(x)-\operatorname{posto}(y))$. 


\section{Correlação parcial}

A correlação parcial mede a força de associação entre duas variáveis, enquanto é controlado o efeito das demais variáveis.

Dois métodos de correlação parcial estão implementados no GEDI: Pearson e Spearman.

Sejam $x, y$ e $z$ os vetores contendo o valor de nível de expressão de três genes. Então, a correlação parcial entre $x$ e $y$, dado por $z$, é definida como:

$$
r_{x y, z}=\frac{r_{x y}-r_{x z} r_{y z}}{\sqrt{\left(1-r_{x z}^{2}\right)\left(1-r_{y x}^{2}\right)}}
$$

onde $r_{x y}, r_{x z}$ e $r_{y z}$ são as correlações simples.

\subsection{Arquivo de entrada}

Por conveniência, o formato do arquivo de entrada do GEDI é bem simples, facilitando sua formatação e também o acoplamento entre este e outros programas de análise. Informações sobre o experimento ou plataforma do microarray de DNA não são incluídas. $\mathrm{O}$ arquivo deve ser um texto simples e ter cada um dos seus campos delimitado por tabulações. Assim, o mesmo arquivo de entrada pode ser utilizado para qualquer tipo de análise realizada pelo GEDI, sem a necessidade de edição do arquivo para cada um dos métodos. A primeira linha pode ou não conter o nome de cada array. A primeira coluna deve conter o nome ou número de acesso de cada um dos genes. Os demais campos devem conter o valor de expressão obtido no experimento.

Exemplo de arquivo de entrada:

\begin{tabular}{|cccccc|}
\hline & microarray 1 & microarray 2 & microarray 3 & $\ldots$ & microarray $n$ \\
gene 1 & 0.489129231 & 0.12543429 & 0.98540688 & $\ldots$ & 0.33734236 \\
gene 2 & 0.259703602 & 1.05016689 & 1.45466056 & $\ldots$ & 1.04463906 \\
$\vdots$ & $\vdots$ & $\vdots$ & $\vdots$ & $\ddots$ & $\vdots$ \\
gene $m$ & 1.410835303 & 0.64067782 & 1.31748604 & $\ldots$ & 0.45943997 \\
\hline
\end{tabular}




\subsection{Interface}

Pretendemos tornar a interface de uso do GEDI amigável e disponível na linguagem $\mathrm{R}$ (http://www.r-project.org) para os sistemas operacionais Windows e Linux. A interface gráfica foi desenvolvida de forma que não houvesse a necessidade do pesquisador, em geral um pesquisador da área biomédica que está analisando os dados, programar.

Os resultados podem ser visualizados na própria tela do computador. Além disso, podem ser gerados arquivos de texto simples com os resultados numéricos e figuras em PostScript, sendo que a imagem é salva em um arquivo no formato PostScript ".ps" para que não haja perda de resolução quando se deseja aumentar o tamanho da figura, ou seja, é gerada uma imagem vetorial.

A Figura 4.1 mostra a interface do GEDI e dois exemplos de saídas: o resultado obtido pela normalização de microarrays de DNA pelo método SVR e a rede de conectividade dinâmica construída através da aplicação do DVAR. 


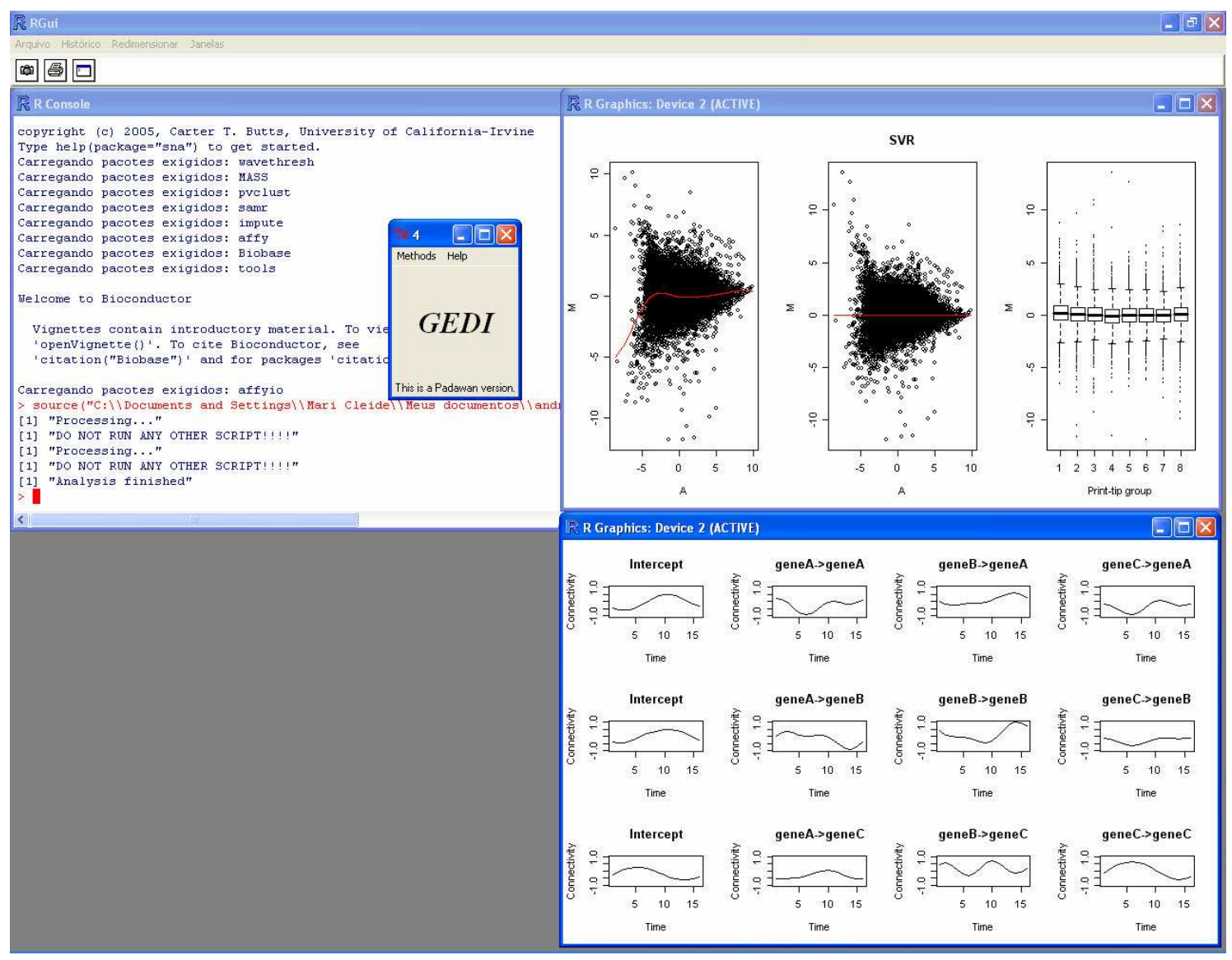

Figura 4.1: Interface gráfica do GEDI. A interface gráfica do GEDI é mostrada à esquerda da figura, e as saídas relativas à normalização dos dados de microarrays e a rede regulatória gênica modelada pelo DVAR à direita. 
CAPÍtulo 5

\section{Conclusões}

Os avanços tecnológicos dos últimos anos levaram à geração em larga escala, de dados biológicos, em particular, de níveis de expressão gênica em diferentes condições fisiológicas, contribuindo, assim, para a descoberta de novos alvos terapêuticos para diversos tipos de doenças. Logo, a análise dos dados de microarrays de DNA se torna de suma importância para que novos experimentos possam ser projetados com maior acurácia. Grande parte desses estudos estão concentrados na identificação de genes diferencialmente expressos, porém, além da expressão diferencial, é importante saber a quais vias seus respectivos produtos gênicos pertencem, pois se sabe que a célula é uma complexa máquina composta por uma grande rede de proteínas que interagem entre si para regular os diversos processos biológicos. Dessa forma, a identificação das estruturas das redes de regulação é essencial para um melhor entendimento da célula como um todo, além de proporcionar uma interpretação para os genes diferencialmente expressos, já que é possível inferir as vias a que elas pertencem.

Nesta tese apresentamos metodologias para a análise dos dados brutos de microarrays de DNA para que possam ser analisados posteriormente por métodos estatísticos e matemáticos. São mostrados também dois métodos de modelagem de redes regulatórias com os quais resolvemos dois problemas: o problema da dinâmica das redes regulatórias e o da dimensionalidade, nos caso em que o número de genes é muito maior que o número de experimentos. A seguir detalhamos as conclusões obtidas. 


\subsection{Normalização de microarrays}

Propusemos um método de normalização de dados de microarrays de DNA chamado SVR e o testamos em diversas simulações. Os resultados obtidos com o SVR se mostram superiores às demais técnicas de normalização como Loess, Splines e Wavelets. O SVR mostrou-se mais robusto a outliers em diferentes localizações, sendo útil na identificação de genes diferencialmente expressos. Além disso, o SVR é superior mesmo nos diferentes formatos de microarrays. Assim, mostramos que o SVR é um método promissor na normalização de dados provenientes de microarrays de DNA.

Este trabalho está publicado na revista BMC Bioinformatics (Fujita et al., 2006) e foi classificado pela revista como "Highly accessed", uma vez que foi consultado mais de 2000 vezes nos 3 primeiros meses de sua publicação.

\subsection{Modelagem de redes regulatórias}

A modelagem de redes regulatórias genéticas é um passo essencial para o entendimento das funções celulares. A complexidade gerada pela expressão gênica, variando ao longo do ciclo celular, registrada por técnicas como os microarrays de DNA, são obstáculos para modelos clássicos de redes regulatórias. A técnica apresentada nesta tese permite analisar diferentes estruturas de redes para cada ponto no tempo, sendo útil para detectar qual gene é ativado ou reprimido. Diferentemente do tradicional vetor autoregressivo que infere causalidades de Granger estacionárias, o DVAR é capaz de inferir causalidades de Granger variantes no tempo, aumentando, assim, o poder do teste e revelando causalidades mais reais.

Aplicando a técnica para dados reais de microarrays, obtivemos resultados plausíveis, que são úteis para a descoberta das vias e do momento em que estão sendo ativadas / reprimidas, além de comparar redes obtidas em diferentes condições experimentais como, por exemplo: respostas à drogas e antígenos ou comparações entre células ou tecidos sadios versus patológicos. O trabalho relacionado foi publicado na revista Bioinformatics (Fujita et al., 2007a).

Além disso, introduzimos o método SVAR para modelar redes regulatórias de genes no contexto atual, onde o número de observações é geralmente menor que o número de 
genes. Com este método, é possível modelar naturalmente feedbacks e inferir causalidades de Granger sem informações a priori. Apresentamos, também, um teste estatístico para controlar a taxa de falso positivos, que antes não estava presente nos demais modelos de redes regulatórias devido ao problema da dimensionalidade. O trabalho correspondente foi aceito para publicação na revista BMC Systems Biology (Fujita et al., 2007b).

\subsection{Pacote de ferramentas}

O pacote de ferramentas GEDI, que integra diversas técnicas de análise de dados, inclusive as descritas neste trabalho, possibilita a pesquisadores da área biomédica, o acesso a métodos mais avançados, tornando mais rápida, fácil e padronizada as análises, permitindo, assim, que diversos laboratórios possam compartilhar e reproduzir resultados analíticos.

O artigo referente ao GEDI está submetido.

\subsection{Trabalhos futuros}

Ainda existe muito trabalho a ser feito na área de análise de dados de expressão gênica, em particular, na modelagem de redes regulatórias. Tanto o DVAR quanto o SVAR possuem limitações no fato de conseguirem inferir somente causalidades de Granger lineares, porém, nada impede que na natureza, essas causalidades não sejam não-lineares. Logo, pretendemos estudar modelos que não exijam linearidade para estender o modelo VAR para casos não-lineares. Além disso, nesta tese abordamos as redes baseadas no conceito de causalidade de Granger, contudo, para a inferência dessa causalidade, é necessário ter uma série temporal. Para dados não temporais, que é a maioria dos dados gerados nos experimentos de microarrays, não é possível inferir a causalidade de Granger. Existem entretanto, outros conceitos de causalidade como o proposto por Judea Pearl que serão estudados na tentativa de resolver essa limitação. 


\section{Referências Bibliográficas}

[1] Akutsu T, Miyano S, Kuhara S. Algorithms for identifying Boolean networks and related biological networks based on matrix multiplication and fingerprint function. J. Comput. Biol. 7:331-343, 2000.

[2] Albert R, Jeong H, Barabasi AL. Error and attack tolerance of complex networks. Nature. 406:378-382, 2000.

[3] Archambeau C. Probabilistic models in noisy environment and their application to a visual prosthesis for the blind. Tese de doutorado. Université catholique de Louvain, Applied Sciences Faculty, 2005.

[4] Baird D, Johnstone P, Wilson T: Normalization of microarray data using a spatial mixed model analysis which includes splines. Bioinformatics. 17:3196-205, 2004.

[5] Balagurunathan Y, Dougherty ER, Chen Y, Bittner ML, Trent JM. Simulation of cDNA microarrays via a paramterized random signal model. Journal of Biomedical Optics. 7:507-523, 2002.

[6] Barabási AL, Albert R. Emergence of scaling in random networks. Science. 286: 509$512,1999$.

[7] Barrera J, Cesar Jr RM, Martins Jr DC, Merino EF, Vencio RZN, Leonardi FG, Yamamoto MM, Pereira CAB, del Portillo HA. A new annotation tool for malaria based on inference of probabilistic genetic networks. In: Critical Assessment of microarray data analysis (CAMDA 2004), 2004, Durham, 36-40, 2004. 
[8] Bash J, Zong WX, Gelinas C. c-Rel arrests the proliferation of HeLa cells and affects critical regulators of the G1/S-phase transition. Mol Cell Biol. 17:6526-6536, 1997.

[9] Baugh LR, Hill AA, Brown EL, Hunter CP. quantitative analysis of mRNA amplification by in vitro transcriptation. Nucleic Acids Research. 29:E29, 2001.

[10] Beheshti B, Braude I, Marrano P, Thorner P, Zielenska M, Squire JA. Chromosomal localization of DNA amplifications in neuroblastoma tumors using cDNA microarray comparative genomic hybridization. Neoplasia. 5:53-62, 2003.

[11] Benjamini Y, Hochberg Y. Controlling the false discovery rate: a practical and powerful approach to multiple testing. J. Roy. Statist. Soc. Ser. B. 57:289-300, 1995.

[12] Bishop JO, Morton JG, Rosbash M, Richardson M. Three abundance classes in HeLa cell messenger RNA. Nature. 250:199-240, 1974.

[13] Bolstad BM, Irizarry RA, Astrand M, Speed TP. A comparison of normalization methods for high density oligonucleotide array data based on variance and bias. Bioinformatics. 19:185-193, 2003.

[14] Brazma A, Hingamp P, Quackenbush J, Sherlock G, Spellman P, Stoeckert C, Aach J, Ansorge W, Ball CA, Causton HC, Gaasterland T, Glenisson P, Holstege FC, Kim IF, Markowitz V, Matese JC, Parkinson H, Robinson A, Sarkans U, Schulze-Kremer S, Stewart J, Taylor R, Vilo J, Vingron M. Minimum information about microarray experiment (MIAME)-toward standards for microarray data. Nat. Genet. 29:365-371, 2001.

[15] Breiman, L. Better subset regression using the nonnegative garrote. Technometrics. $37: 373-384,1995$.

[16] Brown RT, Ades IZ, Nordan RP. An acute phase response factor/NF-kappa B site downstream of the junB gene that mediates responsiveness to interleukin-6 in a murine plasmacytoma. J. Biol. Chem. 270:31129-31135, 1995.

[17] Brown MPS, Grundy WN, Lin D, Cristianini N, Sugnet CW, Furey TS, Ares M, Haussler D. Knowledge-based analysis of microarray gene expression data by using support vector machines. Proc. Natl. Acad. Sci. 97:262-267, 2000. 
[18] Bryd RH, Lu P, Nocedal J, Zhu C. A limited memory algorithm for bound constrained optimization. SIAM J. Scientific Computing. 16:1190-1208, 1995.

[19] Buckbinder L, Talbott R, Velasco-Miguel S, Takenaka I, Faha B, Seizinger BR, Kley N. Induction of the growth inhibitor IGF-binding protein 3 by p53. Nature. 377:646-9, 1995.

[20] Chargaff E. Chemical specificity of nucleic acids and mechanism of their enzymatic degradation. Experientia. 6:201-9, 1950.

[21] Chargaff E, Lipshitz R, Green C, Hodes ME. The composition of the deoxyribonucleic acid of salmon sperm. J Biol Chem. 192:223-30, 1951.

[22] Chargaff E. Some recent studies on the composition and struture of nucleic acids. J Cell Physiol Suppl. 38:41-59, 1951.

[23] Chargaff E, Lipshitz R, Green C. Composition of the desoxypentose nucleic acids of four genera of sea-urchin. J Biol Chem. 195:155-60, 1952.

[24] Chen F, Castranova V, Shi X, Demers LM. New insights into the role of nuclear factor-kappaB in cell growth regulation. Am J Pathol. 159: 387-97, 2001.

[25] Chen M, Ghosh G. Regulation of DNA binding by Rel/NF-kappaB transcription factors: structural views. Oncogene. 18:6845-6852, 1999.

[26] Chirgwin JM, Przybyla AE, MacDonald RJ, Rutter WJ. Isolation of biologically active ribonucleic acid from sources enriched in ribonuclease. Biochemistry. 18:52949, 1979.

[27] Chui CK. An introduction to wavelets. San Diego: Academic Press, 1992.

[28] Cleveland WS, Grosse E, Shyu WM. Local regression models. S. Wadsworth \& Brooks/Cole, 1992.

[29] Cullane AC, Perriere G, Considine EC, Cotter TG, Higgins DG. Between-group analysis of microarray data. Bioinformatics. 18:1600-1608, 2002.

[30] Dameron KM, Volpert OV, Tainsky MA, Bouck N. Control of angiogenesis in fibroblasts by p53 regulation of thrombospondin-1. Science. 265,1582-4, 1994. 
[31] Daubechies I. Ortonormal bases of compactly supported wavelets. Commun. Pure Appl. Math. 4:909-996, 1997.

[32] De la Cueva E, Garcia-Cao I, Herranz M, Lopez P, Garcia-Palencia P, Flores JM, Serrano M, Fernandez-Piqueras J, Martin-Caballero J. Tumorigenic activity of p21Waf1/Cip1 in thymic lymphoma. Oncogene. 25:4128-32, 2006.

[33] Dias R. A review of non-parametric curve estimation methods with application to Econometrics. Economia. 2:31-75m 2002.

[34] Dojer N, Gambin A, Mizera A, Wilczynski B, Tiuryn J. Applying dynamic Bayesian networks to perturbed gene expression data. BMC Bioinformatics. 7:249, 2006.

[35] Dorris DR, Nguyen A, Gieser L, Lockner R, Lublinsky A, Patterson M, Touma E, Sendera TJ, Elghanian R, Mazumder A. Oligodeoxyribonucleotide probe accessibility on a three-dimensional DNA microarray surface and the effect of hybridization time on the accuracy of expression ratios. BMC Biotechnol. 3:6, 2003.

[36] Dreyfus DH, Nagasawa M, Gelfand EW, Ghoda LY. Modulation of p53 activity by IkappaBalpha: evidence suggesting a common phylogeny between NF-kappaB and p53 transcription factors. BMC Immunol. 6:12, 2005.

[37] Drucker H, Burges CJC., Kaufman L., Smola A., Vapnik V. Support Vector Regression Machines. Advances in Neural Information Processing Systems 9, NIPS 1996, 155-161, MIT Press, 1997.

[38] Dudoit S, Yang YH, Callow MJ, Speed TP. Statistical methods for identifying genes with differential expression in replicated cDNA microarray experiments. Stat. Sin. 12:111-139, 2002.

[39] Durbin BP, Hardin JS, Hawkins DM, Rocke DM. A variance-stabilizing transformation for gene-expression microarray data. Bioinformatics, 18:S105-110, 2002.

[40] el-Deiry WS, Tokino T, Velculescu VE, Levy DB, Parsons R, Trent JM, Lin D, Mercer WE, Kinzler KW, Vogelstein B. WAF1, a potential mediator of p53 tumor suppression. Cell. 75:817-25, 1993. 
[41] Elson D, Chargaff E. On the desoxyribonucleic acid content of sea urchin gametes. Experientia. 8:143-5, 1952.

[42] Erdös P, Rényi A. On random graphs. Publicationes Mathematicae. 6:290-297, 1959.

[43] Fan JQ, Li RZ. Variable selection via nonconcave penalized likelihood and its oracle properties. J. Am. Stat. Assoc. 96:1348-1360, 2001.

[44] Fan JQ e Peng H. Nonconcave penalized likelihood with a diverging number of parameters. Ann. Stat. 32: 928-961, 2004.

[45] Friedman N. Inferring cellular networks using probabilistic graphical models. Science. 303:799-805, 2004.

[46] Fukushima Y, Oshika Y, Tsuchida T, Tokunaga T, Hatanaka H, Kijima H, Yamazaki H, Ueyama Y, Tamaoki N, Nakamura M. Brain-specific angiogenesis inhibitor 1 expression is inversely correlated with vascularity and distant metastasis of colorectal cancer. Int J Oncol. 13:967-70, 1998.

[47] Fujita A, Sato JR, Rodrigues LO, Ferreira CE, Sogayar MC. Evaluating different methods of microarray data normalization. BMC Bioinformatics. 7:469, 2006.

[48] Fujita A, Sato JR, Garay-Malpartida HM, Morettin PA, Sogayar MC, Ferreira CE. Time-varying modeling of gene expression regulatory networks using the wavelet dynamic vector autoregressive method. Bioinformatics. 23:1623-1630, 2007a.

[49] Fujita A, Sato JR, Garay-Malpartida, Yamaguchi R, Miyano S, Sogayar MC, Ferreira CE. Modeling large gene expression regulatory networks with the sparse vector autoregressive model. BMC Systems Biology, 2007b (no prelo).

[50] Fujita A, Sato JR, Sogayar MC, Ferreira CE. GEDI: a user-friendly gene expression data toolbox. (submetido).

[51] Furey TS, Cristianini N, Duffy N, Bednarski DW, Schummer M, Haussler D. Support vector machine classification and validation of cancer tissue samples using microarray data. Bioinformatics. 16:906-914, 2000.

[52] Gartel AL. Is p21 an oncogene?. Mol Cancer Ther. 5:1385-6, 2006. 
[53] Granger CWJ. Investigating causal relation by econometric and cross-sectional method. Econometrica. 37:424-438, 1969.

[54] Graybill FA. Theory and application of the linear model. A:Duxbury, North Scituate, 1976.

[55] Härdle W. Smoothing techniques with implementation. New York: Springer-Verlag, 1990.

[56] Hastie T, Tibshirani R, Friedman J. The elements of statistical learning: data mining, inference, and prediction. New York: Springer. 2001.

[57] Hildesheim J, Bulavin DV, Anver MR, Alvord WG, Hollander MC, Vardanian L, Fornace AJ Jr. Gadd45a protects against UV irradiation-induced skin tumors, and promotes apoptosis and stress signaling via MAPK and p53. Cancer Res. 62:73057315, 2002.

[58] Hill AA, Brown EL, Whitley MZ, Tucker-Kellogg G, Hunter CP, Slonim DK. Evaluation of normalization procedures for oligonucleotide array data based on spiked cRNA controls. Genome Biol. 2:RESEARCH0055, 2001.

[59] Hisanori K, Oshima T, Asai K. Extracting relations between promoter sequences and their strengths from microarray data. Bioinformatics. 21:1062-1068, 2004.

[60] Hoerl AE, Kennard RW. Ridge regression: biased estimation for non-orthogonal problems. Technometrics. 12:55-67, 1970.

[61] Huang S. Gene expression profiling, genetic networks, and cellular states: an integrating concept for tumorigenesis and drug discovery. J Mol Med. 77:469-80. Review, 1999.

[62] Hunter DR. MM algorithms for generalized Bradley-Terry models. Ann. Stat. 32: 384-406, 2004.

[63] Hunter DR, Lange K. A tutorial on MM algorithms. Am. Stat. 58:30-37, 2004.

[64] Imoto S, Goto T, Miyano S. Estimation of genetic networks and functional structures between genes by using Bayesian networks and nonparametric regression. Pac. Symp. Biocomput. 175-186, 2002. 
[65] Inoue J, Gohda J, Akiyama T, Semba K. NF-kappaB activation in development and progression of cancer. Cancer Sci. 98:268-74, 2007.

[66] International Human Genome Sequencing Consortium. Initial sequencing and analysis of the human genome. Nature, 409:860-921, 2001.

[67] Jeong H, Tombor B, Albert R, Oltvai Z, Barabasi A. The large-scale organization of metabolic networks. Nature, 65:651-654, 2000.

[68] Jin S, Zhao H, Fan F, Blanck P, Fan W, Colchagie AB, Fornace AJ Jr, Zhan Q. BRCA1 activation of the GADD45 promoter. Oncogene, 19:4050-7, 2000.

[69] Jin S, Fan F, Fan W, Zhao H, Tong T, Blanck P, Alomo I, Rajasekaran B, Zhan Q. Transcription factors Oct-1 and NF-YA regulate the p53-idependent induction of the GADD45 following DNA damage. Oncogene, 20:2683-90, 2001.

[70] Jin S, Levine AJ. The p53 functional circuit. J.Cell Sci. 114:4139-4140, 2001.

[71] Jin S, Mazzacurati L, Zhu X, Tong T, Song Y, Shujuan S, Petrik KL, Rajasekaran B, Wu M, Zhan Q. Gadd45a contributes to p53 stabilization in response to DNA damage. Oncogene, 22:8536-8540, 2003.

[72] Jing N, Tweardy DJ. Targeting Stat3 in cancer therapy. Anticancer Drugs. 16:601-7, 2005.

[73] de Jong H. Modeling and simulation of genetic regulatory systems: a literature review. J Computat Biol. 9:67-103. Review, 2002.

[74] Kaltschmidt B, Kaltschmidt C, Hehner SP, Droge W, Schmitz ML. Repression of NF-kappaB impairs HeLa cell prolifera-tion by functional interference with cell cycle checkpoint regulators. Oncogene. 18:3213-3225, 1999.

[75] Karush W. Minima of function of several variables with inequalities as side constraints. Tese de mestrado. University of Chicago. 1939.

[76] Kepler TB, Crosby L, Morgan KT. Normalization and analysis of DNA microarray data by self-consistency and local regression. Genome biol. 3:RESEARCH0037, 2002. 
[77] Knudsen S. A biologist's guide to analysis of DNA microarray data. Wileyinterscience. A John Wiley \& Sons, INC., Publication. 2001.

[78] Krikos A, Laherty CD, Dixit VM. Transcriptional activation of the tumor necrosis factor alphainducible zinc finger protein, A20, is mediated by kappa B elements. J Biol Chem. 267:17971-6, 1992.

[79] Kuhn HW, Tucher AW. Proceedings of the 2nd Berkeley Symposium on Mathematical Statistics and Probabilistics Berkeley University of California Press. 481-492, 1951.

[80] Lohrum, MA, Vousden, KH. Regulation and activation of p53 and its family members. Cell Death Differ. 6:1162-8, 1999.

[81] Lorena AC, Carvalho ACPLF. Protein cellular localization prediction with support vector machines and decision trees. Computers in biology and medicine. 37:115-125, 2007.

[82] Lütkepohl H. Introduction to multiple time series analysis. Springer-Verlag. New York, 1993.

[83] MacQueen JB. Some methods for classification and analysis of multivariate observations. Proceedings of 5-th Berkeley Symposium on Mathematical Statistics and Probability, Berkeley, University of California Press, 1:281-297, 1967.

[84] Magasanik B, Vischer E, Doniger R, Elson D, Chargaff E. The separation and estimation of ribonucleotides in minute quantities. J Biol Chem. 186:37-50, 1950.

[85] Matsumura I, Tanaka H, Kanakura Y. E2F1 and c-Myc in cell growth and death. Cell Cycle. 2:333-8, 2003.

[86] McCormick GP. Nonlinear programming theory algorithms and application. New York: John Wiley and Sons, 1983.

[87] Mangasarian OL. Nonlinear programming. New York: McGraw-Hill, 1969.

[88] Masuda M, Suzui M, Yasumatu R, Nakashima T, Kuratomi Y, Azuma K, Tomita K, Komiyama S, Weinstein IB. Constitutive activation of signal transducers and 
activators of transcription 3 correlates with cyclin D1 overexpression and may provide a novel prognostic marker in head and neck squamous cell carcinoma. Cancer Res. 62:3351-5, 2002.

[89] Mestl T, Plahte E, Omholt SW. A mathematical framework for describing and analyzing gene regulatory networks. J. theor. Biol. 176:291-300, 1995.

[90] Meyer Y. Wavelets algorithms and applications. Philadelphia: SIAM, 1993.

[91] Nadaraya EA: On estimating regression. Theory of probability and its applications. 10:186-190, 1964.

[92] Niu G, Wright KL, Ma Y, Wright GM, Huang M, Irby R, Briggs J, Karras J, Cress WD, Pardoll D, Jove R, Chen J, Yu H. Role of Stat3 in regulating p53 expression and function. Mol Cell Biol. 25:7432-40, 2005.

[93] Noda M, Oh J, Takahashi R, Kondo S, Kitayama H, Takahashi C. RECK: a novel suppressor of malignancy linking oncogenic signaling to extracellular matrix remodeling. Cancer Metastasis Rev. 22:167-75, 2003.

[94] Oh J, Diaz T, Wei B, Chang H, Noda M, Stetler-Stevenson WG. TIMP-2 upregulates RECK expression via dephosphorylation of paxillin tyrosine residues 31 and 118 . Oncogene. 25:4230-4, 2006.

[95] Pal R, Datta A, Bittner ML, Dougherty ER. Intervention in context-sensitive probabilistic Boolean networks. Bioinformatics. 21:1211-8, 2005.

[96] Perou CM. Show me the data! Nat. Genet. 29:373, 2001.

[97] Prenter PM. Splines and variational methods. New York: John Wiley \& Sons, 1975.

[98] Quackenbush J. Microarray data normalization and transformation. Nat. Genet. 32:496-501, 2002.

[99] Ramakrishnan R, Dorris D, Lublinsky A, Nguyen A, Domanus M, Prokhorova A, Gieser L, Touma E, Lockner R, Tata M, Zhu X, Patterson M, Shippy R, Sendera TJ, Mazumder A: An assessment of Motorola CodeLinkTM microarray performance for gene expression profiling applications. Nucleic Acids Research. 30, 2002. 
[100] Roninson IB. Oncogenic functions of tumour suppressor p21(Waf1/Cip1/Sdi1): association with cell senescence and tumour-promoting activities of stromal fibroblasts. Cancer Lett. 179:1-14, 2002.

[101] Saeed AI, Sharov V, White J, Li J, Liang W, Bhagabati N, Braisted J, Klapa M, Currier T, Thiagarajan M, Sturn A, Snuffin M, Rezantsev A, Popov D, Ryltsov A, Kostukovich E, Borisovsky I, Liu Z, Vinsavich A, Trush V, Quackenbush J. TM4: a free, open-source system for microarray data management and analysis. Biotechniques. 34:374-378, 2003.

[102] Sato JR, Amaro Jr E, Takahashi DY, de Maria Felix M, Brammer MJ, Morettin PA. A method to produce evolving functional connectivity maps during the course of an fMRI experiment using wavelet-based time-varying Granger causality. NeuroImage. $31: 187-96,2006$.

[103] Schäfer J, Strimmer K. An empirical Bayes approach to inferring large-scale gene association networks. Bioinformatics. 21:754-764, 2005.

[104] Segal E, Shapira M, Regev A, Pe'er D, Botstein D, Koller D, Friedman N. Module networks: identifying regulatory modules and their condition-specific regulators from gene expression data. Nat. Genet. 34:166-76, 2003.

[105] Schadt EE, Li C, Ellis B, Wong WH. Feature extraction and normalization algorithms for high-density oligonucleotide gene expression array data. J Cell Biochem. $37: 120-125,2001$.

[106] Schäfer J, Strimmer K. An empirical Bayes approach to inferring large-scale gene association networks. Bioinformatics. 21:754-764, 2005.

[107] Shmulevich I, Dougherty ER, Zhang W. Gene perturbation and intervention in probabilistic Boolean networks. Bioinformatics. 18:1319-1331, 2002.

[108] Schumaker LL. Spline functions basic theory. New York: John Wiley \& Sons, 1981.

[109] Simpson AJG et al. The genome sequence of the plant pathogen Xylella fastidiosa. 406:151-157, 2000. 
[110] Smola AJ, Schölkopf B. A tutorial on support vector regression. Statistics and Computing. 14:199-222, 2004.

[111] Soussi T. p53 alterations in human cancer: more questions than answers. Oncogene. 26:2145-56, 2007.

[112] Storz P, Doppler H, Ferran C, Grey ST, Toker A. Functional dichotomy of A20 in apoptotic and necrotic cell death. Biochem J. 387:47-55, 2005.

[113] Takahashi C, Sheng Z, Horan TP, Kitayama H, Maki M, Hitomi K, Kitaura Y, Takai S, Sasahara RM, Horimoto A, Ikawa Y, Ratzkin BJ, Arakawa T, Noda M. Regulation of matrix metalloproteinase- 9 and inhibition of tumor invasion by the membrane-anchored glycoprotein RECK. Proc Natl Acad Sci. 95:13221-6, 1998.

[114] Takahashi S, Saito S, Ohtani N, Sakai T. Involvement of the Oct-1 regulatory element of the gadd 45 promoter in the p53-independent response to ultraviolet irradiation. Cancer Res., 61:1187-95, 2001.

[115] Tamada Y, Kim SY, Bannai H, Imoto S, Tashiro K, Kuhara S, Miyano S. Estimating gene networks from gene expression data by combining Bayesian network model with promoter element detection. Bioinformatics. 19: ii227-ii236, 2003.

[116] Tibshirani R. Regression shrinkage and selection via the Lasso. Journal of the Royal Statistical Society. Series B. 58:267-288, 1996.

[117] Tusher V, Tibshirani R. Significance analysis of microarrays applied to the ionizing radiation response. PNAS. 98:5116-5121, 2001.

[118] Vanderbei RJ. An interior point code for quadratic programming. In Statistics and operations research. Princeton University, NJ, 1997.

[119] van Helden J, Naim A, Mancuso R, Eldridge M, Wernisch L, Gilbert D., Wodak SJ. Representing and analysing molecular and cellular function in the computer. Biol Chem. 381:921-35, 2000.

[120] Vapnik VN. The Nature of Statistical Learning Theory, Springer. 1995.

[121] Vapnik VN. Statistical learning theory. New York: Wiley, 1998. 
[122] Vapnik VN, Chervonenkis A. A note on one class of perceptrons. Automatics and remote control. 25. 1964.

[123] Vapnik VN, Chervonenkis A. Theory of pattern recognition. Moskow:Nauka, 1974.

[124] Vapnik VN, Lerner A. Pattern recognition using generalized portrait method. Automatic and remote control. 24:774-780, 1963.

[125] Wade M, Wahl GM. c-Myc, genome instability, and tumorigenesis: the devil is in the details. Curr Top Microbiol Immunol. 302:169-203, 2006.

[126] Wang J, Ma JZ, Li MD: Normalization of cDNA microarray data using wavelet regressions. Combinatorial Chemistry \& High Throughput Screening. 9:783-791.

[127] Watson GS. Smooth regression analysis. Sankya A, 26:359-372, 1964.

[128] Watson JD, Crick FH. Molecular struture of nucleic acid. Nature. 171:737-738, 1953.

[129] Whitfield ML, Sherlock G, Saldanha AJ, Murray JI, Ball CA, Alexander KE, Matese JC, Perou CM, Hurt MM, Brown PO e Botstein D. Identification of genes periodically expressed in the human cell cycle and their expression in tumors. Molecular Biology of the Cell. 13:1977-2000, 2002.

[130] Woolf PJ, Wang Y. A fuzzy logic approach to analyzing gene expression data. Physiol Genomics. 3:9-15, 2000.

[131] Workman C, Jensen LJ, Jarmer H, Berka R, Gautier L, Nielsen HB, Saxild HH, Nielsen C, Brunak S, Knudsen S. A new non-linear normalization method for reducing variability in DNA microarray experiments. Genome Biology. 3(9):research0048.10048.16, 2002.

[132] Xiong M, Li J, Fang X. Identification of genetic networks. Genetics. 166:1037-52, 2004.

[133] Xu X, Wang L, Ding D. Learning module networks from genome-wide location and expression data. FEBS Lett. 578:297-304, 2004.

[134] Yamaguchi R, Yoshida R, Imoto S, Higuchi T, Miyano S. Finding module-based gene networks in time-course gene expression data with state space models. IEEE Signal processing magazine. 24:37-46, 2007. 
[135] Yakovlev AG, Di Giovanni S, Wang G, Liu W, Stoica B, Faden AI. BOK and NOXA are essential mediators of p53-dependent apoptosis. J Biol Chem. 279:28367-74, 2004.

[136] Yang IV, Chen E, Hasseman JP, Liang W, Frank BC, Wang S, Sharov V, Saeed AI, White J, Li J, Lee NH, Yeatman TJ, Quackenbush J. Within the fold: assessing differential expression measures and reproducibility in microarray assays. Genome Biol. 3:research0062, 2002.

[137] Yang YH, Dudoit S, Luu P, Lin DM, Peng V, Ngai J, Speed TP. Normalization for cDNA microarray data: a robust composite method addressing single and multiple slide systematic variation. Nucleic Acids Res. 30:e15, 2002.

[138] Yang YH, Speed T. Design issues for cDNA microarray experiments. Nat. Rev. Genet. 3:579-588, 2002.

[139] Yoshida T, Maeda A, Horinaka M, Shiraishi T, Nakata S, Wakada M, Yogosawa S, Sakai T. Quercetin induces gadd45a expression through a p53-independent pathway. Oncol Rep., 14:1299-303, 2005.

[140] You M, Ku PT, Hrdlickova R, Bose HR Jr. ch-IAP1, a member of the inhibitorof-apoptosis protein family, is a mediator of the antiapoptotic activity of the v-Rel oncoprotein. Mol. Cell. Biol. 17:7328-7341, 1997.

[141] Yu H, Kortylewski M, Pardoll D. Crosstalk between cancer and immune cells: role of STAT3 in the tumour microenvironment. Nat Rev Immunol. 7:41-51, 2007. 